Principles of

Agriculture

WINSLOW 

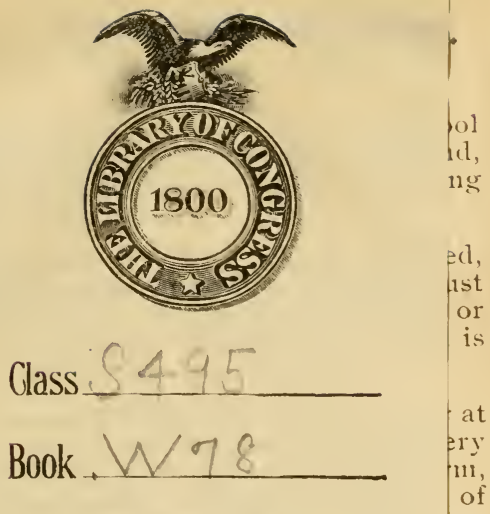

to replace by a new nook any nuk wus or damaged by their children or wards, within ten days after receiving a written notice from the teacher, and in case of a neglect or refusal to replace the book within a specified time, the pupil in whose possession the lost or damaged book was placed shall be deprived of all books furnished by this County until this Rule be complied with. Teachers are required to strictly enforce this Rule.

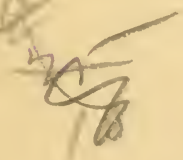


gessie troet 


THE

\section{PRINCIPLLS OF AGRICULITURE}

FOR

\section{COMMON SCHOOLS}

BY

I. O. WINSLOW, A.M.

II

NEW YORK : : CINCINNATI : • CHIICAFO

AMERICAN BOOK COMPANY 


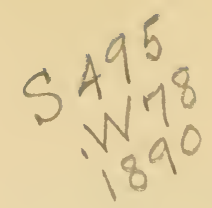

Copyright, 1890,

BY I. ก. WINSLOW.

VIN. AC

E-P 9

TRANSTERRED FROE

DERTINB RLOS

踏Y is 1920 


\section{P REF A CE.}

A KNOWLEDGE of the principles of agriculture, A which simply means a knowledge of the natural laws and principles which underlie rural life and rural pursuits, is not only important for those who are actually engaged in the pursuits of agriculture, but may in general be regarded as an important element in the education of the young.

For the large number of pupils who are unable to pursue an extended academic course of study, the natural sciences should not, as is too often the case, be wholly neglected.

Although the time of the school course may not admit of a thorough mastery of any one of these sciences, a selection of the fundamental and elementary principles of each may be consistently and profitably presented.

Education of this kind, impressing upon the young the mysteries and the beauties of nature, tends to increase the fondness for our native soil, and to develop a spirit of genuine patriotism.

This book is designed primarily for use in the public schools, and contains no difficulties too great for ordinary pupils of twelve or fourteen years. 
It has been the aim to observe a careful analysis, separating the subjects into distinct topics, and treating each briefly and concisely.

Many minor and subordinate topics have been purposely omitted. The experience of the author leads him to believe that a thorough knowledge of the few main points of a subject is worth more to the pupil than a confused idea of the whole.

There are many problems connected with the subject of agriculture which have not yet been solved, and many points which have not been definitely settled. 'These are either wholly avoided or briefly mentioned. There is enough which is established beyond question to engage the attention of begimners.

The first chapters of the work contain but little that belongs peculiarly to the science of agriculture, but they necessarily form the foundation of that science. They comprise some of the leading facts and principles of chemistry, natural philosophy, geology, physical geography, and botany, particularly such as bear directly upon agriculture and rural life.

The questions at the end of each chapter are inserted for the especial purpose of assisting such teachers as are not familiar with the subjects, and do not feel competent to present them. As the work is arranged, it is believed that no teacher will find any difficulty in understanding it or making it interesting.

JUNE, 1891. 


\section{CONTENTS.}

Pages

Suggestions to Teachers . . . . . . . . . . . . 6

CHAPTER I.

The Substances of the Earth . . . . . . . . 7-25

\section{CHAPTER II.}

Land and Water . . . . . . . . . . . . 26-40

CHAPTER III.

The Atmosphere . . . . . . . . . . . . . 41-53

CHAPTER IV.

Plants . . . . . . . . . . . . . . 54-76

CHAPTER V.

Fertilizers . . . . . . . . . . . . . 77-99

CHAPTER VI.

Cultivation . . . . . . . . . . . 100-113

CHAPTER VII.

Animals . . . . . . . . . . . . 114-144

Glossary • . • . . . . . . . . . 145-146

Index . . . . . . . . . . . . . . 147-152 


\section{SUGGESTIONS TO TEACHERS.}

RUE teaching requires activity and ori ginal work on the part of
the teacher. To rely mainly upon the text-book, and simply require pupils to commit to memory the statements of the text, is not teaching.

The aim should be to stimulate in the minds of pupils the habit of observing and thinking for themselves. The text should simply serve as a guide, or starting point, for the work of the class.

This is particularly true of subjects related to the natural sciences, like those of which the present work is composed. Many topics in the text are necessarily treated with brevity, but it is expected that teachers will avail themselves of the opportunity to amplify and illustrate them with familiar examples.

The questions at the end of each chapter may be used for review exercises or for examinations. They may also be used in daily recitations, but teachers will naturally ask many similar questions of their own.

The teaching will be rendered much more interesting and effectual by the free use of object lessons and simple experiments. Those who are accustomed to teach the natural sciences and are supplied with apparatus for the purpose, need no suggestions upon this point.

The outfit of a chemical laboratory is not necessary, however, as the ingenious teacher will find abundant means for the purpose within reach. Specimens of rocks, soils, and plants from the neighboring fields, pots of soil with a few varieties of seeds and of fertilizers, for experiments in the growth of plants, a small quantity of some common and familiar chemicals purchased for a few cents of the nearest apothecary, and a small microscope, either purchased or borrowed for occasional use, are among the means available.

It will serve a useful purpose, particularly with the older pupils, to have at hand. for reference and comparison, other works on chemistry, geology, physical geography, botany, and agriculture.

The subject is naturally interesting, and. if wisely presented, can not fail to afford enjoyment to both teacher and pupils, and to yield satisfactory results.

(vi) 


\title{
TIE PRINCIPLES OF AGRICULTURE.
}

\author{
CHAPTER I. \\ THE SUBSTANCES OF THE EARTH.
}

Simple Substances. - All matter of which the earth, the atmosphere, and all plants and animals are composed consists of a comparatively small number of simple substances or elements.

We are accustomed to think of the ordinary objects about us as simple in their nature, and as composed of but one kind of matter.

This is true of a few substances, like pure gold, silver, and iron; but the greater number of the objects with which we are familiar are composed of several simple substances mixed or combined.

Water is composed of two gases. Wood may be divided into ten or more different elements. If we burn a pile of wood we see the smoke, we know that there are gases escaping which we cannot see, and we find a small quantity of ashes remaining. Neither the smoke, the gases, nor the ashes appear at all like wood, and yet we know that in some way the wood has been transformed into these substances, 
The whole number of elementary substances at present known is from sixty-five to seventy. Some of them, however, are very rare.

Only fourteen elements are generally found in soil, plants, and animals. Knowledge of these is of importance in the study of agriculture.

They are as follows :-

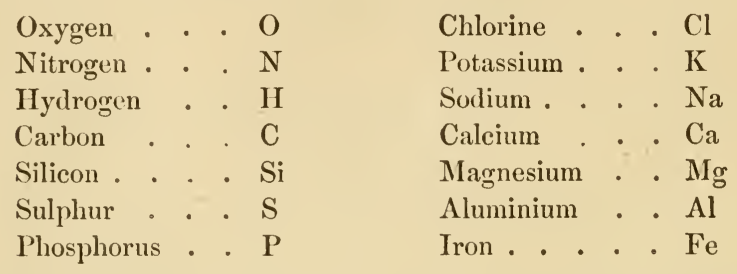

These names are used so often that, for convenience, they are abbreviated, each being represented by one or two letters. The abbreviations are called symbols. The symbols for potassium, sodium, and iron are taken from the ancient and foreign names of those substances.

Atoms. - All matter is composed of minute particles called atoms. These are so small that they have never been seen. We eannot even imagine the size of them. Millions of atoms might rest upon the point of a pin.

The belief that they exist is embodied in what is called the acomic theory. This theory is believed to be true, becanse all known facts are consistent with it. All the facts in nature with which we are acquainted, and the results of all experiments that have ever been tried, are just what they would be if the theory were true. The fact that atoms cannot be seen is no reason for doubting their existence. We are limited in our power to see and understand. $\Lambda$ s we are mable to comprehend the distance to the sun, and the immensity of space, so, on 
the other hand, we cannot form any idea of the minuteness of matter.

Powerful microscopes have revealed forms of animal life which had never before been conceived of. It is known that multitudes of living beings may occupy a single drop of water.

An atom is the smallest particle into which matter can be divided. We may repeatedly subdivide a piece of gold until it is reduced to the thousand-millionth part of an ounce, and yet we shall be far from reaching a single atom. If it were possible to

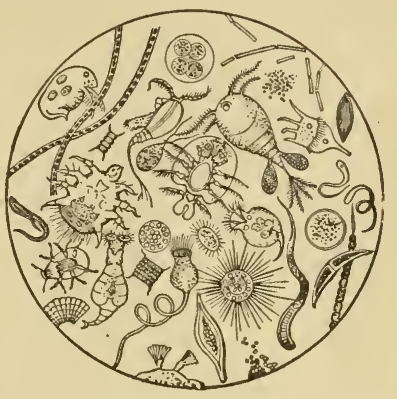

A Drop of Water. (Magnified.) continue the process long enough, a particle would finally be obtained which could no longer be divided or changed in any respect.

An atom of oxygen is always exactly the same, whether it forms a part of the soil, or of the air, or enters into the structure of a plant or an animal.

An atom is represented by the symbol which is used to denote the kind of substance. The symbol $\mathrm{O}$ may denote a quantity of oxygen in general, or an atom of oxygen. A number of atoms is indicated by a figure written below, and to the right. $\mathrm{O}_{2}$ denotes two atoms of oxygen, $\mathrm{H}_{6}$ six atoms of hydrogen.

Molecules. - Atoms do not generally exist alone. They possess a force of attraction which causes them to unite with other atoms, either of the same kind or of a different kind.

This force is called chemical affinity. It causes atoms to 
unite in regular groups. A group of this kind is called a molecule, which means a little mass.

Two atoms of hydrogen uniting with one of oxygen form a molecule of water. Twelve atoms of carbon, twenty-two atoms of hydrogen, and eleven atoms of oxygen, produce a molecule of sugar.

Molecules, though larger than atoms, are yet too small to be seen.

A molecule is represented by writing together the symbols of the different kinds of atoms of which it is composed, giving the number of atoms of each kind. The expression $\mathrm{H}_{2} \mathrm{O}$ represents either a molecule of water or water in general. $\mathrm{H}_{2} \mathrm{SO}_{4}$ denotes sulphuric acid, and indicates that in a molecule of the acid there are united two atoms of hydrogen, one of sulphur, and four of oxygen.

When more than one molecule is to be represented, the number is indicated by a figure prefixed. $2 \mathrm{CO}_{2}$ represents two molecules of carbonic acid.

In all molecules of the same substance the atoms are supposed to maintain a uniform order of arrangement.

They always hold regular positions with respect to each other. The positions depend upon the relative degree of attraction which the atoms have for each other.

The arrangements are supposed to be somewhat like the following :

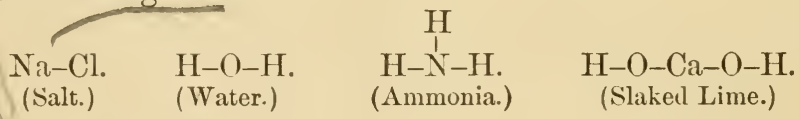

The Nature of Matter. - The nature of any substance depends upon the nature of the molecules of which it is composed. It may be entirely different from the substances whose atoms unite to form the molecule. 
Hydrogen and nitrogen are both odorless, but when united they form ammonia $\left(\mathrm{NH}_{3}\right)$ which is noted for its strong odor. Chlorine alone is poisonous, but with sodium it forms common salt $(\mathrm{NaCl})$. The great variety of different kinds of matter is produced by the great number of possible combinations of atoms of the elementary substances.

Chemical Action. - Molecules are the smallest particles into which a substance can be divided without changing its nature. Whatever change is wrought upon matter, its real nature remains the same so long as its individual molecules are not broken up.

A substance may be melted, or converted into a gas, or mixed with some other substance, and yet it is the same substance; but if its molecules are divided into their separate atoms, and these unite again with other atoms in different combinations, it is no longer the same.

The force which divides molecules into their separate atoms, and permits them to form other combinations, so as to produce new substances, is called chemical force, or the chemical action of one substance upon another.

When two molecules of different kinds are brought together, if some of the atoms of one are more strongly attracted by atoms in the other than by neighboring atoms in their own molecule, one or both of the molecules will be broken up and new molecules will be formed.

When water is poured upon quicklime, the atoms of the water molecule unite with those of the lime molecule, forming molecules of a new substance, or slaked lime.

When some of the atoms are not needed in making up the new molecule they are set free. If pieces of zinc are placed in hydrochloric acid, the chlorine of the acid will 
unite with the zinc, and the atoms of hydrogen unite with one another, forming molecules of free hydrogen.

Chemical force sometimes changes the nature of a substance by simply changing the arrangement of atoms in its molecules. The molecules of cane sugar, and those of gum arabic, for instance, contain exactly the same number of corresponding atoms $\left(\mathrm{C}_{12} \mathrm{H}_{22} \mathrm{O}_{11}\right)$. There are other instances in which the same is true. The only explanation of this is that the atoms must occupy different positions with respect to one another in the molecules of the different substances.

Chemical Equations. - The action of chemical force in breaking up molecules of different kinds when they are brought together, and forming new molecules, is represented by an equation.

In the case of water and lime the equation is:

$$
\underset{\text { (Lime.) }}{\mathrm{CaO}}+\underset{\text { (Water.) }}{\mathrm{H}_{2} \mathrm{O}}=\underset{\text { (Slaked Lime.) }}{\mathrm{CaO}_{2} \mathrm{H}_{2} .}
$$

For zine and hydrochloric acid it would be:

\section{$2 \mathrm{HCl}+\mathrm{Zn}=\mathrm{ZnCl}_{2}+\mathrm{H}_{2}$.}

(Acid.) (Zine.) (Zinc Chloride.) (Hydrogen.)

In the latter case it requires two molecules of the acid to combine with one of zinc, forming a molecule of zinc chloride and liberating two atoms of hydrogen.

Acids, Bases, and Salts. - There are three general classes of substances with which we must become acquainted in order to understand the chemical principles of agriculture.

They are called acids, bases, and salts.

The acids are a class of substances which generally have a sour taste. Vinegar contains acetic acid.

Some of the more common acids are: sulphuric acid 
$\left(\mathrm{H}_{2} \mathrm{SO}_{4}\right)$, muriatic or hydrochloric acid $(\mathrm{HCl})$, phosphoric acid $\left(\mathrm{H}_{3} \mathrm{PO}_{4}\right)$, silicic acid $\left(\mathrm{H}_{4} \mathrm{SiO}_{4}\right)$, carbonic acid $\left(\mathrm{CO}_{2}\right)$, nitric acid $\left(\mathrm{HNO}_{3}\right)$, etc.

Bases are a class of substances whose nature is very different from that of acids. A portion of them are called alkalies, or alkaline substances, and have a hot, sharp taste.

Some of the bases are potash $\left(\mathrm{K}_{2} \mathrm{O}\right)$, sodium (Na), lime $(\mathrm{CaO})$, magnesia $(\mathrm{MgO})$, oxide of iron or iron rust $(\mathrm{FeO})$, etc.

Acids and bases have a strong attraction for one another, and when united form a class of substances called salts. They are so named because many of them have a taste similar to that of common salt.

They are called sulphates, chlorates, phosphates, etc., as chlorate of potash $\left(\mathrm{KClO}_{3}\right)$, phosphate of lime $\left(\mathrm{CaOP} \mathrm{O}_{5}\right)$, nitrate of soda $\left(\mathrm{NaNO}_{3}\right)$, ete.

Gypsum, or land plaster, is sulphate of lime and water. It is the result of a combination of sulphuric acid and quicklime :

$$
\mathrm{I}_{2} \mathrm{SO}_{4}+\mathrm{CaO}=\left(\mathrm{CaSO}_{4}+\mathrm{H}_{2} \mathrm{O}\right) \text {. }
$$

Phosphate of lime is produced by a union of phosphoric acid and quicklime:

$$
2 \mathrm{H}_{3} \mathrm{PO}_{4}+\mathrm{CaO}=\mathrm{CaOP}_{2} \mathrm{O}_{5}+3 \mathrm{H}_{2} \mathrm{O} .
$$

If a feather is dipped in hydrochloric acid and held over an open bottle of ammonia, the ammonia, escaping by evaporation, will unite with the acid and form a white powder upon the feather, called ammonic chloride:

$$
\mathrm{NH}_{3}+\mathrm{HICl}=\mathrm{NH}_{4} \mathrm{Cl} \text {. }
$$

When the two parts of a rochelle powder are dissolved and poured together, the acid of the one unites with the base of the other, producing a salt, which remains dis- 
solved in the water; and carbonic acid, which escapes in the form of a gas, eausing the effervescence.

Cohesion and Adhesion. - As atoms have attractions which cause them to unite in moleeules, so the molecules themselves have similar attractions for one another.

When the attraction is between molecules of the same kind, it is called cohesion; when between molecules of different kinds, it is ealled adhesion.

Molecules of water have an attraction of cohesion for one another, but the adhesion between water and glass is sufficient to overcome this, and to cause a piece of glass to be moistened when dipped in water. On the other hand, an oily stick will not be moistened by water, because the cohesion in water is stronger than the adhesion between water and oil.

The adhesive attraction of water for gases causes the moisture of the atmosphere to absorb impurities and bring them down with the rain.

The attraction of charcoal for various substances renders it useful as a filter for cleansing water, refining sugar, etc.

In order that the forces of cohesion and adhesion may act, it is necessary to bring the molecules very near to one another. In breaking a piece of iron, we exert a force upon it sufficient to pull its molecules so far apart that the force of cohesion no longer acts.

In order to weld the separated parts it is necessary to heat them until their molecules will move more easily, and then beat them together by hammering until the molecules are again brought within the range of cohesive force.

In stretching a piece of rubber, we draw the molecules farther and farther apart, until finally the force applied 
is sufficient to overeome the force of eohesion by which the molecules are attracted to one another, and they are separated or the rubber is broken.

The Porosity of Matter. - All matter is more or less porous. This is not only true of loose substances like soil, but also of more solid substances, like wood and iron. The pores in the latter are, like atoms and molecules, too small to be seen.

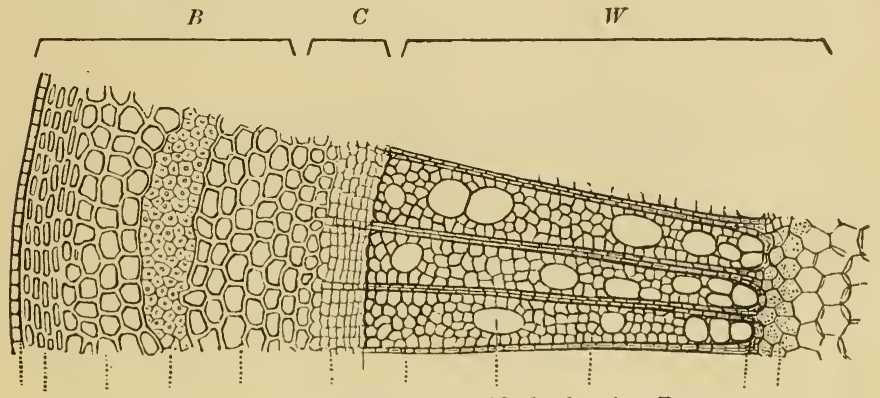

Cross-section of Wood, magnified, showing Pores.

$B$, the bark; $C$, the cambium layer; $W$, wood.

It is believed that neither atoms nor molecules ever remain in absolute contact with each other, but that there are always spaces between them. Through these spaces atoms and molecules of other substances are able to pass.

A eertain amount of salt and sugar may be dissolved in water without increasing the volume of water. The molecules of salt and sugar oceupy the vacant spaces between the molecules of water.

Under heavy pressure water has been foreed through the pores of iron. A piece of iron may be made smaller by hammering. Its molecules are then driven nearer together.

A bottle filled with gas will hold as much of another kind of gas as if it were empty. 
Solids, Liquids, and Gases. - Matter exists in one of three states: either as a solid, a liquid, or a gas. The same substance may assume one of these forms at one time, and another at another time.

The state is supposed to depend upon the degree of attraction by which its molecules are bound together.

When they are firmly united, the substance is a solid. When the force that binds them is weaker, allowing them to move freely upon one another, it becomes a liquid. When the force is entirely overeome, it becomes a vapor or gas. The molecules then fly apart, tending to occupy as much space as possible.

The state of a substance is partly dependent upon the temperature.

Heat tends to orercome the attraction, and so to change a substance to the liquid or gaseous form. A moderate amount of heat will change a block of ice, first to water and then to vapor. A higher temperature will produce a similar effect upon other solids.

Heat, by overcoming the force that draws molecules together, increases the distance between them, and so increases the space which they occupy and the size of the body. So, on the other hand, a low temperature allows the molecules to come nearer together, and renders the body smaller.

There are a few exceptions to the general rule that heat expands and cold contracts. When water is cooled enough to freeze, or become a solid, it is crystallized; that is to say, its molecules arrange themselves in certain forms which require more space than if they were packed closely together. The same is true of a few other substances when changing from the liquid to the solid state. 
The expansive force of water in freezing, or crystalhaing, is very great. A pitcher filled with water, and allowed to freeze, is sure to be broken. 'The moisture of the soil in freezing beneath a building lifts it perceptibly every winter.

Snowflakes illustrate the tendency of freezing water to crystallize. When examined with a microscope, they present a great variety of regular forms whose beauty and accuracy it would be difficult to imitate.

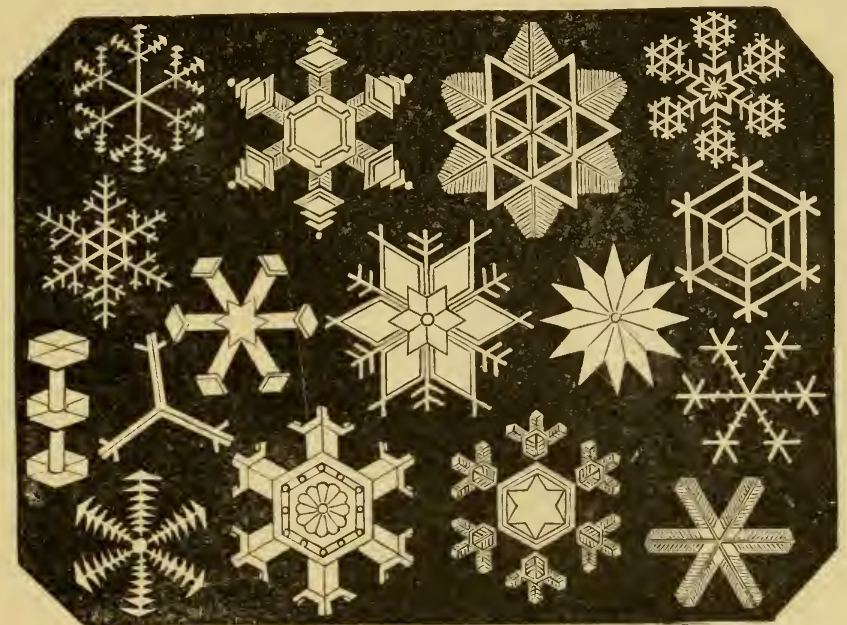

Snow Crystals.

Other substances, like sugar, salt, and alum, show the same tendency. When these are dissolved in water, as their molecules slowly come together again by the evaporation of the water, they tend to arrange themselves in regular forms.

Organic and Inorganic Matter. - Matter is sometimes divided into two classes: organic and inorganic.

WINS. AgR -2 
Organic substances are those which have been con. verted into living organisms; or, in other words, which either form or have formed a part of the bodies of plants and animals. They are produced by the processes of life. All other matter is called inorganic.

When organic matter is burned or decays, it returns again to an inorganic condition.

Pieces of stone or iron, for instance, are not organic, because they have no organs such as exist in anything which has life. On the other hand, wood, hay, flesh, and bones are examples of organic matter, since they have been produced by the growth of living plants and animals, and retain the same matter and the same form which they had when in a living state. Soil may be partly organic and partly inorganic, since it not only contains mineral matter, but also vegetable and animal matter, left by the death of plants and animals, which has not yet become so far changed as to lose its organic condition.

Organic substances have never been produced by artificial means. For articles of food, - fruit, vegetables, and meat, - as well as for the materials used for clothing, - cotton, wool, linen, and silk, - the world must depend upon nature's processes in agriculture.

All attempts to imitate nature by producing these substances have failed.

Combustible and Incombustible Matter. - When any substance is burned, some of its elements escape into the atmosphere in the form of gases and floating particles, and the remainder become ashes. The carbon unites with the oxygen of the air, and escapes as carbonic acid gas. Some of the nitrogen is converted into ammonia gas. The water is converted into vapor. 
The elements which escape include the carbon, hydrogen, oxygen, and nitrogen, and sometimes the sulphur. The remaining elements are found in the ashes. The former are called combustible or volatile, and the latter incombustible or fixed.

The following is a brief description of the more common elements :-

0xygen is the most common and interesting of the elements. It forms about one half of the solid parts of the earth, eight ninths, by weight, of all water, and one fifth of the air. It has powerful attractions for many other elements. The substances formed by its union with these are generally called oxides. Water $\left(\mathrm{H}_{2} \mathrm{O}\right)$ is sometimes called hydric oxide. Lime $(\mathrm{CaO})$ is calcic oxide; iron rust ( $\mathrm{FeO})$, ferric oxide. There are three familiar processes in nature in which oxygen takes a leading part:-

1. Combustion. - The ordinary process of burning, or combustion, consists of the union of the oxygen of the air with carbon and some other elements of the fuel. This union with carbon produces a gas $\left(\mathrm{CO}_{2}\right)$ called carbon dioxide, or carbonic acid gas.

Heat is a result of the union. It is regarded as a kind of force. The force or clash with which atoms come together in burning is converted into another kind of force called heat. The degree of heat depends upon the rapidity of the process. A draft through a fire increases the heat, because it furnishes a larger supply of oxygen.

2. Oxidation. - In the rusting of metals, and the decay of wood, a process is going on precisely similar to that of burning, except that it is much slower. New combinations are formed, and the same amount of heat 
is produced as if the iron or wood were burned, or oxidized more rapidly. The process is so slow that the heat is not noticeable.

The decomposition and decay of all substances, in general, is largely a process of oxidation. Articles of food are preserved from decay by separation from the oxygen of the air. The decay of soft regetable substance, as well as the erumbling of the hardest rock, shows the power of oxygen in transforming the products of nature.

3. Respiration. - Respiration or breathing in animals is similar to combustion and oxidation. The oxygen of the air, taken into the lungs, enters the blood, where it unites with carbon. The carbonic acid gas thus produced escapes with the breath into the atmosphere.

The heat which results from this union serres to keep up the temperature of the body of the animal. The amount of heat per day produced in the system of a man by breathing is about equal to that obtained by burning a pound of coal.

Plants breathe to a slight extent, taking in oxygen through the pores of their leaves, and giring off carbonic seid gas.

Hydrogen is the lightest substance known. It weighs only one sixteenth as much as oxygen. It combines most readily with oxygen and chlorine. When burned or combined with oxygen, it forms water. It is an essential part of plants and animals. It is produced by the decay of animal and regetable matter, or from molecules of water, by separating it from the atoms of oxygen.

Nitrogen, in a free state, forms four fifths of the air. It is an odorless and harmless gas. Its purpose in the air seems to be to dilnte the oxygen with which it is mixed and diminish its force. 
It forms an essential part of plants and animals, and is of great importance for agricultural purposes. Its force of attraction for other elements is very weak. This fact increases the difficulty of retaining it in permanent forms. It is the most expensive part of fertilizers. With hydrogen it forms ammonia $\left(\mathrm{NH}_{3}\right)$; with hydrogen and oxygen, nitric acid $\left(\mathrm{HNO}_{3}\right)$. These are the two forms in which nitrogen most commonly becomes a source of fertility, and of importance in agriculture.

Carbon is found in nature in three forms: as charcoal and similar substances; as graphite, which is used in making lead pencils; and as diamonds, which are simply crystallized carbon.

It forms a large part of all animal and vegetable substances. Coal, wood, and woody substances are largely composed of it. It is the element which gives value to substances used as fuel.

Charcoal, which is largely composed of free carbon, is produced by burning wood in a partially smothered fire. The process releases the carbon from other elements with which it is combined, and retains it by excluding the oxygen of the air, with which it would otherwise unite and escape as carbonic acid gas.

If a piece of wood is placed in sulphuric acid and allowed to remain for some time it becomes black. The acid remores the other elements of the wood and leaves the carbon.

If a piece of glass is held orer the flame of a candle it becomes "smoked," or corcred with minute particles of carbon, which escape faster than they can be consumed.

All plants contain a large proportion of carbon. In cotton fiber it is almost pure. Sugar, which is a product of plants, is forty-two per cent. carbon, by weight. 
Silicon is the most abundant solid substance known. It forms about one fourth of the solid parts of the earth. It is commonly combined with oxygen in the form of silica $\left(\mathrm{SiO}_{2}\right)$. Quartz rock is a variety of silica. It forms a large part of granite rock, sandstone, and common sand. It serves, like an acid, to unite with bases, forming what are called silicates. Common glass is a mixture of different silicates. Clay is chiefly composed of silicate of alumina.

Silica is found in plants, particularly in the grasses. It gives to the stalks and branches greater firmness and hardness.

Sulphur is a familiar substance, commonly known as brimstone, or flowers of sulphur. With hydrogen and oxygen it forms sulphuric acid $\left(\mathrm{H}_{2} \mathrm{SO}_{4}\right)$, one of the most common acids. This acid forms a great variety of useful salts, as sulphate of potash $\left(\mathrm{K}_{2} \mathrm{SO}_{4}\right)$, sulphate of lime $\left(\mathrm{CaSO}_{4}\right)$, etc.

Sulphur is always found in plants and animals. The strong flavor of such regetables as turnips and onions is due to the presence of sulphur.

Phosphorus is a soft, yellow substance, which unites with the oxygen of the air and takes fire so easily that it can only be kept under water. It is used in manufacturing matches. It combines with hydrogen and oxygen, forming phosphoric acid $\left(\mathrm{H}_{3} \mathrm{PO}_{4}\right)$, a substance of great importance in fertilizers. It forms about ten per cent. of the bones of animals, in the form of calcium phosphate.

Chlorine is a gas which is found only in combination with other elements. With hydrogen it produces hydrochloric or muriatic acid ( $\mathrm{HCl})$; with sqdium, sodium chloride or common salt $(\mathrm{NaCl})$. 
Potassium is a soft, light sulustance, whose affinity for oxygen is so strong that it can only be kept pure in some substance containing no oxygen. When placed upon a piece of ice it burns freely.

With oxygen it forms potash $\left(\mathrm{K}_{2} \mathrm{O}\right)$, and with oxygen and hydrogen caustic potash (KOH). Potash unites with acids producing a variety of salts of potash, as chlorate of potash $\left(\mathrm{KClO}_{3}\right)$, sulphate of potash $\left(\mathrm{K}_{2} \mathrm{SO}_{4}\right)$, etc.

Sodium is somewhat similar to potassium. It forms a great variety of salts, of which common salt $(\mathrm{NaCl})$ is a familiar example. Caustic soda is prepared in large quantities for manufacturing soap.

Calcium is a common substance, found in combination with other elements, from which it is not easily separated. In limestone and marble it is united with carbonic acid, forming calcium carbonate $\left(\mathrm{CaCO}_{3}\right)$.

Compounds of calcium constitute a large part of the shells of clams, oysters, and other shell-fish, and also of the bones of all animals.

Magnesium is a metal found in some rocks. The pure metal burns brilliantly, and is sometimes used for illuminating purposes when a very strong light is required. It is found to some extent in plants and animals. With oxygen it forms magnesia ( $\mathrm{MgO})$.

Aluminium is somewhat similar to magnesium. It resembles silver in appearance. It is used to a small extent in making jewelry and ornamental work. The sapphire and ruby are beautiful forms of alumina. It exists largely in common clay in combination with silica.

Iron is found in many parts of the earth in the form of ore, which is purified and used for manufacturing purposes. It exists to some extent in all soils. It gives clayey soils their dark brown colør. 


\section{QUESTIONS.}

How many different elementary substances are there in the earth? Name those which are most common. Name as many others as you can think of. What is meant by the symbol of a substance? Name the symbols of the most common substances.

What is an atom? Have atoms ever been seen? How do we know that they exist? How are atoms represented? Give an idea of the size of an atom. Can an atom be divided? Can it be destroyed?

What is a molecule? What causes atoms to form molecules? How is a molecule represented? How are the atoms of a molecule arranged?

Upon what does the nature of matter depend? Must all substances composed of carbon, hydrogen, and oxygen be alike? Can the molecules of a body be broken or divided? How can this be done? What effect does this have upon a body? What would be the effect of making a different arrangement of the atoms in the molecules of a substance?

What is chemical action? Give an example of chemical action, and explain it.

What are acids? Bases? Salts? Name some of each.

Give a chemical equation showing how bases are formed.

What is cohesion? What is adhesion? Why does your hand become wet when dipped in water? Why are the feet kept dry by greasing the boots? How is water purified by leaching through charcoal? Why are not two pieces of wood touching each other held together by cohesion?

How many porous substances are there? How do we know that iron is porous? Why ean salt be added to a glass full of water without causing it to run over? Why may two gases appear to occupy the same space at the same time?

Explain the difference beween solids, liquids, and gases? Why is a substance melted by heating it? How is it that heat expands and cold contracts? Why does water expand in freezing?

What is the difference between organic and inorganic matter? Is hay organic or inorganic? A potato? Water? Milk? Sand? Ordinary soil? 
Explain the difference between combustible and incombustible matter. Mention some common substances which are partly combustible. Mention some which are entirely combustible. Name some that are entirely incombustible.

How much oxygen is there in the earth? What is an oxide? Explain the process of burning. What is heat? Why does a fire burn better in a draft of air? Why has decayed woorl lost a part of its value for fuel? Why do we seal fruit to preserve it? How does breathing keep the body warm?

What are the peculiarities of hydrogen? Why is water produced by burning hydrogen? Where is nitrogen to be found? Why is it so difficult to obtain it for practical purposes?

Name some objects that contain carbon. What proportion of the earth is silicon? Name some forms in which it is found. Name some of the uses of sulphur. Describe phosphorus. Name some useful forms of chlorine.

Describe potassium. Name some of the salts of potash. Mention some useful forms of sodium. Where is calcium found? IIow may magnesium be distinguished? Name some forms of aluminium. Where does iron exist? 


\section{CHAPTER II.}

\section{LAND AND WATER.}

The Former Condition of the Earth. - The earth has not always been as it now is, but has been gradually changing through long periods of years. It is believed that it was once very hot, - so hot that all the solid substances now upon it were melted, or converted into gases. As it gradually cooled upon the outside, some of these liquids and gases became solid, and formed a crust upon the surface. It is believed that the interior of the earth remains to the present day in a very hot condition. There are sereral indications of this:-

1. In descending into the earth, after passing below the effect of the sun's heat, the temperature becomes higher the farther we descend.

2. Earthquakes are, in some way, due to morements of the melted substances or gases, or of the crust abore them.

3. Some of the hot liquids and gases are often poured forth from volcanoes.

It is hardly to be supposed that the whole of the earth's interior is a liquid, because, while the temperature may be sufficiently high to melt all known substances, the immense pressure under which all matter is placed at any great depth below the surface must be sufficient to retain it in a solid form, notwithstanding the excessive heat. 
As the process of eooling went on, the moisture of the atmosphere became condensed; and, falling as rain, covered the earth's surface with water.

Out of this primitive earth, this erust of mineral substances, and the water and atmosphere surrounding it, and out of the plants and bodies of animals that have lived and died upon its surface, have been formed the soil and rocks of our present earth.

The Age of the Earth. - The processes by which this great ehange has been brought about have been, for the most part, silent and gradual. Many of them are still going on. Our earth, with the variety of substances upon it, is not to be considered as a thing completed, but as constantly undergoing changes in the great workshop of Nature.

The period of time that has elapsed since the first solid crust was formed must be exceedingly long. Some of the lowest estimates made by careful students have been from fifteen to twenty million years.

Continents. - It is a common prineiple in nature that heating a body eauses it to expand, and eooling eauses it to contract, or beeome smaller. Now, it is impossible for a spherical body, with a solid surface, to become smaller without forming upon its surface dents and ridges, or depressions and elevations. As the ancient earth became still eooler and smaller, after having first formed a crust, it was natural that this erust should beeome irregular in shape, producing low and high places. The water naturally sank into the lower places, leaving the elevated regions as continents.

The continents that thus first appeared above water were very small, and gradually increased in size, extending their eoasts as the continued shrinking of the erust 


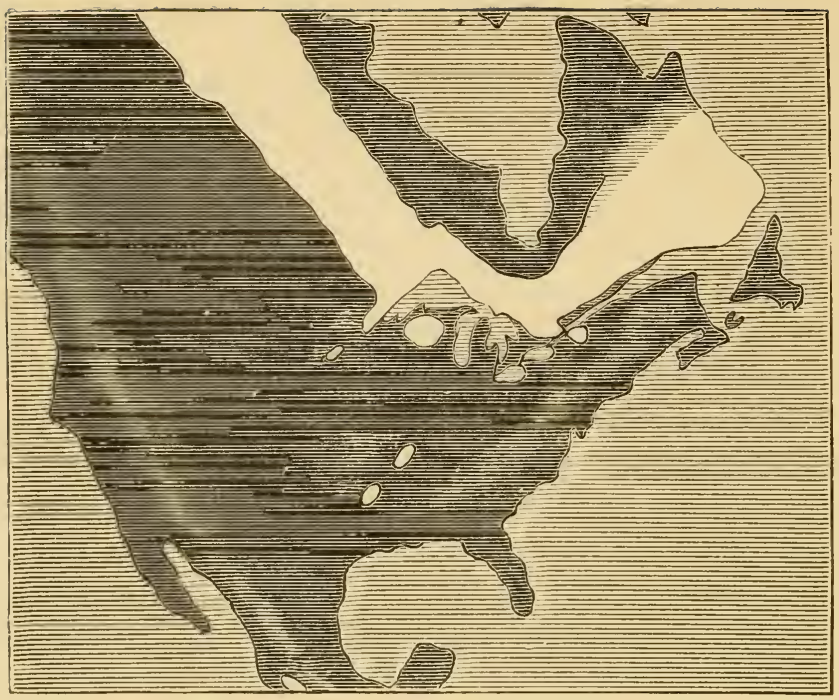

The Beginnings of North America. (White indicates land.)

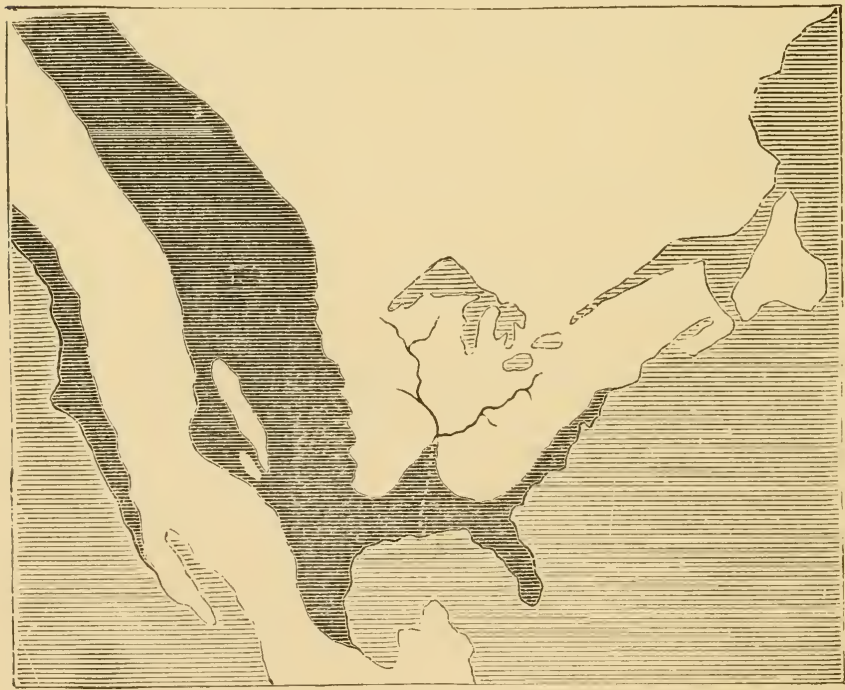

North America in the Secondary Era. (White indicates land.)

(2) 
raised them more and more above the level of the water. The first appearance of the North American continent was in a small, angular section, extending from the Great Lakes northeast to Labrador, and northwest to the Arctic Ocean.

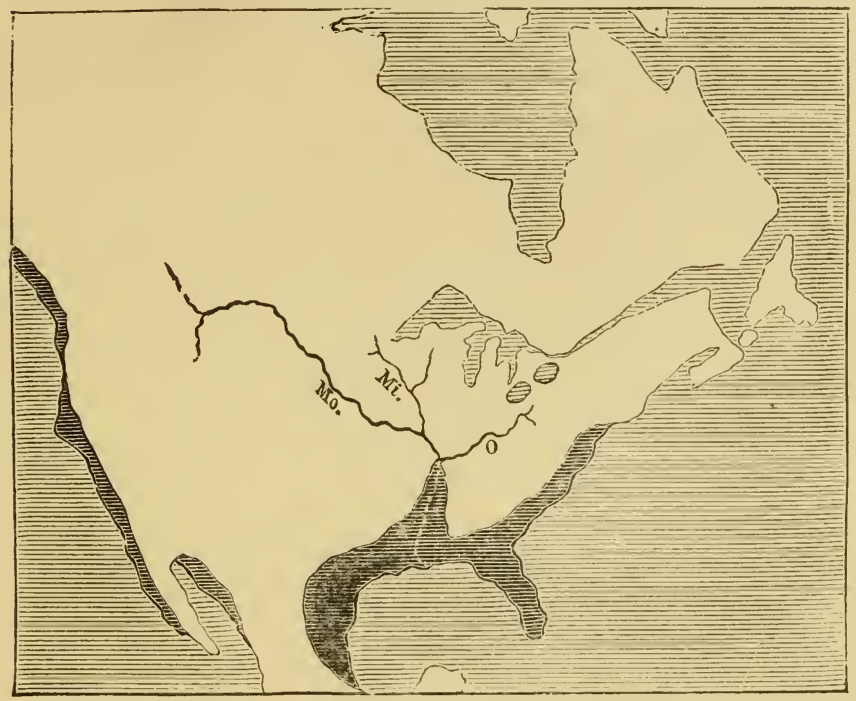

North America in the Tertiary Era. (White indicates land.)

Mountains and Hills. - The cooling and shrinking of the continent has also given rise to mountain ranges and valleys. The inward pressure and sinking of certain sections caused long cracks in the earth's crust, and the upturned edges have formed some of the great mountain ranges of the earth.

Some mountains have also been formed by an accumulation of melted matter poured from these cracks and from volcanoes. 
Many of the smaller hills have been formed by bodies of moving water and ice, which have ground out valleys between them.

The formation of hills, and other changes upon the face of nature, have been brought about gradually. Falling rains and running streams are slowly reducing the size of the hills by wearing them away and carrying them to the valleys below. In some cases, on the other hand, swift running streams and rivers are wearing out and increasing the depth of the valleys between the hills.

The Soil. - If we examine some soil with a microscope, we shall find that, while it contains some other substances of a different nature, a large part of it is composed of finely divided particles of rock. These are generally of a similar nature to the larger rocks that are scattered through the soil, and have been produced from large rocks by the grinding and erumbling forces of nature.

The greater part of our present soil, however, was not formed directly out of the original rocks of the first crust of the earth. The soil formed by the first crumbling of the original rocks generally solidified, or petrified, into rock again, and this process of crumbling and solidifying continued through several alternations until our present soil was formed.

Nearly all the present rocks were at some time soil. Conglomerate stones, sometimes called "pudding-stones," are examples of an ancient soil, containing stones of different kinds, which has been transformed into solid rock. Sandstone was once a bed of sand.

Specimens of rocks from the original crust are now to be found only in a few scattered localities in those sections which first appeared above water, where, by virtue 
of their elevated position, they have partly escaped the forces that would tend to destroy them.

The process of rock-making is still going on. There is often to be found, beneath the surface soil, a stratum of "hard pan," through which it is difficult to penetrate. This is gradually becoming solidified by the action of chemical forces, and at some time in the distant future will become stone.

The chief agencies in nature which have done the work of grinding rocks, and preparing the soil of the earth, are:-

1. The Atmosphere.-Nearly all rocks, when exposed to the atmosphere above ground, undergo chemical changes upon their surface by which portions are continually crumbling and falling off. This effect upon some rocks will cause them to waste away in a very few years, while with others the process is much slower.

Some varieties of sandstone are found near the surface, so much affected by the atmosphere, which has reached them through the porous soil, as to be easily crumbled into powder.

The most enduring kinds of marble, used for erecting monuments, are generally covered with fine marble dust, showing that even they are not exempt from the unirersal tendency.

2. Running Water. - With every shower and rain storm, and with the melting snows in spring-time, streams and brooklets are constantly wearing away the rocks, and washing away soil from the sides of hills and mountains, and carrying it into the rivers below. As the current of the river becomes less rapid, this soil settles, forming deposits on the banks of the river at its mouth, or on the neighboring shores of the ocean. 
When the streams and rivers are much swollen, they wash out and bear away many rocks in their swift current. As these are rolled and tumbled one upon another, they are ground into soil, which is added to the general deposit. The momtains and hills are thus gradually carried away to fill the valleys below, and to extend the coasts of the continent. 'The rich alluvial lands in river valleys have been formed in this way.

3. The Oceun. - The morements of water on the shores of the ocean produce an effect similar to that of rivers. The flow and ebb of the tide, and the breaking of waves on the beach, grind rocks into sand, or wash up shells from deeper water, grinding them into fine powder. This process has been going on since land first appeared above water, forming the origin of our continent.

The ocean has been continually forming beds of sand and mud on or near its shores. These have been raised above the surface, as the waters have receded, and in many cases have become consolidated into rock. Sandstone and limestone have been mostly produced in this manner, the former from the sand beds, and the latter from mud formed by the grinding of shells. A similar effect has been produced by large lakes, some of which have become entirely dry, leaving deposits of sand, lime, or other mineral matter.

4. Ice. - Ice forming in the cracks and crevices of rocks, year after year, tends by its expansion to burst the rocks or open crevices, thus admitting the atmosphere, and hastening the work of erumbling.

Minute particles are also detached from the rocks by the freezing and thawing of the moisture upon their surface. If a number of clean stones are placed in a pail of pure water, and the water is allowed to frecze 


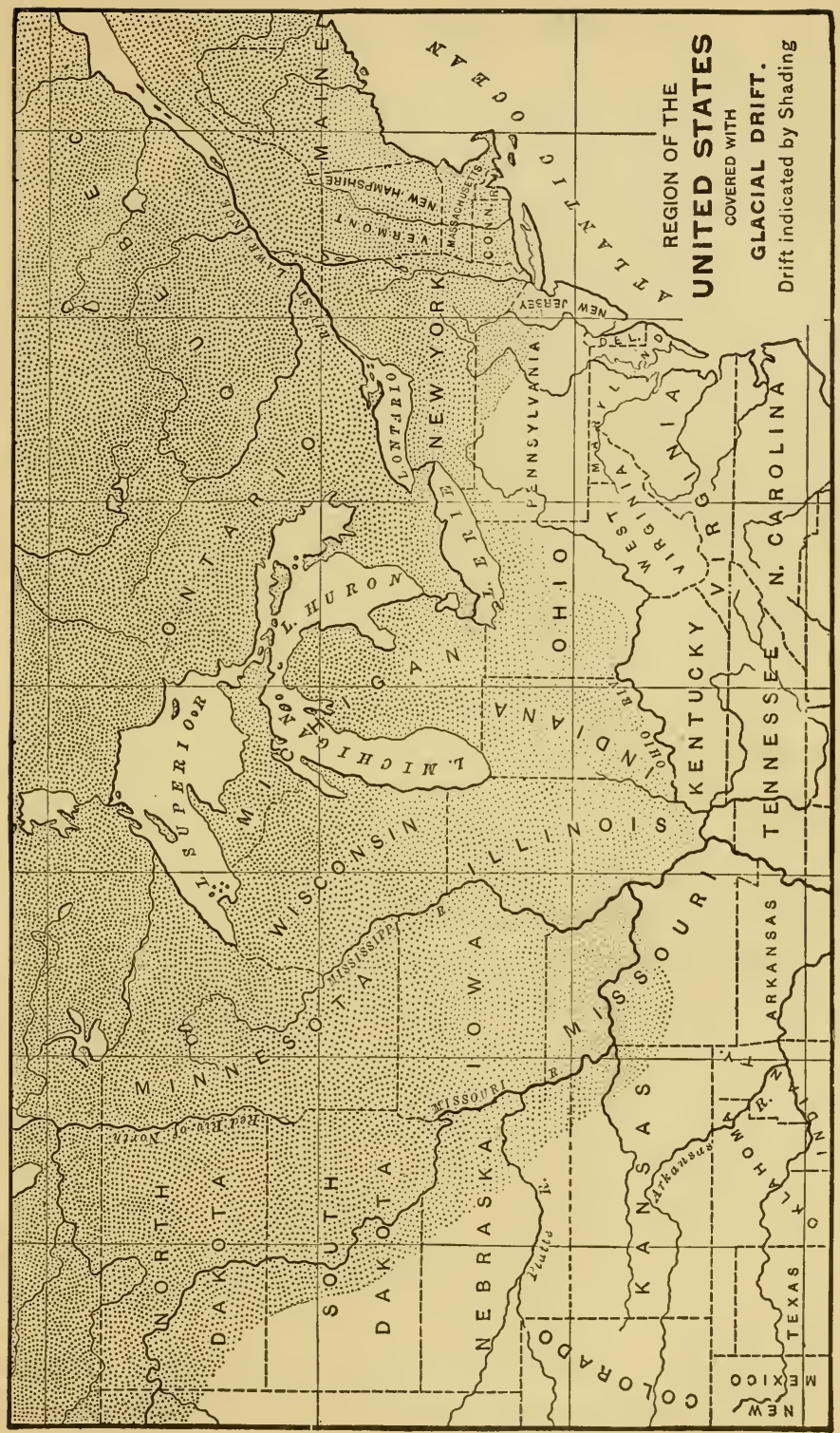

(33) 
and thaw several times, there will be found a perceptible quantity of fine particles at the bottom.

But the greatest effect of ice in forming soil, and changing the face of nature, has been through glaciers.

In high, mountainous regions, and in cold latitudes, snow steadily accumulates, forming immense masses of ice in the deep valleys. These are steadily, but very slowly, pushed along by their own weight until they reach a lower and warmer region, where they melt away. These huge rivers of moving snow and ice are called glaciers. Rocks in the course of the glacier are torn up and borne along, grinding upon one another, and grinding paths through other solid beds of rock, until they are deposited as bowlders and soil at the point where the glacier melts.

It is believed that, at some time in the history of the earth, the regions to the north of the equator became for a time much colder than at present, causing perpetual snow to fall upon large portions of North America and Europe, deep enough to bury most of the hills and mountains beneath vast, continuous glaciers.

These glaciers, moving toward the equator, ground enormous quantities of rock into soil, and deposited it over a large extent of country, together with the rocks which remained unground. Huge bowlders, as well as smaller rocks, scattered over the country, may be traced back northward many miles, to their original bed. In New England they have been carried two or three hundred miles, and in the Mississippi Valley one thousand miles. Soil and rocks which have been transported in this way are called drift.

5. Winds. - Winds have also taken some part in forming soil, and especially in changing its location. In 
some sandy regions, large rocks have been partly worn away by the sand which has for centuries been blown across their surface. Whole hills have, in some instances, been thus worn away and deposited in other localities.

The Composition of Soil. - The soil of the earth may be considered as composed of four different classes of substances :-

1. Finely Divided Particles of Rock. - Crumbled rock, or sand, constitutes the bulk of many varieties of soil. Even soft, peaty soil will be found, upon careful examination, to contain a greater or less percentage of gritty substance.

2. Decaying Vegetable Matter. - Nearly all kinds of soil contain more or less of a soft, pasty, dark-colored substance called humus, or vegetable mold. The grass, leaves, and falling trees, which are continually accumulating upon the surface of the soil, and are mixed with it by cultivation, furnish a perpetual source of this humus. It forms a large part of the peaty soil found in low places. In peat or muck beds it is nearly pure.

Peat, or swamp muck, is an accumulation of vegetable matter which has been formed through long periods of the ancient history of the earth.

In low, marshy places, certain kinds of rank vegetation have grown year by year, or from age to age, and, falling, have been buried one upon another in water and mud. These accumulations have undergone a process of slow decay, or smothered combustion, under water, which has reduced them to a uniform mass of black or brown matter. The dark color is due to the presence of carbon which results from the slow combustion, as charcoal is obtained from the smothered burning of wood. 


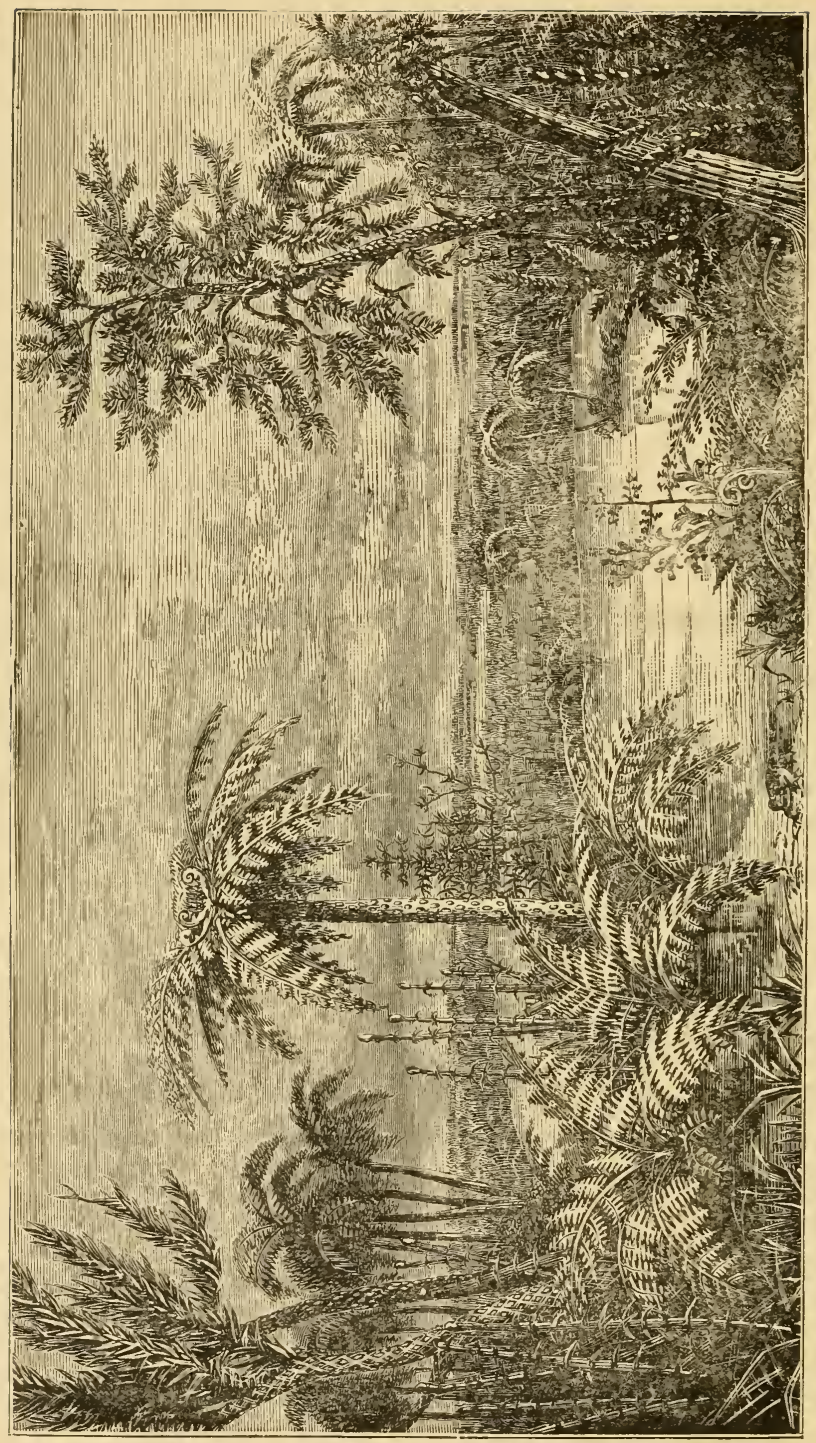

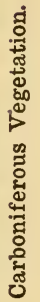


In some cases, in low places, the process has been continued further, until the peat has been petrified, or converted into coal.

Peat beds are very numerous. Some of them are of very large extent. The great "Dismal Swamp" of North Carolina is a vast peat bed.

Many of the smaller muck swamps are partly composed of ordinary suil, which has been washed in from the surrounding hillsides.

3. The Remains of Animals. - The bones and shells of all the great numbers and rarieties of animals that have lived and died on the land, and in the ocean, have contributed to the formation of certain kinds of soil. Limestone, and limy matter in soil, have been produced from shells which have accumulated in the ocean, and in lakes which have become dry. The rock of coral reefs, and the soil formed by the crumbling of such rock, are largely composed of the remains of minute animals.

The bones of land animals, when decomposed or ground, add desirable elements to the soil.

4. Substances formed by Chemical Action from the three Classes mentioned. - The presence of these substances gires fertility to the soil. Neither crumbled rock, nor the remains of plants or animals, in their crude original condition, would furnish any food for the support of plants; but by chemical processes in the soil new combinations are gradually formed which are adapted to the support of regetable life.

Soils are commonly classified according to the substances of which they appear to be largely composed, as follows:-

1. Sandy. - Pure sand, which is composed entirely 
of particles of quartz rock, would be of little value for agricultural purposes. It can furnish no food for the support of plants. It is generally, however, mixed with other substances which give it some fertility. Sandy soil has but little power to retain moisture. Rain water readily soaks through it and runs away. Such land suffers severely from a drought. It is, furthermore, unable to retain for any length of time the supplies of plant food which are formed in it or added to it. These substances are washed out as water passes through it. It is called light soil, and has the advantage of being easy to till. It becomes dry and warm enough for cultivation earlier in the spring than other kinds of soil.

2. Gravelly. - Gravel is like sand, except that the rocks of which it is composed have not been ground so fine. Gravelly soil is largely composed of rocks ground to various degrees of fineness. It has the same general properties as sandy soil. When nearly pure, it is even less valuable than the latter for agricultural purposes.

3. Clayey. - Clay consists of certain kinds of decomposed rock. Pure clay, of itself, contains but little plant food, but it possesses in a remarkable degree the property of absorbing and retaining other substances which tend to render it fertile. Fertilizers which have been applied to clayey soil are retained for a long time, until withdrawn by growing crops.

Water leaching through such soil is found to come away as pure as when it enters, washing away no valuable substances.

It is called heary soil. Water passes through it very slowly, so that it cannot be tilled until late in the spring, or for a long time after heary rains. If handled and 
pressed together when wet, it has the peculiar tendency to form hard lumps, requiring considerable labor to pulverize them and provide a fine seed-bed for crops.

4. Peaty, or Mucky. - This is one of the most valuable kinds of soil for agricultural purposes. It consists of a mixture of ordinary soil with large quantities of vegetable mold. It has great power to retain moisture through periods of dry weather. It contains large supplies of some kinds of plant food, which are gradually converted into suitable form to meet the demands of successive crops year after year.

5. Limy, or Calcareous. - Most soils contain some lime. In some cases the quantity is so large as to give a name to the soil. The variety of soil called marl con. tains large quantities of carbonate of lime.

The lime in soil serves to some extent as food for plants, as all plants require a small quantity of it. It also serves a good purpose indirectly, as a base, by com. bining with acid substances in the soil, and forming salts which are desirable as plant food.

6. Loam. - This is simply a general name applied to ordinary soil, which contains a mixture of the varieties mentioned, combined in varied proportions. If quite sandy, it is called sandy loam; if quite clayey, clayey loam.

\section{QUESTIONS.}

What was the original condition of the earth? How did the surface become solid? What is the present condition of the interior of the earth? How do we know it? What caused the appearance of water upon the earth? How old is the earth?

How were the continents formed? Explain the origin of mountain ranges and hills. Of what is soil largely composed? How has it been formed? Give the history of most of our present rocks. 
Is any of the first crust of the earth still in existence? Name the five natural agencies that have ground rocks into soil.

What is the effect of the atmosphere? What work do streams and rivers perform? What has the ocean done? Explain the effect of ice upon rocks in winter. What is a glacier? Where are glaciers to be found at the present time? How have glaciers assisted in forming soil? What has been the effect of winds?

Name the classes of substances of which soil is composed. Explain the origin of humus, or vegetable mold. Give the history of the formation of peat beds. What is the origin of limestone? Name the different varieties of soil. Give the peculiar properties of each. 


\section{CIIAPTER III.}

\section{THE ATMOSPHERE.}

'THE atmosphere includes the air and other gases 1 and vapors which surround the earth. Its composition is as follows:-

1. Air. - Air forms the bulk of the atmosphere. It is composed of oxygen and nitrogen, in the proportion of one part oxygen to four parts nitrogen. The two are not chemically united into molecules, but the molecules of each are thoroughly mixed together. It is the oxygen of the atmosphere that is essential to plant and animal life. The purpose of the nitrogen seems to be to dilute the oxygen and reduce its force.

2. Water Vapor. - There is always present in the air, and distributed through it, more or less moisture, or vapor of water. The quantity varies from one fiftieth to one two-hundredth part of the bulk of the air. This moisture passes into the air by evaporation from the surface of bodies of water, from the surface of the land, and from all moist substances.

We are reminded in various ways that the air contains moisture, as in the drops that form upon the outside of a pitcher of cold water, in the moisture that accumulates upon the window-pane and forms a thick covering of frost in winter and in the moisture that appears upon the grass in the morning. 
When the air becomes overcharged with moisture, the surplus comes to the earth again in the form of rain.

3. Carbonic Acid Gas. - The chief sources of this gas in the atmosphere are the breathing of animals, the burning of fuel, and the decay of organic matter.

It is thrown off from the systems of animals as useless, but is essential to the life and growth of plants.

It may be seen that the escaping breath contains carbonic acid, by breathing through a tube into clear limewater. There will be formed in the water a white powder, which is carbonate of lime, produced by the union of the carbonic acid and the lime.

Although the air always contains some carbonic acid gas, when too large a quantity is present it becomes poisonous. For this reason it is unwholesome to sleep in a small, close room, without some ventilation, or for many persons to remain long in any closed room. The burning of lamps in a room, or the decay of vegetables in a cellar, produces the same effect as the breathing of persons, by adding to the proportionate amount of carbonic acid gas.

4. Impurities. - The air contains small quantities of various substances, as ammonia, nitric acid, etc., besides smoke and dust.

These are largely absorbed by the water vapor, and brought to the earth in raindrops. They give rain-water its dark color, and render it of some value as a fertilizer for crops.

Weight of the Atmosphere. - The atmosphere has weight as truly as the objects which we can see and handle. The height, or distance from the earth to which it extends, is not definitely known. It is rariously estimated at from one hundred to five hundred miles. 
It produces a pressure upon every spot equal to the weight of the whole column above. This pressure amounts to about fifteen pounds upon every square inch.

The pressure is not simply upon the top of an object, but upon the sides and underneath as well. It is not like one solid body resting upon another. The particles of gases and liquids move about so freely that the pressure upon any object contained in them is evenly distributed in every direction.

As the pressure of the air is evenly balanced upon all sides, we are not conscious of it.

Upon the outstretched hand there rests a column of air that would weigh two or three hundred pounds. We are not conscious of it, because there is an equivalent pressure underneath the hand to support it. When the pressure underneath is removed by placing the hand upon the receiver of an air-pump, and exhansting the air, the pressure upon the top becomes painful. If the moistened palms are rubbed closely together, so as partially to remove the air, some force is required to pull them apart. If the air is removed from the mouth by expanding the lungs, the pressure of air outside forces the cheeks inward.

The atmosphere near the earth is more compressed and heavy than at some distance above it, because there is more air above to press down. There is a marked difference between the pressure and density of air in a valley and on a high mountain.

The barometer is an instrument for determining the pressure of the air. It really consists of a tube sealed at one end, filled with mercury, and inverted into a cup or bag of mercury. The pressure of air upon the mer- 
eury in the cup or bag forces this up into the tube until the column of mercury in the tube is heavy enough to balanee the pressure of the air. The heavier the air, the more it will press, and the higher the colunn will

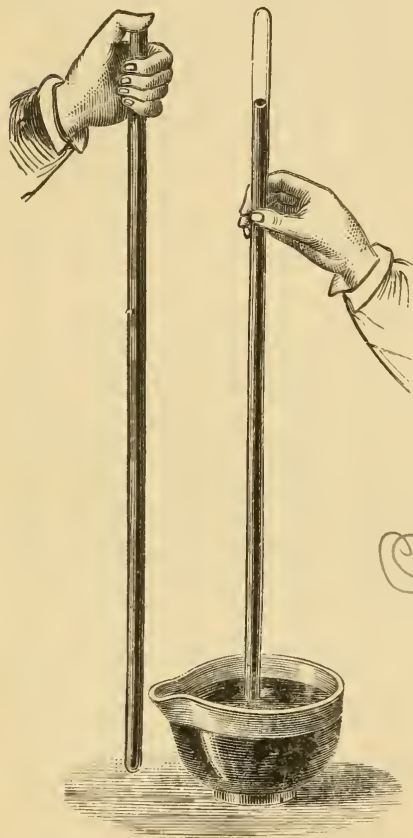

A Barometer Tube. rise in the tube. On the other hand, the lighter the air, the lower the columm will fall.

Changes of temperature and morements in the atmosphere eause the weight and pressure to vary. As this variation is correctly determined by the barometer, this instrument beeomes of great service in calculating probable changes of weather.

- Temperature. - The thermometer is used to determine the temperature, or the amount of heat that the atmosphere eontains. It eonsists of a tube, with a bulb at the lower end, containing mereury or alcohol. On the principle that heat expands and cold contracts, when the atmosphere becomes warm the mercury or alcohol expands and rises in the tube, and as the atmosphere becomes cooler it contracts and falls.

Winds. - Since the atmosphere is invisible, we are apt to forget that it exists, until reminded by the force of the wind that it is a real substanee. Wind is simply 
air in motion. Its force depends upon the rate at which the air is moving, varying from a slight motion, which gives a gentle breeze, to a velocity of forty or fifty miles per hour, producing a hurricane, a tornado, or a whirlwind.

Cause of Winds. - Winds are always caused by the unequal density or weight of different portions of the atmosphere. This is generally due to differences in temperature. It is true of the air, as of other substances, that heat expands it, making a given bulk of it lighter; and that cold contracts it, making a given bulk heavier. If a quantity of oil is poured into a body of water, the water, which is heavier, will push the lighter oil to the surface. So, if the atmosphere in any locality becomes warmer and lighter than the surrounding atmosphere, the latter will push it into the upper regions, and will rush in to fill the space underneath.

The high wind that accompanies a thunder-storm at the close of a hot day is due to the fact that the atmos. phere, which has been heated during the day, is now rapidly rising, while the cooler atmosphere around is rushing in.

The land and sea breezes, which are common on the sea-coast, are due to the unequal heating of the atmosphere over land and water at different times of day.

Rain. - Rain is an accumulation of the vapor of the atmosphere into drops, which, by their weight, fall to the ground. There is a limit to the quantity of water which the air is capable of absorbing and retaining as an invisible vapor. When it contains as much as possible, it is said to be saturated. Now, warm air is able to hold more moisture than cold air ; hence, when air which is saturated becomes colder, for any reason, it can no longer 
retain all its moisture. A portion is liberated, accumulates in drops, and falls to the earth. This is in all cases the explanation of rain.

The different ways in which the air is cooled, and rain is produced, are:-

1. By Rising into the Upper Regions. - The higher we ascend from the earth's surface, the cooler we find the atmosphere. Mountains are sometimes clothed with grass and flowers at the foot, while their summits are covered with perpetual snow.

The atmosphere is warmed chiefly by the warm earth. The heat of the sun's rays is accumulated upon the surface of the earth. The earth then, like a heated stove, throws out or radiates its heat, and warms the atmosphere. So, as in case of the stove, the atmosphere nearest it is always the warmest.

As the air in any locality becomes heated in this way, it is pressed upward by cooler and heavier air from other sections, where it is cooled; and, if it contains sufficient moisture, rain is produced.

Ascending air is also cooled by expanding. When air is compressed so as to occupy a smaller space, it becomes warmer. On the other hand, when air expands, it becomes cooler. As the air ascends, the pressure upon it from the air above becomes less, and consequently it expands and becomes cooler. This, of itself, is a common cause of rain.

2. By Passing over Mountains. - Hills and mountains are sometimes called "rain condensers." As the rising currents of air pass over mountainous regions, the air expands and is cooled, and parts with its surplus moisture. Hilly regions are more abundantly supplied with rain than level tracts. That side of a range of mountains 
which the wind reaches first in its customary course receives more rain than the opposite side, since the currents of air lose moisture in passing over it. The absence of rain on some parts of the coast of South America is due to the fact that the wind, which blows constantly from the east in those regions, causes the atmosphere to deposit rain, and become comparatively dry in passing the Andes Mountains.

3. By the Mixture of Warm and Cool Currents of Air. - In the changing courses of variable winds, warm currents of air often meet and mingle with cooler currents. When the air is saturated, this is liable at any time to cause rain.

Snow and Hail. - Snow and hail are frozen forms of atmospheric moisture. In the case of snow, the minute particles of moisture are frozen as they form, and arrange themselves about each other in beautiful crystals, producing the snowflake.

Hailstones are often formed by whirling currents of wind, which carry raindrops or minute snowballs first into the upper, cold regions, where they are frozen, then downward through a warmer section, where more water is added, and then upward again. The size of the stones is thus gradually increased until they become too heavy to be carried upward again, and are flung to the earth.

Fogs, Mists, and Clouds. - These are all of the same nature. They are simply particles of water or ice which have formed at points where currents of air of different temperatures meet each other, but not in sufficient quantity to produce raindrops.

Clouds are formed wherever the air, in rising, is cooled enough to condense rapors. When the air is quite dry, 
clouds will not be formed until a high point is reached, if at all. When it is well saturated, they may be formed so low as to touch the earth, and are then called fogs or mists.

Dew. - Dew, like rain, fog, etc., is caused by the cooling of the atmosphere. The earth during the night becomes cooler than the air above it, and tends to condense moisture from the air which comes in contact with it.

There is less dew on a cloudy night, because clouds prevent the earth from cooling. They obstruct the rays of heat as these pass from the earth, and turn them back, thus preserving an equality of temperature between the earth and the air.

A strong wind prevents the formation of dew by keeping the air well mixed, and leaving no part of it in contact with the ground long enough to become cool and deposit moisture.

A slight breeze increases the amount of dew by removing those portions of air which have already deposited their moisture, and bringing other portions successirely in contact with the ground.

The quantity of water that forms upon the ground as dew is much larger than is generally supposed. It is only a portion of it that appears in the morning on the blades of grass. A large part is absorbed into the soil.

In Great Britain, where dews are heary, it is estimated that the whole amount deposited in a year would be equal to a depth of several inches of water. In some tropical regions it is deposited so fast as to be equal to a light rain.

Frost. - Frost is simply frozen moisture from the atmosphere. When the temperature at the point where dew would form falls below $32^{\circ}$, the point at which water 
freezes, the moisture condensed from the air, instead of forming dew, forms crystals of ice, or frost.

When there is no dew, there can be no frost of this kind, and regetation is not injured unless the temperature falls low enough, and remains low long enough to freeze the sap within the plant.

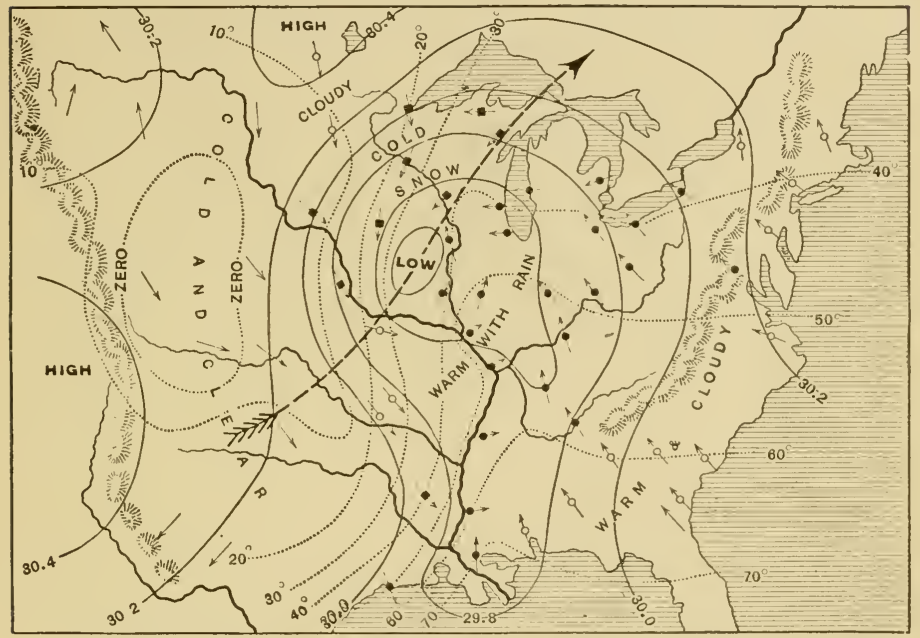

Isobars, every ${ }_{10}^{2}$ ths of an inch difference of pressure.

.............. Isotherms, eremy 10 clegrees temperature.

"Low" = Center of Cyclone.

"High" = Inticycloues.
Direction of wind \& clear weather

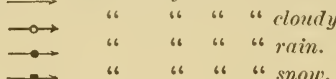

path of Cyclone.

Weather Map.

The Weather. - The changes of weather which are constantly taking place are not irregular and accidental. They occur according to certain laws, and as the result of certain causes. By ascertaining these causes, it is possible to predict changes, so that a storm, or a cold or war'm wave of temperature, may be foretold some hours before it appears.

Wins. Ag. -4 . 
The provision made by the United States for noting conditions, and announcing indications, in all parts of the country, is of great importance. It is of great value in agriculture. The farmer, relying upon these indications, may select favorable weather for planting his seed or harvesting his crops.

Storms. - The central section of a storm is noted by an area of low barometer, or low pressure. That is to say, it is where the atmosphere is lighter than usual, and on that account is rising. In front and in the rear of the storm center, the barometer is high, or the atmosphere is heavy. In the United States, these sections of low pressure, which mark the location of storms, are generally long and narrow, extending across the country from north to south. Storms usually appear first in the western or southern parts of the country, and move in an easterly or northeasterly direction.

Naturally, the winds on both sides of the storm center blow toward it. They are the heavier sections of air passing in to take the place of the lighter sections, which are rising; hence, storms are generally preceded by east, northeast, or southeast winds, and followed by west, northwest, or southwest winds.

Climate. - The climate of a region is its condition with regard to heat and moisture. It may be considered a hot or cold, a moist or dry climate.

The temperature in any locality depends chiefly upon the following conditions:-

1. Latitude. - The extent to which the earth and the atmosphere near it become heated depends upon the directness with which the rays of heat from the sun fall upon it. Sections near the poles are therefore colder 
than those near the equator, which have the sun more directly overhead.

2. Elevation. - As the atmosphere is cooler the higher we ascend, so the climate of elevated tracts is colder than that of low plains and valleys. Although the high regions receive the full benefit of the sun's heat, they lose heat rapidly, since the atmosphere in these regions, being thin and dry, permits the heat to pass off easily by radiation.

3. Nearness to the Ocean. - The tendency of the ocean is to render the climate uniform,- cooler in summer and milder in winter. As the water upon the surface of the ocean becomes heated by the sun, it mingles with the cooler water below. This prevents the surface water from becoming very warm, and from imparting heat rapidly to the atmosphere.

As the ocean has stored a large amount of heat, and has become heated to a considerable depth, it is not quickly cooled as winter approaches, but parts with its warmth gradually during the entire winter.

The solid land, on the other hand, does not become heated to a great depth. The heat of the sun is concentrated upon its surface, and is more readily radiated into the atmosphere.

In the fall of the year the ground is more quickly cooled, and has less influence in tempering the severity of winter.

Near the coast, the climate is rendered comparatively uniform by receiving the benefit of cool winds from the sea in summer and mild winds in winter.

The amount of moisture depends mostly upon the nature of the surroundings and the direction of prevalent winds. 
Hilly and mountainous regions, which the winds reach first in their usual course, are generally well supplied, while more level regions farther on have a drier climate.

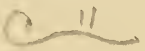

\section{QUESTIONS.}

Of what is the atmosphere composed? What are the two elements of air? Which of them is the more important? Of what use is nitrogen in the air? IIow much water vapor loes the air contain? Where does the air get it? What becomes of it when there is more than the air can hold? In what three ways is the carbonic acid gas of the atmosphere formed? Name some of the impurities found in the atmosphere. What finally becomes of these?

How much does the atmosphere weigh? Why is its pressure greater in a valley than on a mountain? Is the atmosphere heavier or lighter in stormy weather?

What is a barometer? Why does the barometer fall before a storm? In which direction does the atmosphere press? Ilow many pounds of air rest upon your outstretched hand? How are you able to lift so great a weight?

What is a thermometer? What causes the mercury to rise and fall in a thermometer?

What is the wind? What causes the wind to blow? Describe the direction of the eurrents of air in a room with a hot stove at one side. What causes a sea breeze in a hot day on the coast? Why is a thunder-shower usually accompanied by wind?

What is rain? In what three ways is rain produced? Why is the air always warmer near the earth than away from it? Why are hills and mountains cooler than low places? Why is there generally an abundance of rain on that side of a mountain range from which the wind blows?

What is snow? Explain the formation of hailstones. Why does it sometimes hail when the temperature is below the freezing point? How can it snow when the temperature is above freezing?

What are fogs, mists, and clouds? What determines the height of clouds? Why is it always clonly before it rains?

Explain the cause of dew. How do elouds prevent the formation of dew? Why is there no dew upon a windy night? What is the 
effect of a slight breeze? Give some idea of the quantity of dew. What causes drops of water to form upon a pitcher of cold water on a hot day?

What is frost? When is frost liable to occur, and when not? Upon which side of a window does frost form? Why is there less frost on the windows of a vacant room than on those of a room full of people?

Are the changes of weather accidental? What is the work of the Weather Bureau, established by the government? Of what advantage is it to the farmer? What is the general cause of a storm? Describe the general course of storms in the United States. Which way do the winds naturally blow at the time of a storm, and why?

What is meant by climate? What three general conditions determine the temperature of a locality? Why is the temperature over the ocean more uniform than over the land? Why are winters usually most severe in the center of a continent? What generally determines the amount of rain in any locality? 


\section{CHAPTER IV.}

\section{PLANTS.}

Seeds. - The growth of a plant begins with the seed. A seed contains all the essential parts of the plant itself, ready to be extended outward into the soil and into the atmosphere as soon as farorable conditions are supplied. This minute plant found in the seed is called the "embryo," or " germ."

Besides the germ, a seed contains a quantity of food, stored up to supply the young plant as it begins to grow,
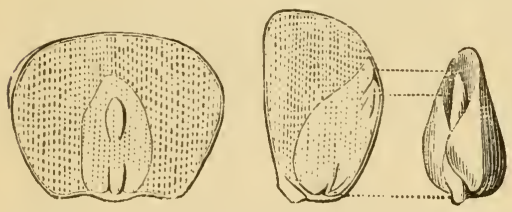

Sections of a Grain of Corn, and the Germ detached. until it is able to provide for itself from the soil and the atmosphere.

In the "chit" of a kernel of corn, and at the "eye" of a bean, the embryo is to be found. The remainder of the seed is composed of starch and other substances for the young plant to feed upon.

The Vitality of Seeds. - Different varieties of seeds differ greatly in the length of time they maintain their vitality, or power to sprout and produce growth. The seeds of some trees will not sprout at all after once becoming dry. On the other hand, some seeds, if kept dry, will grow after many years. When sealed away from the air, these seem to retain their vitality almost (54) 
indefinitely. Peas are said to have sprouted which were taken from an Egyptian mummy three thousand years old.

It is better to select new seeds for planting. Older seeds may grow, but will generally produce weaker plants.

Unripe Seeds. - Seeds used for planting should always be thoroughly ripe. The loss from planting unripe eorn, or "pinched" wheat, may be many times as great as the extra cost of better seeds.

While the difference in yield resulting from poor seeds may not always be apparent the first season, if the practice is continued through a number of years the erop will "rum out" and beeome unprofitable.

On the other hand, by selecting the best specimens of seeds, year after year, the erop will be greatly improved. The yield of different erops has, in some instances, been doubled by a continuous selection of the best seeds.

Conditions of Growth. - There are three conditions required for the growth of seeds, all of which must be supplied in order to produce germination.

1. Moisture. - When a dry seed is placed in soil, or some other moist substance, it immediately begins to absorb moisture; it swells, and if the temperature is favorable and sufficient air is supplied, it puts forth its root, and begins to grow.

The amount of moisture favorable for growth varies with different seeds. Some varieties will grow in water, some thrive best in very moist soil, while others require comparatively dry soil.

It is believed that some varieties of seeds are covered with a coating through which water cannot penctrate, and that these may remain in the soil for an indefinite 
period without germinating, until the hull is accidentally scratched, or broken, so as to admit moisture. This may account for the fact that so many weeds unexpectedly and repeatedly spring up after the soil is stirred in cultivating crops.

2. Warmth. - There is a certain range of temperature within which a seed will grow, and outside of which it will fail to do so.

The seeds of some plants, whose native home is in cold climates, will sprout at a low temperature, while others, which are accustomed to a warmer climate, require a higher temperature. The lowest point of temperature at which wheat, barley, oats, and peas will sprout is about $40^{\circ}$, and the highest about $103^{\circ}$. The lowest for corn and squashes is about $50^{\circ}$, and the highest about $115^{\circ}$.

Although the seeds may sprout at any point within this range of temperature, at a point near either extreme growth will be very slow, and the plants weak and small. There is a certain degree of heat for each variety of seeds in which they will produce the best growth. That point for wheat, oats, and barley is about $84^{\circ}$, and for corn and squashes about $94^{\circ}$. The nearer we approach to this favorable point in choosing the land and the time for planting, the better the results. The mistake is often made of planting seeds too early in the spring, before the ground is sufficiently warm to insure quick and strong growth. The early plant is so weakened by low temperature as to gain nothing in the end over the later plant, which thrives better, and yields larger results.

3. Oxygen.-Oxygen, which is essential to support life in animals, being taken into their systems through the air in their lungs, is also essential to the life and 
growth of plants, and even to the sprouting of seeds. Soil is always more or less porous near its surface, and it is filled with air, which supplies the sprouting seed with oxygen.

Depth of Planting. - Most seeds would sprout and grow if dropped upon the surface of the soil in a rainy season, when the atmosphere is damp enough to supply the needed moisture, but it is generally safer and better to cover them with soil.

The proper depth of planting will depend upon the nature of the soil, climate, crop, etc. In very wet or cold seasons, it is better to cover the seed but little, so that it may have better access to the air and the warmth of the sun. In warm, dry seasons, it should be buried more deeply, so as to secure sufficient moisture.

In some sections of the country, and in some special seasons, Indian corn will thrive best when planted at a depth of several inches, while ordinarily a light covering is better.

Many kinds of seeds will not grow at all if buried deeply. The seeds of weeds remain dormant in the soil, until they are brought near the surface by plowing or harrowing, where sufficient air and heat are supplied, and then they spring up and grow vigorously.

Seeds are supposed to contain a supply of nourishment sufficient to support the young plant until the ascending stem can reach the open air.

In some cases of deep planting, while there may be oxygen enough to produce growth, the supply of food in the seed becomes exhausted before the surface is reached, and the plant perishes.

Germination. - The process of germination, or sprouting of seeds, includes three points. 
1. The Absorption of Moisture. - It is evident that the nutritive substances contained in the seed cannot pass into the plant and support growth while in a dry state. The seed must be saturated with moisture, so that there may be a medium through which these substances may pass to the point in the growing plant where they are needed.

2. A Chanye in the Nutritive Substances. - The supplies of food stored in the seed are not generally in a suitable form to support the plant, but must first be changed. They are dissolved in the moisture, and conrerted by chemical processes into the proper forms. An instance of this is the conversion of starch into sugar. The formula for starch is $\mathrm{C}_{6} \mathrm{H}_{10} \mathrm{O}_{5}$, and for the glucose sugar obtained from it, $\mathrm{C}_{6} \mathrm{H}_{12} \mathrm{O}_{6}$. The latter is obtained from the former by the addition of oxygen and hydrogen.

In the process of malting barley and other kinds of grain, the aim is to obtain these same chemical changes. The grain is soaked and allowed to sprout until the starch and other substances are converted into sugar, dextrine, etc. The process is then stopped by drying, and the new substances are extracted from the grain to form malt.

3. The Production of Heat. - The changes above referred to are largely due to oxidation, or the combination of oxygen with the substances of the seed. This, as in other instances of oxidation, produces heat.

If a large number of seeds are heaped together, as in manufacturing malt, the mass becomes very warm, - so much so that care is required to prevent the grain from spoiling. This heat, developed in the sprouting seed, is of some service at times when the temperature ontside is too low. 
Growth from the Seed. - From the seed first appears a shoot, called the radicle, which extends downward into the soil, and shortly afterward another shoot, called the plumule, which sceks to find its way upward into the air and sunlight. The radicle is the origin of the roots of the plant, and the plumule the origin of the stem, with its branches and leaves.

The reason why the root thus turns downward and the stem upward is an unsolved mystery. It cannot be due to any attractive force of light upon the stem, or any repelling force upon the root, as it has been found that the same directions are followed when a seed is sprouted in the air, in absolute darkness. From this and from other habits of plants, it would seem that they are endowed with a kind of instinct, similar to the instincts of animals. Some plants always turn their leares toward the sunlight, while others turn them away. Some flowers close in the afternoon and open in the early morning. These facts we cannot account for with certainty, in a scientific way, any more than we can ac-

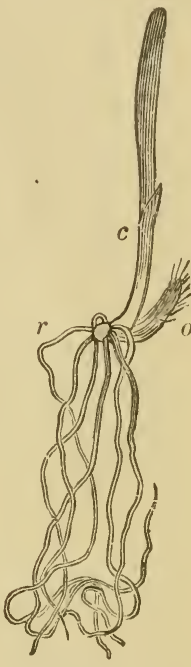

Germination of Wheat.

$o$, the grain, con trining the cotyledon; c, plumule; $r$, radicle. count for the very principle of life which causes the seed to begin to germinate and its growth to continue.

Two Worlds for the Plant. - A plant has two worlds, or feeding grounds: the atmosphere above and the soil beneath. One is as essential to the life and welfare of the plant as the other. As plants cannot live when their roots are withdrawn from the soil, so also most plants will die if the portion above the surface is repeatedly cut 
off. Out of the soil and the atmosphere they obtain the food which sustains their life and growth.

The Food of Plants. - If we analyze the substances of which a plant is composed, and ascertain the elements which it contains, we shall know exactly what food it requires, and what the soil and atmosphere must contain in order to afford proper nourishment.

The following elements are found in all plants, and are essential to their growth: carbon, hydrogen, oxygen, nitrogen, sulphur, phosphorus, potassium, calcium, magnesium, and iron. Besides these, there are generally

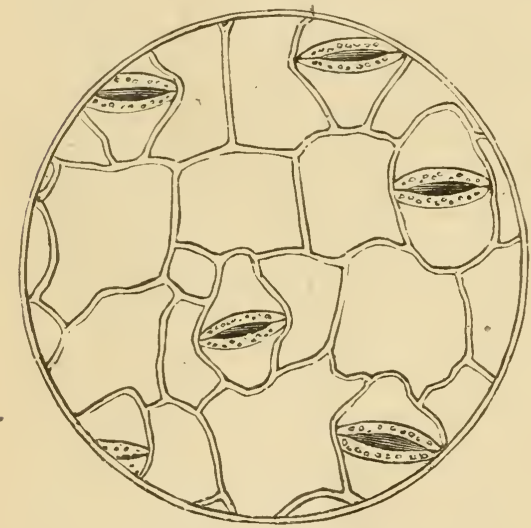

The Under Side of a Leaf.

(Mragnified, showing Cells and Mouths, or Stomata.) found sodium, silicon, chlorine, and traces of some other substances.

Food from the Atmosphere. - The food which plants obtain from the atmosphere is mostly carbon. The leaves absorb carbonic acid gas $\left(\mathrm{CO}_{2}\right)$, and separate the carbon from the oxygen, retaining the former and returning the latter to the atmosphere. This earbon, combining with hydrogen and oxygen in the plant, is converted into starch, sugar, cellulose, etc., and thus enters into the structure of the plant.

This process of absorbing and decomposing carbonic acid gas takes place only in sunlight. In some unknown way, the influence of the rays of light is required to 
effect the change. For this reason a continuation of dark, rainy weather is injurious to the growth of most plants. In such weather they turn pale from the absence of coloring material, which requires the aid of sunlight for its formation.

The air is admitted to the interior of a leaf through minute openings, or mouths, which generally exist in great numbers. Upon an ordinary apple leaf there may be found as many as 100,000 of these openings.

Plants Purify the Air. - This absorption of carbonic acid, and liberation of oxygen are of the greatest importance to animal life.

In the lungs of men and other animals, oxygen from the air is continually absorbed into the blood, and in place of it carbonic acid gas passes from the lungs with the breath. An accumulation of this gas in the atmosphere would soon become poisonous, but the danger is avoided, and the balance maintained, by the fact that all growing vegetation is constantly withdrawing carbon and setting oxygen free. It is estimated that an acre of forest trees will consume the carbonic acid produced by the breathing of fifteen men.

In this way vegetable and animal life mutually benefit each other, each requiring and making use of that element which is rejected by the other.

Do Plants Breathe? - While plants are taking in carbon and throwing out oxygen, they are at the same time, though only to a slight extent, doing exactly the reverse,taking in oxygen and throwing out carbonic acid. This is very similar to the act of breathing in animals.

It would seem unnecessary for the plant to take these two seemingly opposite courses, but they are for entirely different purposes. 
The process of breaking up the molecules of carbonic acid, and retaining the carbon, requires the aid of sunlight, and is really a process of feeding, or upbuilding the plant; but the act of breathing, or taking oxygen from the air, goes on contiuuously through the night, and is a process of oxidation or slow burning and destruction of the plant.

Absorption of Water. - But little water, if any, is absorbed by leaves from the atmosphere. A drooping plant is quickly revived by watering, or by a shower of rain, not so much by absorling moisture through its leaves as by the rapid passage of water into the stem and leaves through its roots.

Nitrogen from the Air. - While free nitrogen constitutes four fifths of all the air, it has generally been believed that none of this is directly available for the use of plants. Recent investigations, however, show that certain varieties of plants are probably able, in some way, to make direct use of atmospheric nitrogen. This seems to be especially true of the family of plants called leguminous, or pod-bearing plants. This family includes peas, beans, clover, lucern, etc.

Ammonia, which exists in small quantities in the atmosphere, is partly composed of nitrogen, and it is thought the plant may obtain a little nitrogen by absorbing this gas through its foliage.

Roots. - The purpose of the root is to give the plant support, holding it firmly in position ; to absorb nourishment from the soil; and, in the case of biennial plants, to store up a supply of food to support the plant the second year.

The radicle, or first root which descends into the soil from the seed, soon subdivides into a number of small 
roots which extend in different directions, or sends out small branches on all sides.

Sometimes the radicle continues to enlarge and grow downward, forming what is called a tap-root, from which small fibers extend out into the soil. Clover, Canada
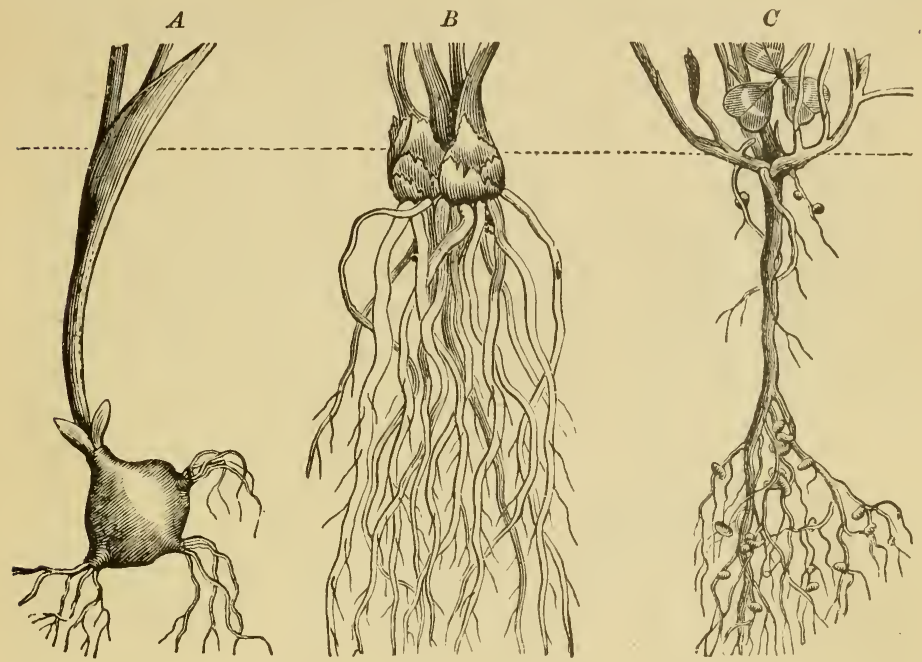

The Roots of Plants.

A, Erigenia, with tuberous ront. B, Buttercups, with fibrons ronts. $C$, White Clover, with long tap-root and branches.

thistles, and oak trees, for example, generally have such a tap-ront. The root crops, beets, turnips, carrots, etc., are simply an enlargement of the tap-root, which serres to store up food intended for the support of the plant the following season.

The growth of roots consists mostly of lengthening by building on additions at the extremities. In this way the difficulty of moving the root through its entire length is avoided, and every part, as soon as formed, is left in 
undisturbed contact with the soil. In some eases the tip of the root is provided with a kind of eap, or shield, to protect it from injury as it forces its way through the soil.

The Number and Extent of Roots. - The process of subdividing and multiplying small roots goes on to a greater

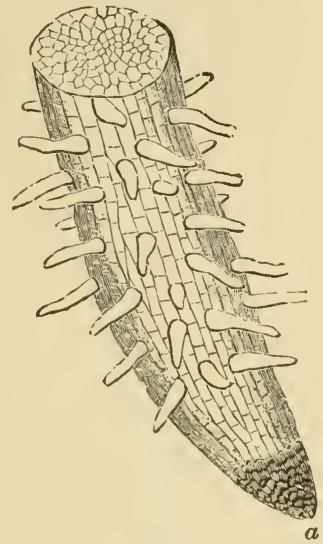

Extremity of a Rootlet of Maple. extent than is generally supposed. Rich soil in the vicinity of the roots of some plants becomes completely filled with hair-like rootlets. Sometimes these are so small as to require the aid of a mieroscope to detect them.

When a plant is pulled from the soil, these fibers are mostly broken off, only the larger roots remaining attached to the stem.

The entire length of all the roots of a plant is sometimes almost incredible. In the case of barley, oats, and wheat, growing in rich, mellow soil, it has been

found that the total length of all Hairs and root-cap (a), magnified 50 diameters. the roots of one plant will amount to from one hundred to one hundred and fifty feet.

Under favorable conditions, roots sometimes descend to a great depth. In deep, mellow soil, the roots of most agricultural plants reach a depth of several feet. The roots of Indian corn, which in common soil do not extend more than two or three feet below the surface, have been known to penetrate into the earth to a depth of fifteen feet. Clover roots have been traced to a depth of eight feet. 
Food from the Soil. - The only substances that plants obtain from the atmosphere are carbon, small quantities of oxygen, and probably some nitrogen in the case of certain particular plants. All other nutritive substances, generally including nitrogen, must come from the soil.

A plant obtains these nourishing substances from the soil through the moisture in which they have been dissolved. The moisture of the soil passes through the membranous covering of the root fibers, and thence upward into the plant, forming its salp or juice. Substances dissolved in this juice are thus able to find their way to all parts of the plant. In order to understand the rise and flow of sap, and the distribution of nutritive substances, it is necessary to consider three principles of natural philosophy called diffusion, osmose, and capillary attraction.

1. Diffusion.--Diffusion is the term applied to the tendency of different liquids, and solids dissolved in liquids, to become thoroughly mixed when placed together. If alcohol and water are placed together in the same vessel, they yuickly mingle, so as to form a uniform mixture. If a handful of salt is thrown into a pail of water, it is quickly dissolved, and evenly distributed, so that all parts are equally salted.

The same is true if several substances, as salt, sugar, and alum, are dissolved in the same water. Each is equally distributed as if no other were present. These facts are due to the attraction of molecules of alcohol for those of water, and the attraction of molecules of water for those of salt, sugar, etc. The fact that all the molecules of water have equal attraction for salt causes the salt to be equally distributed between them. If, in any way, some of the salt could be withdrawn from a portion Wins. Ag. -5 
of the water, some of the remaining salt would immediately more forward and fill the racancy, so as to maintain an equal distribution.

The diffusion of water and sulphuric acid may be seen by partially filling a glass jar or tube with water colored with blue litmus, and pouring through a tube, to the bottom, water containing a few drops of sulphuric acid. 'The effect of the acid would be to change the blue to red. Sulphuric acid is heavier than water, and would otherwise remain at the bottom; but according to the law of diffusion, it gradually mingles with the water aboxe until the eolor of the whole is changed to red.

2. Osmose. - The term osmose, from a Greek word which means to push, is applied to the fact that substances which tend to mingle by diffusion will pass through a porous partition separating them, and become as thoroughly mixed as if no partition were present. If a quantity of salt water and a quantity of sweetened water are separated by a porous membrane, some salt will pass through the membrane one way, and some sugar the other way, until both are equally distributed through the whole.

The same is true of other substances dissolved in water, and of different liquids separated by a membranous partition.

This prineiple may be illustrated by placing in a hlad. der, or some other membrane, a small quantity of eolored alcohol, lowering this into a glass of water, and allowing it to remain until the water becomes colored, showing that some of the alcohol has passed through the membrane into the water.

While the membrane, or other substance, must be porous, the pores may be very minute. Water, and sub- 
stances dissolved in it, will find their way through a medium whose pores are too small to be seen, even with the aid of a microscope.

3. Capillary Attraction - The attraction of solids and liquids for each other, in the case of solids which will no: dissolve, is shown in the fact that the two adhere to each other when brought in contact.

If the edge of a piece of glass is dipped into water, the water will rise a little distance upon the glass, and when it is withdrawn some moisture will remain upon it. If a small glass tube is placed in water, the attraction between

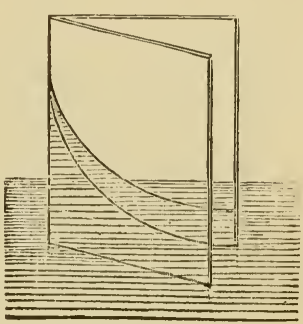

The Capillary Curve. the two will cause the water to rise in the tube. The smaller the tube, the higher the water will rise.

This principle of attraction between

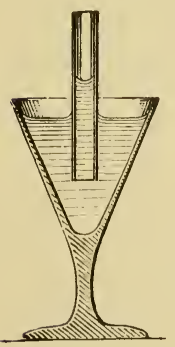
solids and liquids, which causes a liquid to pass readily through the minute tubes or pores of a solid, even upward against the force of gravitation, is called capillary attraction, from a Latin word, capillus, which means a hair. The application is to the small, hair-like nature of the tubes through which the principle works. $\Lambda$ Direct Capillarity. familiar example of capillary attraction is the rise of oil in the wick of a lamp. The attraction of cotton for oil causes the oil to pass rapidly upward through the pores of the wick.

If one end of a towel is placed in a bowl of water, the water will gradually pass along the cotton or linen fibers until the whole towel is moistened. 


\section{Application of these Principles to Plant Growth. - These} three principles all have an application in the passage of substances into plants from the soil. Roots are covered with a kind of membranous coating. 'The moisture of the soil, passing through this coating, and upward into the plant, saturates the plant, or completely fills it with moisture, by the force of capillary attraction. 'The nutritive substances dissolved in the moisture likewise pass into the plant through its roots.

By the principle of diffusion, these substances tend to distribute themselves equally, not only through the moisture of the soil about the roots, but throughout the juice or sap of the plant.

The Absorbing Power of Roots. - The material of which the roots of plants are composed has a rery strong attraction for water. On this account, the moisture of the soil is drawn upward through the roots into the stem and leares with considerable force. This pressure, by filling all parts of the plant, assists in keeping it in a firm, upright position. When the supply of moisture is cut off by drought, or by severing the root, the plant withers and droops.

It has been found that this force is sufficient to assist in the extension of buds and leaves in their growth. It is supposed to explain also the tall, slender growth of crops in a wet season. 'The upwara pressure of the moisture, which is abundantly supplied to roots in such a scason, is sufficient to force the different parts of the plant out of their normal dimensions.

The Structure of Plants. - The roots, stems, and leares of plants, and in fact all vegetable substances, are originally composed of a great number of small cells. These generally consist of little membranous vesicles or bags, 
which are filled with liquid or solid matter. The cells of a potato contain little grains of starch, floating in a watery liquid. As the potato ripens, these grains become larger. When a ripe potato is boiled, the starch grains swell so as to burst the cells, and give the potato a "mealy" appearance. Starch is obtained from potatoes by grinding to break the cells, and then washing out the starch.

Growth consists in the multiplication of these colls, either by dividing the old eell into several new ones, or by forming

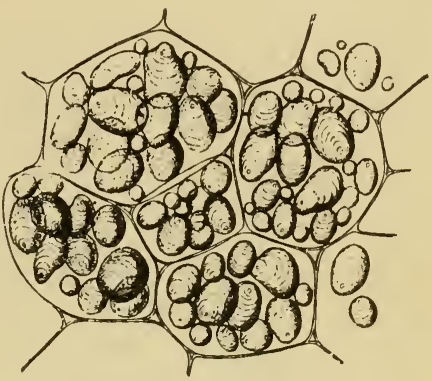

Cells from Potato Tuber.

(Showing Starch Grains.) several new cells upon the outside of the old one.

In the lower orders of plants there are some that consist of single cells, each new cell forming a separate plant. Others are composed of a number of these simple cells loosely attached to each other.

The mushroom that grows in a single night, ordinary mold, and the blight or smut that sometimes forms upon corn and grain, are examples of plants entirely composed of these simple, loose cells.

In the higher orders of plants, ripe fruit and some other soft, succulent parts, are also composed of simple cells, so loosely connected as to be easily separated from one another.

In the more substantial parts of most plants, however, the cells are not so soft and loose, but are firmly connected together, forming what is called vegetable tissue.

Cells are of difierent shapes in the different varieties 
of plants, and often also in different parts of the same plant. In their simplest forms they are generally spherical, or globular. In the fiber of wood they are long and tapering, firmly joined together by their sides.

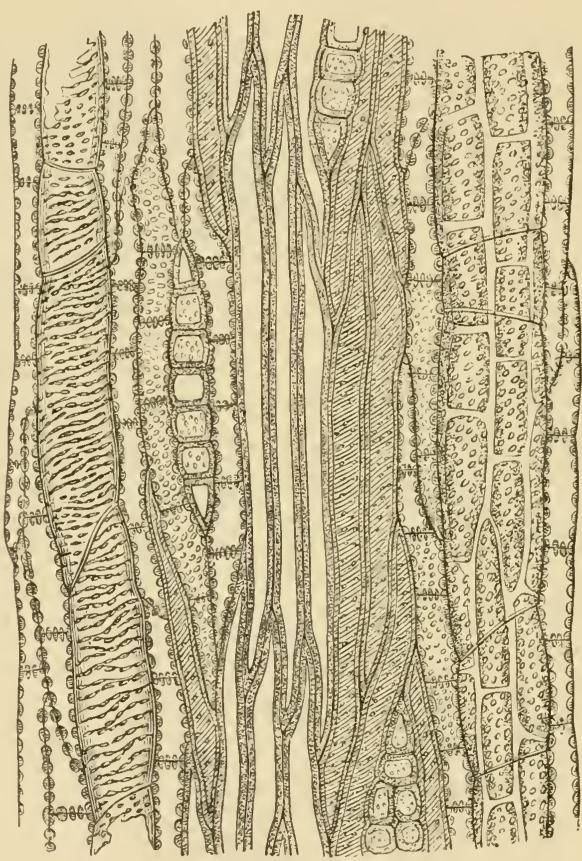

Section of Wood.

Lengthurise Stice of Woor from an Ailanthus glandulosa, or "Tree of Heaven," highly magnified.

Sometimes the corering of the ends of these long cells is remored, so that they open into each other, and form a continuous tube, through which the sap may flow more freely. Fibers of cotton and flax are simply long, single cells. 
The Flow of the Sap. - The sap is the moisture of the soil which has passed upward, through the roots, into the plant. The plant is entirely filled, or saturated, with sap.

By the principle of usmose and the force of capillary attraction the sap moves partly along the tubes formed by the union of long cells, and partly through the membranes from cell to cell, until every part of the plant is filled.

When a plant has become saturated, there can be no more flow of sap until room has been made for more. The flow is kept up, partly by the growth or enlargement of the plant, forming new cells which need to be filled with moisture, but mostly by the evaporation of the moisture or sap from the leaves.

Leaves contain a great number of minute openings, particularly on the under side, which bring the air in immediate contact with the sap within. Through these openings the moisture of the sap is continually escaping into the air by evaporation.

In damp weather evaporation is slow, and hence the upward flow of sap is likewise slow; but in dry weather, and especially under the influence of the warm sunlight, it goes on more rapidly.

The quantity of water conveyed in this way into the atmosphere is very large, amounting during the season to many times the weight of the full-grown plant. Soil occupied with crops is thus dried much faster than that upon which no vegetation is growing.

The abundant flow of sap from a maple in the spring is due to the fact that the tree is not only filled with sap, but this is placed under some pressure by the force of capillary attraction. As the tree contains no leaves at 
this season, there can be no evaporation to relieve the pressure. 'The sugar of the sap is chemically formed in the tree, out of the starchy substances stored during the previous autumn.

Nutrition. - 'The nutritive substances which are designed to serve as food for plants, and are dissolved in the moisture of the soil, include a great variety.

Each of these is needed in nearly all parts of the plant. 'The most of them, hoverer', must undergo chemical changes before they are ready to be assimilated, or to enter into the structure of the plant. Some of them must first rise to the leaves to receive certain changes by contact with the atmosphere, and must then pass downward again to all points where they are required.

The sap of plants, like the blood of animals, furnishes a medium through which the elements of food may find their way to the points where they are needed, but the fow of sap is not at all similar to the circulation of the blood. The blood, in its circulation, actually carries substances to all parts of the body, and deposits them at the points of destination, but there is no such complete system of conreyance in the sap. It is true that the elements of plant food are aided, in passing from the soil into the plant, by the upward movement of the sap; but when once in the plant they must act independently of this movement, passing sidewise, downward, and in every other dirsetion.

This is to be explained by the principles of diffusion and osmose.

As salt, when dissolved in water, will extend itself to all parts of the water, making its way through intervening membranes, so these nutritive substances find their way to every part of the plant. 
The Power of Selection. - 1 plant has, in a certain sense, the power to make a selection of its food. While any substances dissolved in the moisture of the soil will naturally find their way into the plant, only such of these as are needed will be taken up and made use of.

Both the sap of timothy grass, and that of clover, for instance, contain silica. The timothy makes use of this to some extent, but clover, having little use for silica, permits it to remain in the sap.

It is believed that, in some cases, the roots of plants are able to produce chemical changes in some elements of soil, and eren of rocks, with which trey are brought in contact, withdrawing such parts as are
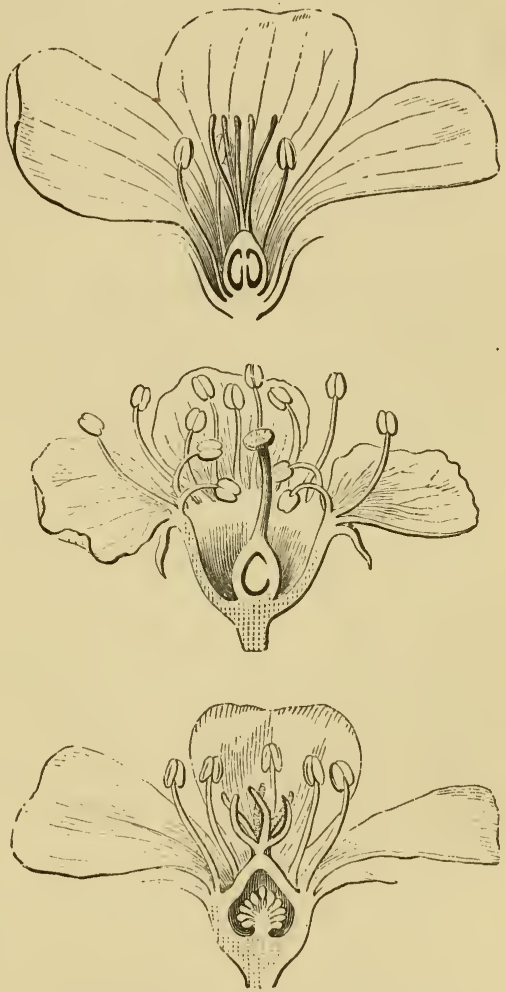

The Essential Parts of a Flower. required, and leaving the remainder in the soil.

Flowers and Seeds. - In a general sense, the aim and tendency of plants is finally to produce flowers, and then seeds, which, in their season, are to spring up and produce similar plants, so that the variety may continue perpetually in existence. 
The essential parts of a flower are the central, or interior organs, by which the seeds are formed. These are generally surrounded by floral envelopes, called the calyx and the corolla, whose individual leaves, the sepals and petals, give the flower its beauty.

The central organs are of two kinds, called pistils and stamens.

The pistils contain germs from which seeds are formed, and the stamens produce a fine dust, generally of a yellow color, called pollen.

This pollen, falling upon the pistils, fertilizes them, and starts the formation of seeds.

Usually both stamens and pistils grow upon the same plant, and near each other in the same flower. In some varieties, however, the pistils are borne upon one plant and the stamens upon another. This is true of some varieties of strawberries, and of hop and hemp plants.

On account of this peculiarity, it is necessary, in cultivating these crops, to mix plants of both kinds.

Sometimes the pistils are borne upon one part of a plant, and the stamens upon another. An example of this is seen in Indian corn. The pollen produced upon the tassel falls upon the silk, which is connected with the pistils within the ear.

Pollen dust is produced by some plants in large quantities, and is carried long distances by the wind. This, falling upon different plants of the same species, causes a mixture.

By a transfer of pollen dust in this way, an almost endless variety of some species of plants is obtained. A green variety of squashes growing beside a yellow variety yields a variety partly green and partly yellow. Grains of pollen dust, carried by the wind from one corn- 
field to another, will produce scattering kernels in the latter field of the variety contained in the former.

\section{QUESTIONS.}

What are plants? What are the two essential parts of a seed? What is the embryo? How long will seeds preserve their vitality? Why should new seeds be used for planting? What is the effect of planting unripe seerls? What is the effect of selecting the best specimens of seeds for planting?

What are the three conditions necessary for the growth of seeds? How much moisture is most favorable? What is the effect of planting seeds in soil either too warm or too cold? What is the effect of planting seerls too early in the spring? Why will seeds fail to grow where there is no air? Under what circumstances is it best to plant seeds deeply? When is it better to cover them but lightly? What eauses weeds to spring up after ground has been plowed? Why have these weeds failed to grow before?

What are the three processes involved in germination? Why must the seed be filled with moisture? Why is grain allowed to sprout in making malt? Why does sprouting produce heat?

What are the radicle and the plumule? Why do they start from the seed in opposite directions? Which is more essential to the plant, the atmosphere or the soil? In what points do plants, in their growth, resemble animals?

Name the elementary substances that are essential to the growth of plants. What food do plants obtain largely from the atmosphere? Explain the process by which it is obtainerl. What has the sunlight to do with it? Why do plants become pale in dark weather? How do plants purify the air? Do they remove oxygen from the air? Do they purify the air in the night? Are they beneficial to the air in a dwelling-house? How are drooping plants revived by watering? Do plants obtain nitrogen from the air?

What are the purposes of roots? Name some plants which have taproots? By what method do roots grow? How many roots have plants? How deep do they sometimes extend?

Name all the elements of foorl that plants obtain from the atmosphere. Name those that they obtain from the soil. How do they 
obtain foor from the soil? Explain the principle of diffusion. What causes substances to mingle and dissolve so readily? Explain osmose. How are liquids, and substances dissolved in them, able to pass through a membrane? To what fact is the term capillary attraction applied? Why is it so named? Why will a whole towel become wet if one end is placed in water? Why will water rise higher in a very small tube than in a larger one?

How, aceording to these principles, do the substances of the soil pass into plants? What effect is produced upon plants by the attraetion of their roots for water? Why does a plant droop when the soil becomes too dry?

Of what do the roots, stems, and leaves of plants consist? In what way is growth produced? Name some plants composed of loose cells. What is veretable tissue? What is the form of cells in different plants?

Explain how moisture reaches all parts of the plant? What two causes tend to keep up a continuous flow of sap? How does the moisture of sap eseape into the atmosphere? Why does sap flow slowly in damp weather? Explain the cause of the abundant flow of sap from the maple in the spring? Why does the flow cease as soon as the leares begin to grow? Does the flow of sap resemble the circulation of the blood of animals?

In what direction do the nutritive substances move within the plant? What causes them to move? Can plants choose their foorl?

What is the natural purpose of the growth of plants? Name the different parts of a flower. Explain the purpose of the pistils and the stamens. Name some plants that have only one of these upon a single plant. Name some that have the two upon different parts of the same plant. How are many different varieties of the same speries of plants obtained? Why will not peas and beans mix and produce new varieties? 


\section{CHAPTER V.}

\section{FER'TILIZERS.}

Fertile Soil. - The fertility of soil depends upon its ability to supply plants with all the elements of food which they require. No one of the elementary substances which have been enumerated as always found in the composition of a plant can be dispensed with.

As an animal cannot live or thrive without a proper supply of the ordinary elements of food, so a plant requires a regular supply of these various elements from the soil. A plant poorly supplied with potash or nitrogen, for instance, would produce only a sickly growth, and if entirely deprived of these, or of any other essential element, would die.

Fertile soil, therefore, must contain not only large quantities of plant food, but suffieient quantities of every kind of food which plants obtain from the soil to supply the wants of the crop.

So, too, soil must not only contain these elements, but they must be in a form in which plants can make use of them. An acre of soil may contain many tons of nitrogen or phosphoric acid, and yet may be totally unfit to produce a crop, becanse these camnot be conrerted into suitable forms fast enough to supply the amount of food required.

The following list gives the percentage of different sub. stances which may exist in ordinary dry, fertile soils. 


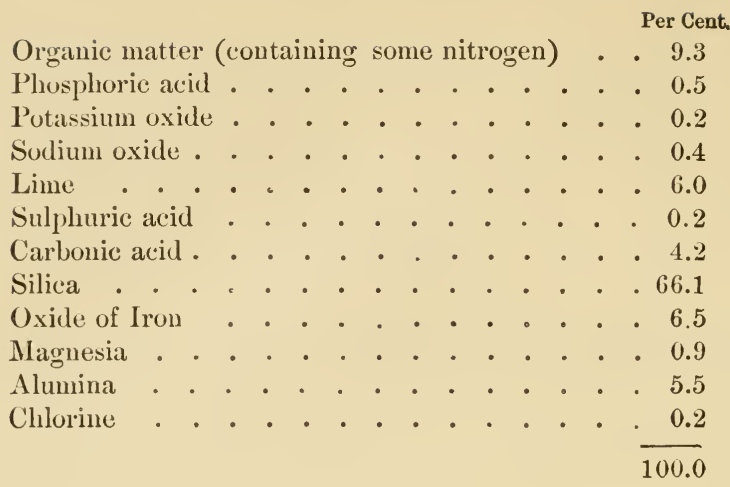

The percentage of many of these seems small, but it amounts to a large quantity per acre. One tenth of one per cent. of the dry soil of an acre would generally amount to two or three tons.

The quantity of many of these substances required by crops is so small that they are practically inexhaustible. Of those substances which crops require in larger quantities there would be enough to last many years, provided they could be changed and made available as fast as required.

The ordinary crop of wheat raised upon an acre might require, among other elements, fifteen pounds of phosphorie aeid and eighteen pounds of potash. If the entire amount of these substances naturally contained in good soil could be made useful as fast as needed, there would be no lack for many year's.

The Effect of Agriculture. - In a state of nature fertility is naturally maintained. Plants that grow upon the soil die and decay upon it. 'Thus, those elements of fertility which have been withdrawn from the soil by plants in their growth are returned to it by their death. 
In the process of agriculture, by removing crops we take away a quantity of these clements, year by year. If this is continued, and nothing is returned to the soil, in the course of time it becomes impoverished. The supply of plant food is exhausted, and not enough is changed to an available form, year by year, to produce a crop.

Land that is "run out" in this way may still contain large quantities of some elements of fertility, being deficient only in a few. By supplying the latter we may still keep up the fertility of the land for many years. If, for instance, the soil of a certain field contains enough available nitrogen to support a crop two years, enough phosphoric acid and potash for five years, enough lime for ten years, and enough of other substances for a longer period, it is evident that after two years we must supply nitrogen, after five years phosphoric acid and potash, and so on, unless some of these elements have been lost in the mean time, or some have been added by natural causes.

The Soil a Storehouse of Plant Food. - Ordinary soil appears to be composed of simple, inactive, unchanging substances, but in reality it is like a vast chemical laboratory, in which plant food is continually prepared, and either furnished immediately to the plant or kept in store for the future.

A portion of the rocky or mineral parts of soil contain substances which, when they have been changed by chemical action, become food for plants. Among the most fertile kinds of soil are those which have been produced by the crumbling and decay of granite and limestone. Vegetable mold, which results from the decay of plants and leaves, and which is found to a certain ex. 
tent in nearly all varieties of soil, is largely composed of the elements of plant food, which are gradually rendered available, year after year.

Chemical action, or the formation of plant food in these substanees, is eheeked by cold weather, but goes on contimnously in the summer season. It is aided by a proper supply of moisture in the soil, by the oxygen and carbonic acid of the atmosphere, and by the small quantities of ammonia and nitric acid which are brought to the soil in rain.

An application of fertilizers to the soil not only directly supplies the clements of plant food, but is also useful in furnishing. sulsstances which are needed to unite chemically with other substances already contained in the soil, in order that the latter may become serviceable.

When roots of growing plants are present, these nutritive substances are immediately alsorbed, so far as they are needed. If formed faster than needed, the surplus is either retained for future use, or is washed away by rains and wasted. Some varicties of soil, particularly those containing clay or vegetable mold, are able to retain large quantities of these elements for a long time, but from loose, gravelly, or sandy soil they are easily washed away.

The Elements Needed in Fertilizers. $-\Lambda$ majority of the elements of fertility are contained in most soils in sufficient quantitics to last many years. Those which generally fail the soonest, and which we must aim to supply in fertilizers, are nitrogen, phosphoric acid, and potash.

Some peculiar soils may be wanting in some other substance, as sulphur or lime; but when soils begin to 
be unproductive, the lack of one or all of the three elements mentioned is almost universal.

Plants require larger quantities of these elements than of any other, and hence they fail the soonest.

Nitrogen. - Nitrogen is an element both essential to plants and difficult to obtain. While the air contains an abundance of it, but few plants can make use of it from that source. It is not generally available to the plant in its free state, but in combination with other elements.

'There are two compounds of nitrogen in which it is believed to be mostly serviceable to plants: they are nitric.acid and ammonia.

The plant secms to obtain most of its nitrogen by tak. ing up through its roots either of these substances, or compounds formed by the chemical action of these upon other substanees.

1. Nitric Acid $\left(\mathrm{HNO}_{3}\right)$. - Nitric acid is formed in the soil by the decay of organic matter. A small quantity of it also exists in the atmosphere, some of which arises from the decay of organic substances, and some is believed to be produced out of the free nitrogen and oxygen of the air by electric currents passing through it.

This acid, either formed in the soil or washed into it from the atmosphere, enters the roots of the plant, either directly, or in the form of salts, called nitrates, produced by its union with alkaline substances.

2. Ammonia $\left(\mathrm{NH}_{3}\right)$. - Ammonia is also produced by the decomposition of animal and vegetable matter, from which, unless absorbed and retained by other substances, it easily escapes into the atmosphere. It is very soluble in water, and is absorbed by various substances, as peat Wins. Agr. -6 
and decaying regetable matter, clay, and other soils. Charcoal will absorb ninety times its own bulk of ammonia gas.

Ammonia is therefore widely diffused, though in small quantities, in the atmosphere, in the land, and in the water of the earth. It readily combines with acids, and in the atmosphere is not generally found in a free state, but combined with carbonic acid, forming carbonate of ammonia. 'This carbonate is dissolved in the moisture of the atmosphere, and brought to the earth, where, together with the ammonia already contained in the soil, it adds to the supply of nitrogenous plant food.

Only a part of the nitrogen required for producing farm crops is furnished in the natural supply of nitric acid and ammonia. The farmer adds to this supply by furnishing fertilizers which either contain these substances or their compounds, or which will produce them in the soil by deeay and chemical changes.

Nitrification. - The vegetable matter which exists in ordinary soil in the for'm of decaying grass, leaves, roots, or stable manure, contains nitrogen combined with carbon. In this condition it is not available as plant food. By a peculiar process called nitrification the nitrogen is separated and converted into nitric acid. This acid again combines with hases in the soil and forms nitrates, as nitrate of lime, nitrate of soda, or nitrate of potash, and these are easily dissolved and readily absorbed by the roots of plants. They are also easily washed away from the soil and lost when there are no plant roots ready to take them up.

The process of nitrification is brought about by the growth of a minute plant. This plant thrives in warm, moist soil, which is sufficiently porous to admit air, and 
which contains some alkaline substance. During the warm summer months nitrates are continuously formed in this way to support plants while they are growing most vigorously. Young plants sometimes suffer from the want of nitrogen in the early spring, before the soil becomes sufficiently warm for the formation of nitrates.

Phosphoric Acid $\left(\mathrm{P}_{2} \mathrm{O}_{5}\right)$. - Phosphoric acid, a combination of phosphorus and oxygen, is not found free, but in eombination with potash, soda, lime, etc.

It is very largely a plant food, and is especially necessary for the proper ripening of plants and the formation of seerls. Its most common form is that of phosphate of lime $\left(\mathrm{CaOP}_{2} \mathrm{O}_{5}\right)$. In this form it constitutes about one half the substance of the bones of animals, which are largely used in preparing this element of fertilizers.

Potash $\left(\mathrm{K}_{2} \mathrm{O}\right)$. - Potash is also an important element of fertility, which does not exist in ordinary soil in suffieient quantity to support a continuous succession of erops.

It is generally obtained and used in the form of salts of potash, as carbonate of potash $\left(\mathrm{K}_{2} \mathrm{CO}_{3}\right)$, chloride of potash $(\mathrm{KCl})$, etc. Carbonate of potash is the important part of wood ashes. "New" land is generally well supplied with potash in the ashes resulting from the burning of trees and brush.

Artificial Fertilizers. - To supply nitrogen, phosphoric aeid, and potash to the soil, as well as eertain other elements which are sometimes needed, substances are either manufactured, or are obtained in a natural state in different parts of the world. To distinguish these from ordinary farm manure, which is the most common 
and natural fertilizer for the farmer, they are called artificial fertilizers.

'I'he materials for them are obtained from a variety of sources, some of the more common of which are as follows:-

Sources of Nitrogen. - 1. Nitrate of soda, or Chili saltpeter, is extensively obtained in a natural state from some parts of South America.

2. Sulphate of ammonia is ol,tained for a fertilizer from "gas liquor," or the water in which illuminating gas has been washed. The anmonia which the liquid contains is obtained by treating it with sulphuric acid, with which the ammonia combines.

3. Fish serap, meat scrap, dried blood, and all forms of animal refuse, are rich in nitrogen, and are generally used for manufacturing fertilizers.

Sources of Phosphoric Acid. - 1. Bones are largely composed of phosphate of lime, which is converted into an arailable form, called superphosphate, by an application of sulphuric acid. Crushed and ground bones are also used directly as fertilizers, but vield their phosphoric acid more slowly. Bone-ash, produced by burning bones until they crumble easily, is less valuable than ground bones, as the process of burning removes from the bones what nitrogen they contain.

2. Bone-black, or charred bone, is used at sugar refincries for cleansing sugar. After it becomes useless for this purpose it is treated with sulphuric acid to convert its elements into a soluble form, and is then sold as a fertilizer.

3. Mineral deposits are found at rarious points of the earth containing a large percentage of phosphate of lime. Their origin is supposed to have been an aceumulation of 
the bones of animals at some period in the ancient history of the earth. Many of these deposits are used as a source of phosphoric acid for fertilizers. Those used in this country are obtained from South Carolina, in what is called "South Carolina rock," and from Canada, in the form of a green mineral, ealled apatite.

4. By a process of manufacturing steel there is formed a waste product, or slag, which contains phosphoric acid. This is sometimes used in preparing fertilizers.

Sources of Potash. - 1. Wood ashes contain to some extent all the mineral or inorganic elements of plant food, but are particularly rich in carbonate of potash. They hare been used as fertilizers sinee very ancient times. Until quite recently they have served as the only source of potash for artificial fertilizers.

2. In the mines of Germany, potash is obtained in the form of salts of several varieties. These are known as "German potash salts." Chloride of potash, commonly called "muriate" of potash, obtained from this source, is largely used in this country for fertilizing purposes.

Guano. - Certain islands off the western coast of South America have for centuries been the haunt of countless numbers of sea birds. 'The dropping's of these birds constitute guano. It has accumulated in some places to the depth of from twenty to fifty feet. The general absence of rain in those regions has prevented the valuable elements from being washed away. Large quantities of this guano are shipped to different parts of the world, and are either applied directly to the soil, or used in preparing other commercial fertilizers.

Prepared Fertilizers. - The various substances cnumerated may be used singly as fertilizers, or in combination. 
The most of them need to undergo chemical treatment to render their elements available. The work of preparing and mixing is mostly done at large factories, from which the ordinary commercial fertilizers are shipped and sold to farmers in all parts of the country.

The aim in preparing these is to produce a mixture containing the three elements, nitrogen, phosphoric acid, and potash, in the proportions in which they are needed for average soils and crops.

To meet the wants of particular crops, so far as they are understood, special fertilizers are sometimes prepared and sold for each crop, containing the three elements in varying proportions.

In addition to the substances mentioned, which furnish the three most essential elements of fertilizers, there are certain others which serve some purpose, either directly or indirectly, in improving the fertility of the soil.

Lime $(\mathrm{CaO})$. - Lime, or oxide of calcium, is obtained in large quantities, in various localities, from "limestone quarries." In its natural state it is found combined with carbonic acid, for which it has a strong attraction, forming calcium carbonate $\left(\mathrm{CaCO}_{3}\right)$.

Calcium oxide, or quicklime, is obtained by heating the ealcium carbonate until the carbonic acid is driven off.

Quicklime has a strong attraction for both carbonic acid and water. When exposed to the atmosphere, it slowly absorbs both these substances, forming air-slaked lime. If brought in contact with water, it unites with it so rapidly as to cause great heat, producing calcium lydrate $\left(\mathrm{CaO}_{2} \mathrm{H}_{2}\right)$.

Lime is beneficial to soil in rarious ways :-

1. It serves directly as plant food. All plants require a small quantity. 
2. It combines with, and decomposes, vegetable substances, and other elements of the soil, preparing them for plant food.

3. In a general way, it has a beneficial effect upon various kinds of soil, rendering them better adapted for agricultural purposes.

It renders heavy, elayey soil more loose and mellow, and sandy soil more compact, so that it will retain more morsture. It neutralizes the injurious acids of cold, peaty soil, and loosens it for the admission of warm air.

Many varieties of soil already contain lime in abundance, but where it is deficient, its application is often of great benefit.

Marl. - Marl is composed of carbonate of lime mixed with other substances, as elayey or sandy soil. It sometimes contains some nitrogen and phosphoric acid. The low places where it is found are supposed to be the beds of ancient lakes which have dried up. The deposit has been formed by the aceumulation of shell-fish at the bottom of these lakes, through long periods of the ancient world. Marl is used as a fertilizer in regions near these beds, where the expense of transportation is not too great.

Gypsum. - Gypsum, or land plaster, is produced by a union of lime and sulphuric acid, giving ealeium sulphate and water $\left(\mathrm{CaSO}_{4}+\mathrm{H}_{2} \mathrm{O}\right)$.

By heating gypsum, the water is driven off, leaving the calcium sulphate, or plaster of Paris.

It is found in nature, in some localities, and is used as a fertilizer where lime and sulphur are needed. It is especially beneficial to clover, and other leguminous crops.

Salt $(\mathrm{NaCl})$. - Common salt is composed of sodium 
and chlorine. As plants contain both these elements, in small quantities, salt is of some value as a fertilizer in soils where they are lacking. It is also of some benefit in preparing plant food by exerting ehemical action upon other substances. It must be used with caution, as in too large quantities it is fatal to regetation.

An intelligent and economical use of fertilizers requires a knowledge of four points :-

1. What the Fertilizer Contains. - As the composition of substances used as fertilizers is determined by chemical analysis, this is beyond the power of the ordinary farmer. The government generally affords protection against the sale of worthless compounds by requiring that the composition of the substance exposed for sale shall be printed upon the package, and by providing for chemical tests of the goods as they are found in the market.

2. What the Soil Requires. - The composition and condition of soil in different localities, and at different times, are so varied, that no general rule for the use of fertilizers can be safely followed.

One field may require nitrogen, while another may be well supplied with this, but may lack phosphoric acid, or potash, or both. The use of a fertilizer in each field, containing an arerage quantity of each element, might be a wasteful practice.

The only method arailable to farmers for determining what their soil needs is to conduct "field experiments," applying different fertilizers to different sections, and noting the results. For such a purpose, the three elements may be obtained singly in "chemicals."

Nitrogen, for instance, may be ol,tained in sulphate of ammonia or nitrate of soda; phosphoric acid, in ground 
bones or dissolved bone-black; and potash, in muriate of potash or sulphate of potash.

3. What the Crop Needs. - The different crops vary considerably in the relative quantity of the three elements needed. It is important that each be supplied with a fertilizer suited to its especial wants.

By a chemical analysis of different crops, we may learn in what proportion the different elements of food are required in their formation, and so may obtain some idea of the propartion in which these elements should be applied to the soil.

4. The Amount Required per Acre - Economy in raising erops, as in raising animals, requires that they shall receive all the food they can consume and properly assimilate. No crop can reach and thus utilize all the food present in the soil; hence, more should be furnished than enough to cover the wants of a single crop. At the same time, a large surplus would involve waste, except in soils which are able to retain it for future crops.

Methods of Applying Fertilizers. --The valuable elements of most prepared fertilizer's are largely soluble in water; and, as the tendency of rain is to wash these parts downward, they should generally be mixed with the surface soil.

These fertilizers are usually so concentrated as to injure or destroy seeds and roots when brought into immediate contact with them. On this account, care should be taken, in planting, to place some soil between them and the sprouting seed.

It is wiser to place them above, rather than beneath the seed, so that the young roots may not be injured, and so that their elements may be gradually washed upon the roots as needed. 
As the roots of plants are rapidly extended to considerable distances in all directions, it is better, where much fertilizing material is to be used, to distribute most of it evenly through the soil, and apply but little to the hill or drill.

Farm Manure. - The chief source of fertility, and that upon which farmers mainly depend, is stable manure. As it is generally impossible to raise good crops without supplying some kind of fertilizer to serve as plant food, the manure of the farm becomes a matter of the greatest importance. The size and nature of the manure heap often determine the profits of the farm. It is sometimes called the farmer's "gold mine."

Success in agriculture depends very largely upon an understanding of the nature, the means of preserving, and the proper methods of applying farm manure.

Its Nature. - It differs from the ordinary commercial fertilizers in three respects :-

1. It contains all the elements of food required by plants. As farm animals live upon the crops or plants of the farm, it is evident that the manure will contain the substances which come from these plants, and of which they are composed, less so much as the animal has assimilated, and converted into flesh, bones, wool, milk, etc., and the carbon which has escaped with the breath.

Only a small part of the elements of food are thus assimilated and retained by the animal in digestion. The amount will depend upon the nature of the animal. In the case of young, growing animals, cows giving milk, or sheep producing large quantities of wool, the proportion retained will be greater than in the case of mature animals yielding no increase. It may be stated, 
as an average, that from eight to nine tenths of the manurial elements of the food of animals exists in the manure.

As the elements of manure are the same as the elements of plants, it is evident that the manure is suited for the growth of other plants, in turn, provided it is all preserved and returned to the soil without loss or waste, and provided sufficient fertilizing material is added to take the place of the part retained by the animal.

2. It is less concentrated. A ton of average manure contains only about 25 pounds of plant food. The remaining 1,975 pounds can be of no direct service as food for crops. This renders it more expensive to handle, which is sometimes a serious objection where it must be conveyed a long distance.

The bulky nature of manure, however, gives it certain advantages. It is of great benefit to heavy soils, by making them mellow and porous for the admission of air, rendering them drier in a wet season, and at the same time enabling them to retain moisture in a time of drought.

The lack of some mechanical " divisor," such as is furnished in common manure, is a serious objection to continuous farming with artificial fertilizers alone. It often becomes necessary to plow in a crop of clover, or some other bulky substance, in order to supply this want. Without some treatment of this kind, soils after a time are liable to become solid and compact, and may suffer from the slightest drought.

3. It yields its supplies of plant food more slowly. A large proportion of the valuable elements of ordinary commercial fertilizers is usually soluble, and immediately available to plants. Probably from one half to 
three fourths of the value of these fertilizers may be obtained in the first crop after they are applied.

In stable manure, only a small proportion of these clements is soluble and available at first. Not more than one fourth of its value is ordinarily obtained the first season. The remainder must wait for chemical action slowly to rerluce it to available forms.

The Care of Manure. - The value to be derived from stable manure depends largely upon the care exercised in preserving it.

Probably nearly one half the value of manure throughout the country is lost. Some loss is, of course, unavoidable, but it may be largely prevented by proper care.

There are three general sources of loss :-

1. Fermentation. - Fermentation is a process of decay, or decomposition, which organic substances undergo when brought in contact with moderately warm air. The chemical process consists partly of oxidation, producing heat. On this account, it is sometimes called heating.

Some kinds of manure ferment much more readily and rapidly than others.

Sometimes, if the process is allowed to continue un. checked, it will give to manure the appearance of having been partially burned, leaving only a light, unsubstantial mass hehind. It is then said to be "fire-fanged."

By fermentation the most valuable elements of manure are converted into gases, and tend to escape into the atmosphere. Nitrogen is converted into ammonia, and carbon into carbonic acid gas. The loss of the former is of far greater importance than that of the latter, since carbon, which plants obtain so largely from the atmosphere, is of less value in manure. 
When the fermentation is going on rapidly, ammonia is sometimes formed so fast as to produce a strong, pungent odor. We may determine whether it is escaping to some extent by suspending over the manure heap a piece of litmus paper in which the blue color has been changed to red by dipping it in some acid. If there is any ammonia escaping, it will gradually restore the color from red to blue.

Slight fermentation would do no harm, and in fact may be of some advaitage in converting the elements of manure into arailable forms, provided there are other substances present ready to unite with the gases, and retain them as soon as they are formed, so as to prevent their escape. It is in this way sometimes desirable for special purposes, as in compost heaps. Generally, however, it is to be aroided, since any advantages gained by the process are overbalanced by the loss of eseaping gases.

The ordinary methods of checking fermentation are:-

(1.) By mixing the manure of different animals. Some kinds of manure are slow to ferment. When these are mixed with other kinds, the fermentation of the mass is checked.

(2.) By keeping the manure heap wet. A certain amomit of moisture aids fermentation, but an excess checks it. It is therefore of some advantage to keep the heap as moist as possible without causing loss by drainage.

(3.) By keeping the heap trodden down, so as to exclude the air. As the process requires the presence of the atmosphere, it is evident that it may be largely prevented by excluding the air as much as possible.

For this reason it is often of great service to allow 
pigs, or other animals, to run upon the manure heap, so as to keep it in a compact condition.

2. The Escape of Liquids. - The liquid parts of manure contain more than one half their value. It is important that some dry, spongy substance, as straw, leaves, dried muck, or dry soil, be used to alusorb and retain them. The nitrogen which serves to form ammonia by fermentation, is largely contained in the liquids, and the presence of these substances in some measure prevents the escape of ammonia, by combining with it or alssorbing it.

The same purpose may be more fully accomplished by applying to the liquids sulphuric acid, or gypsum, which is partly composed of that acid.

3. Exposure to Rain. - The liquid parts contained in manure, and held by absorbents, are readily washed out by heavy rains. Both ammonia and nitric acid, the two available forms of nitrogen, are largely lost in this way, as well as some other elements.

When manure is piled in heaps upon land which is to be cultivated, it is true that these elements are washed into the soil. This, however, involves waste, as the small plots beneath the heaps are too much overstocked with these valuable substances to be able to render any adequate returns in the crops.

To prevent waste by washing, manure should be kept under cover; or, if exposed, should be so protected as to receive only a small amount of rain, which would do no harm.

Methods of Applying Manure. - Whatever particular methods are employed in applying manure to the soil, there are two general principles that should always be borne in mind:-

1. It should be applied as soon as possible. All 
waste, either by fermenting or washing from the heap, is avoided as soon as the manure is scattered upon or incorporated with the soil. By piling it in heaps, and allowing it to ferment, it may be rendered more suitable for the immediate wants of certain crops, but this is at the expense of some of its value. When applied without such fermentation, it may be slow to yield its elements the first season, but these are preserved for future years.

2. It should be rendered as fine as possible, and thoroughly mixed with the soil. Those parts which are soluble at first may be washed out, and distributed evenly enough for practical purposes, under any methods; but in order to secure the benefit of the mechanical effect of mixing the solid parts with the soil, and the chemical effect produced by these upon the soil in decomposition, it should in some way be finely divided, and thoroughly mixed with the soil, so as to bring its particles into contact with as many particles of the soil as possible.

Swamp Muck. - Muck or peat beds are numerous in low, wet places, throughout a large portion of the country. Muck consists of partially decayed vegetable matter, which has aecumulated through past ages. It is of considerable value as a fertilizer. It is especially rich in nitrogen, samples often yielding from one to three per eent. of it.

The fertilizing elements of muek, howerer, are in the form of certain acids, or insoluble compounds, which are not, in their natural state, available to plants. Before it can be of much service it must be treated with some alkaline substance, so that its acids may be neutralized and its elements converted into available forms.

This may be aceomplished in three ways :-

1. By long continued exposure to the air. If taken from its bed and exposed to the air, it will be gradually 
but very slowly changed by contact with ammonia and other substances which exist in small quantities in the atmosphere. This course is not very practicable, as sereral years are required to effect a complete change.

2. By mixing it with some alkaline substance, as lime wond ashes, or some of the salts of potash. If united in a compost with a small quantity of these substances, the desired change is soon obtained.

3. By mixing it with stable manure. This is a very profitable method of treating it. A twofold purpose is accomplished: the manure furuishes the alkaline elements for the muck, and the muck retains those elements of the manure which would otherwise escape into the air by fermentation. For this purpose, one part of manure is regarded as sufficient for three parts of muck.

Muck as an Absorbent. - Muck, like ordinary vegetable mold, possesses the property of absorling large quantities of water. As taken from the swamp, two thirds or three fourths of its weight is water. In drying, its bulk is greatly reduced. 'This property renders dried muck an excellent absorbent for the liquids of the stable. These liquids are exactly suited to produce the proper changes in the muck.

Muck may be profitably applied to land not well supplied with humus, or regetable mold.

The Value of Muck. - The elements of which ordinary muck is composed give it a nominal value about equal to that of stable manure. Its real value is reduced, of course, by the labor and expense of procuring, composting, etc.

There is a wide difference in the quality of muck from different localities, depending upon the nature of the substances out of which it has been formed. 
In some cases it contains a large quantity of ordinary soil, or other comparatively worthless matter. Some samples yield three or four times as much nitrogen as others. Before much expense is incurred in procuring muck from any particular bed, some idea of its value should be obtained, either by chemical analysis or some other experiment.

Some idea may be obtained of the proportional amount of worthless sand, or other mineral matter which the muck contains, by placing a small quantity in a tube or glass of water, shaking the glass thoroughly, and, after allowing it to stand for some time, noting the quantity of mineral substances which settle to the bottom.

\section{QUESTIONS.}

What is fertile soil ? Name the elements neressary to make soil fertile? Would a soil containing no sulphur be fertile? Would scraps of leather, which are largely composed of nitrogen, add to the present fertility of soil? In what way is the fertility of the soil naturally maintained? What is the effect of raising crops?

What processes are going on in the soil? Do rocks furnish food for plants? What effect has cold weather upon the chemical processes in the soil? What is the effect of the atmosphere? How do fertilizers aid the chemical action? What becomes of the fertilizing substances formed in the soil? Why is it more important that loose soil should be always occupied with vegetation than clayey or mucky soil?

What elements are most generally lacking as soil becomes impoverished? Why is nitrogen expensive as a fertilizer? In what forms does it generally become foot for plants? Where is nitric acid found, and how is it produced? How is ammonia formed? Where is it to be found in nature? In what way does the farmer add to the natural supply of nitric acid and ammonia?

What is meant by nitrification? How is the process brought about? What conditions are necessary? Why is the supply of nitrogen smaller in the early spring than in summer?

Wins. AGR. -7 
Of what is phosphoric acid composed? In what forms is it to be found? Of what special use is it to plants? Why is ner land generally well supplied with potash?

What do artificial fertilizers usually contain? From what sources nitrogen obtained for these fertilizers? Name the different solfces of phosphoric acid. How is potash obtained?

What is guano? What other substances are sometimes useful as fertilizers besides those mentioned? In what form is lime found? How is quicklime produced? What is air-slaked lime? In what three ways does lime benefit soil?

What is marl? Give the history of its formation. Of what use is it as a fertilizer?

What is gypsum? How does it benefit soil? Is salt a fertilizer, and how?

What points should be understood in order to make a proper use of fertilizers? How may farmers learn what fertilizers contain? How can they learn what the soil requires? Why does one crop need a different fertilizer from another? Why nust, soil contain more fertilizing material than the crop uses? Would the surplus be wasted in a clayey soil?

Why should chemical fertilizers be placed near the surface of the soil? Why should they not be allowed to come in contact with seeds and roots? Why should but little be used in the hill?

Why is the manure heap sometimes called the farmer's gold mine? In what three respects does stable manure differ from commercial fertilizers? Why is it a complete fertilizer?

What part of the elements of plants is retained in digestion? Of what advantage is the bulky nature of manure? How does it render land more moist in a dry time? What part of the value of manure may be obtained in the first crop? What are the three sources of loss to which stable manure is subject?

What is fermentation? How is the heat proclucerl? What substances are lost by fermentation? Why is fermentation desirable in a compost heap? In what ways may it be partly prevented?

What is the chief advantage of allowing pigs to run upon the manure heap? What is the value of the liquid parts of manure? What element gives them their chief value? What are the benefits of using absorbents in the stable?

Of what special benefit is gypsum in manure? How can there be any 
waste from manure heaps piled upon cultivated land ? Can there be any loss to manure while it is frozen? What two general points should be observed in the use of manure? Why should it be applied to the land as soon as possible? What are the advantages of rendering it fine?

In what does the chief value of swamp muck consist? Why is it of little value when first obtained? In what three ways may the necessary changes in its nature be brought about? Why are alkaline substances needed? Why is the practice of mixing it with stable manure especially profitable? Why is it a good absorbent? Give some idea of the value of muck. 


\title{
CHAP'TER VI.
}

\author{
CULIIVATIUN.
}

Cultivation, or the mechanical handling of soil for the bencfit of crops, includes a large part of the labor of farming.

An understanding of the reasons for the different processes embraced in the tillage of the soil, and of the benefits to be derived from them, is essential to success in agriculture.

Purposes. - The purposes of cultivation may be classified as follows:-

1. To break up the soil, or make it "mellow," so that the roots of plants may easily penetrate it.

The roots of a few varieties of plants are very hard and firm.

Some are provided with a sharp point at the tip, so that they are ahle to penetrate hard sulstances. Quitchgrass roots will sometimes grow entirely through a potato. But the roots of most agricultural plants are more delicate, and make their way with difficulty through hard soil.

In poorly cultivated soil, filled with hard lumps, roots are found to occupy the mellow portions, aroiding the lumps. To leave the soil in a lumpy condition is therefore to reduce the extent of the feeding ground of the plant. 
The depth to which roots penetrate is largely determined by the depth to which the soil is stirred in cultivation.

2. To admit air to the roots.

Most agricultural plants of temperate climates will live and thrive only in soil which is sufficiently porous to admit air.

Experiments show that the roots of such plants, as well as the foliage, require the presence of free oxygen. The plants either die, or produce a feel,le, sickly growth, in compact soil, or in soil continuously saturated with water.

There are exceptions, as in case of the cranberry plant and rice, which thrive best in soil completely covered with water during a portion of the year.

3. To hasten the decomposition of the soil, and the formation of plant food.

The ehemical processes in the soil are hastened by exposure to the air. They are partly dependent upon a supply of oxygen, carbonic acid, etc., from the atmosphere. By loosening the soil, so as to armit air, and by exposing different portions of it to the surface in cultivation, we increase its fertility by hastening the formation of plant food.

The practice of "summer fallowing," which is sometimes followed, consists in preparing ground for a future crop by plowing and harrowing repeatedly, so as to expose it as much as possible to the beneficial influences of the atmosphere.

4. To mix fertilizers with the soil.

Plants thrive best, not where their roots find pure fertilizer in some spots, and poor soil in others, but where the two are so completely mixed as to render the whole a uniform medium of rich soil. 
The benefit to be derived from both fertilizer and soil depends partly upon their combination with each other.

5. To kill weeds.

Weeds are injurious to growing crops in various ways :

(1.) By occupying the soil to the exclusion of cultivated crops, and forming a shade, depriving them of the beneficial influences of sunlight.

(2.) By withdrawing moisture from the soil, which is taken up as sap and transferred to the atmosphere through the leaves. The amount of water thus removed from the soil, where weeds are numerous, may cause a crop to suffer from want of moisture, while a crop upon a neighboring plot free from weeds will be amply supplied.

(3.) By withdrawing food from the soil upon which crops would otherwise feed.

The quantity of available plant food in the soil at any time is limited. The strongest, most vigorous, and quickest growing plants are sure to obtain the greatest share. Most agricultural plants are not so rigorous when young as the ordinary weeds. Weeds grow much faster at first, and so tend to starve out other crops.

Weeds should always be destroyed when young and small. If allowed to grow until they attain considerable size, they damage the erop, and are more difficult to exterminate. They are plants, some varieties of which might be of service in their proper places, but they cannot be made useful when growing in the midst of other crops.

Although returned to the soil, they reduce the available fertility of the farm by taking up the elements of plant food and converting them into regetable tissue, some of which may require years to be again transformed into soluble matter. 
6. To regulate the supply of moisture.

A proper degree of moisture is an essential condition for the growth of crops. Either too much or too little is injurious.

During the hot summer months, however, when crops are growing fastest, they generally suffer more from a lack of moisture than from an oversupply. In the case of "hoed" crops, the amount of moisture in the soil may be increased by proper cultivation.

In dry weather moisture finds its way to the surface by capillary attraction, and evaporates rapidly. A "mulch," or light corering of straw, or leaves, or any other substance, keeps the ground moist by retarding this evaporation. By stirring the surface soil and keep. ing it light and porous, a similar effect is produced, the loose soil serving as a mulch.

Since the pores in this soil are too large for capillary action, the moisture fails to reach the surface.

7. To afford particular treatment to special crops.

There are some crops that require special treatment, or handling of the soil about them, to insure the most successful growth.

1. Some plants, for instance, are supposed to thrive better when the soil is built up into "hills" about them. The ront crops require a soil made mellow to a great de,th.

Plowing. - The plow has been regarded, through all ages of the world, as the characteristic implement of the farmer. The first plow ever used was nothing more than a stick of wood, with which the ground was stirred or seratched. The history of the plow and its improvements corresponds closely to the history of civilization and improvements in the art of agriculture. It is still an indispensable implement of tillage. Thoroughness of 
cultivation and success in farming depend largely upon the plow and the use made of it.

Deep Plowing. - As a general rule, ground is not plowed to a suffieient depth. The soil below that part which is stirred in eultivation is generally of little direct service to crops.

The subsoil is often too hard to allow roots to penetrate it freely. As it is buried away from the atmosphere, the chemical changes which would convert its materials into plant food are very slow.

- By bringing it to the surface, and mixing it with the fertilizers and fertile soil, these materials are made more rapidily available.

Economy in farming requires that large crops shall be produced upon small areas. By deepening the cultivated soil, and thus enlarging the extent of space and increasing the supplies of food available to the roots of plants, we attain this end.

Deep tillage, also, has much to do with regulating the supply of moisture. In wet seasons it affords drainage by providing more space for the surface water to pass into the porous soil beneath.

In a time of drought, as the roots of crops have been able to extend themselves more deeply into the soil, they are able to obtain a supply of moisture, and are not so much injured by the drying of the surface.

While deep plowing has these adrantages, there are some cautions to be observed. To plow land at first much deeper than ever before, would bring to the surface a large quantity of erude soil. Unless a great amount of fertilizer is applied, this poor soil is liable to injure and retard the growth of young plants before their roots can penetrate to the better soil below. This difficulty 
may be avoided by making the deepening of the soil a gradual process, plowing each time a little deeper than before.

Some sandy or alluvial soils are naturally so loose as to admit air and roots freely. Such soil, on the one hand, is not so much in need of deep plowing; and, on the other hand, if the lower portions are brought to the surface, they can do no harm, since they have beeome adapted for plants by the presence of air and the fertilizer's which have been washed downward.

It may not always be wise to plow deeply. In the varied processes of cultivation, there may be occasions when shallow plowing will, for the time being, better accomplish the particular end desired; as, for example, when the lower soil is already sufficiently loose, and we simply wish to destroy weeds or mix fertilizers with the surfaee soil.

Subsoil Plowing. - The subsoil plow follows in the bottom of the furrow made by the ordinary plow, stirring the lower soil and allowing it to remain in the same position. By its use some of the advantages of deep tillage are gained withont the necessity of bringing the poor subsoil to the surface.

The Time to Plow. - It is an important question at what time plowing should be done; whether as long as possible before the seed is planted or just before, - in the fall or in the spring.

There are two sides to the question. After land is plowed, and exposed loosely to the atmosphere, chemical changes go on more rapidly, eonverting the elements of fertility into a soluble form. On the other hand, the soil is more exposed to the washing of rain.

As all vegetation has been destroyed by plowing, de- 
priving the soil of the presence of living roots, which would absorb and hold these elements, they are liable to be lost as fast as formed, unless the soil from its nature is able to retain them.

In general, the answer to the question will depend upon the nature of the soil, the climate, and the particular crop to be raised.

A clayey or mucky soil would be free from the objection mentioned, while in the ease of a sandy or gravelly soil the loss by washing might be greater than the gain by exposure to the atmosphere.

In cold climates, where the ground remains frozen through the winter, there can be no loss during this season, and plowing in the fall gives land the benefit of the crumbling and disintegrating effect of frost.

In climates where the ground does not freeze, and where rain is abundant during winter, there is a liability of large loss both by washing out the soluble elements, and by washing away the finest and richest parts of the soil.

For raising particular crops there may be special reasons for plowing in the fall or in the spring, according to the special wants of the crop. While ground plowed in the fall has received certain changes from exposure to the air and the action of frost, that plowed in the spring will naturally be more loose and porous.

Harrowing. - Next to the plow, the harrow is the most important implement of agriculture. The purpose of harrowing is chiefly to pulverize and level the soil, and a thorough performance of this work affords all the general advantages of tillage. It prepares the soil for roots, admits air, favors the formation of plant food, and thoroughly mixes fertilizers with the soil. Experiments 
havs ohown that land well harrowed will yield better crons than land poorly harrowed, but supplied with a greater: quantity of fertilizers.

Rollirig. - Rolling is a useful process in tillage under certain circumstances. It crushes and pulverizes lumps of soil which have escaped the work of the harrow. When the soil is very dry and loose, rolling presses it more compactly about seeds, bringing them moisture by capillary action, and hastening their germination and growth. It serves a good purpose in the spring, by pressing into the soil the roots of grass which have been thrown out by the action of frost. Clayey land, when wet, is injured by rolling, as the particles of soil are pressed too closely together to admit air, and in drying form a hard crust upon the surface.

Cultivating. - The frequent cultivating or stirring of the surface soil between the rows of hoed crops, during the period of their active growth, is beneficial, both by killing weeds as soon as they appear, and preventing the loss of moisture. In every shower and rain-storm the particles of soil are washed and heaten together so compactly as to cause moisture to rise to the surface by capillary action and evaporate. By loosening the surface soil repeatedly, this is prevented.

As the rootlets of plants ompletely fill the soil, approaching very near to the surface, this cultivation shoula generally be shallow. While the surface soil which is stirred in eultiration retains the moisture beneath, it becomes drier itself because of its loose condition.

By cultivating deeply among crops, we may prevent roots from occupying the upper portions of the soil, not only by repeatedly breaking them, but by rendering this part of the soil too dry. 
Draining. - The draining of land, for the purpose of removing surplus water in wet seasons or in wet places, is accomplished either by surface drains or by underdrains.

Surface drains, or ditches, are of some adrantage in removing the surplus accumulation of water from the surface of the ground. Besides being unsightly and inconvenient, they have the disadvantage of causing some of the richer portions of the surface soil to be washed away.

Underdrains are buried out of sight, involve no waste, and accomplish the purpose more effectually. The general advantages to be gained by underdraining wet land are as follows :-

1. It renders the lower soil available to roots.

As the roots of most agricultural plants cannot live without the presence of oxygen, they cannot occupy soil which is completely saturated with water. Where the lower portions of soil are filled with water, roots are necessarily confined to the surface soil. By draining, we afford them an opportunity to make their way downward.

2. It admits air to the lower soil.

From soil whose pores are filled with water, air is, of course, excluded. In such soil the formation of plant food mostly ceases. In a muck bog the humus retains its elements in an insoluble condition for centuries.

By draining the water out of soil, we admit air, and provide for the formation of plant food.

3. It secures the benefits of rain.

Rain water, containing nitric acid, ammonia, etc., is a source of fertility. In falling upon soil that is already filled with water, it cannot penetrate into the soil, but runs away upon the surface. Thus, the benefits of the rain are lost. Where water is withdrawn from the soil 
by drains underneath, falling rain, instead of flowing away, filters through the soil, and, exeept in case of loose sand or gravel, leaves its fertilizing elements behind.

4. It prevents the injurious effects of a drought.

In a time of drought, while the surface soil becomes very dry, there is generally suffieient moisture below. If the lower portions have been previously saturated so as to prevent roots from oceupying them, the plant is now unable to obtain a supply of moisture, as its roots are surrounded with the dry surface soil ; but if the surplus water has been drained away, so that the roots have been able to make their way downward, when a drought oceurs the plant may obtain its moisture through
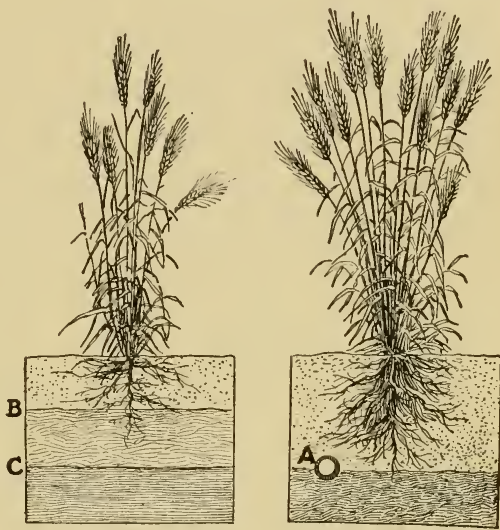

Effect of Underdrainage.

$A$, Drain-pipe. $B$, Point below which the soil is usually saturated. C, Point to which the water settles in a dry time. these lower roots.

5. It renders wet land available for tillage.

It is often the case that the wet lands upon the farm are the richest in plant food. Many low, wet places eontain an aecumulation of vegetable mold, and other fertile matter washed in from the land around them. By draining the water out of these places, we render them permanent sourees of wealth.

Some farms are split up into small, irregular plots, by narrow tracts of land, too wet for tillage. By draining 
these tracts, one continuous field may be formed out of a number of plots, which is of great advantage in the business of farming.

6. It increases the warmth of the soil.

The evaporation of water is a cooling process. It absorbs heat from the substance from which the moisture escapes. An object may be cooled in hot weather by covering it with a damp cloth. Damp clothing gives the body a chill, not so much on account of the presence of the moisture in the clothing, as from its evaporation in drying. So wet land is always cool, because, on account of the presence of water, evaporation is always going on.

The warmth of soil is promoted by drainage, not only by drawing the water away from beneath, and preventing evaporation, but also by admitting warm aix.

Rotation of Crops. - A knowledge of the fertility and cultivation of the soil is not complete without an understanding of the principles involved in the rotation of crops, or an arrangement of different crops to occupy the same land successively.

It is a familiar fact, that, when the same kind of crop is raised upon land year after year, the yield becomes less and less; and that, where one crop fails to yield good returns, another may flourish. This fact leads to the practice of changing frequently from one crop to another.

The advantages of this practice are as follows :-

1. It makes use of all the elements of plant food.

Different crops require the elements in different proportions. It is not often that these elements are supplied by the soil in the exact proportion required by any particular crop.

Potatoes, for example, require more potash than wheat, and wheat requires more phosphoric acid than potatees. 
If potatoes should be raised upon the same land continuously, the supply of availahle potash would soon be exhausted, while there might still remain in the soil an excess of phosphoric acid.

In order to continue to raise potatoes upon this land, it would be necessary to undergo the expense of adding a supply of potash. At the same time, the surplus of phosphoric acid, for which the potatoes have no use, might be washed out of the soil and wasted. If some crop, like wheat, requiring more phosphoric acid should be substituted for potatoes, a good crop might be obtained, and in the mean time the decomposition going on in the soil would render a new supply of potash available.

2. It keeps the land occupied.

Many of the cultivated crops have a short season of growth. After they are harrested, the land remains unoeeupied until the following season.

During this time the formation of plant food in the soil is continued, and is liable to be lost, as there are no growing erops present to make use of it.

By following the erop immediately with some other, as winter grain, or grass, such loss may be avoided.

3. It prevents the loss of substances which have been washed down into the subsoil.

The roots of some plants naturally grow near the surface of the soil. In such cases, some of the elements of food may be washed down below the reach of these roots. By following with a crop whose roots tend to penetrate farther downward, these may be gathered up and sared.

Clover, which has a deep tap-root, will generally grow well after crops having branching roots, like wheat or barley; and, on the other hand, these will thrive well after clover. 
4. It secures the varied advantages of cultivating the soil.

When land is continually occupied with one crop, like grass, it may become too hard and compact, and the formation of plant food may be checked. By stirring such soil, and exposing it to the atmosphere in cultivation, we hasten the chenical changes, and unlock the supply of food which nature has in store.

There are many old meadows and pastures, regarded as worn out and worthless, which, if subjected to thorough cultivation, might yield profitable returns.

5. It prevents the increase of weeds and injurious insects.

In cultivating certain crops, we may supply conditions farorable to the growth of certain varieties of weeds. If the erop is continued in the same soil, these weeds will naturally increase. Proper management requires a change to some other crop) with which such weeds will not thrive.

It is well known that injurious insects, like the potate beetle, will tend to increase on land which is repeatedly occupied by the particular crop upon which they are accustomed to prey.

The following are examples of rotations which are sometimes adopted :-

Indian corn . . One year.
Potatoes . . . One year.
Wheat . . . . One year.
Clover . . . . Two years.

Clover . . . Two years.

Tobaceo . . One year.

Wheat... One year.
Wheat . . One year.

Potatoes... Une year.

Barley . . . One year.

Clover. . . One year.

Cotton . . . One year.

Wheat . . . One year.

Clover or peas . . One year. 


\section{QUESTIONS.}

What are the different purposes of eultivating the soil? What is the effect of leaving land in a lumpy condition? Name all the reasons you can think of why plants will not thrive in hard soil. Why do plants obtain more food in a loose soil? What reasons can you give for mixing fertilizers thoroughly with the soil?

In what three ways do weeds injure crops? How do they dry the ground? Why should they be destroyed when small? Since they are not removed from the soil, how do they reduce its fertility?

In what way does cultivation increase the supply of moisture? Give several arguments in favor of deep plowing. Give several reasons why roots do not generally occupy, to any great extent, the soil below that which is stirred in plowing.

What influence has deep tillage upon the supply of moisture? What has it to do with economy in farming? Why is it unwise to plow very deeply at first? What kinds of soil may not need deep plowing? What are the advantages of subsoil plowing?

Name the arguments in favor of plowing in the fall. Give those in favor of plowing in the spring. What are the general conclusions in the matter? What are the advantages of thorough harrowing?

Name all the reasons you can think of why crops grow better in soil thoroughly pulverized. What are the advantages of rolling ground? Under what circumstanees is it injurions? What are the different benefits of cultivating hoed crops? Why should the ground be stirred after every rain-storm? Why should this eultivation generally be shallow?

II ow may surplus wat: be carried away from a field? What are the disarlvantages of surface drains? Name the different advantages of underdrains? Why do roots grow deeper where drains are provided? In what two ways do they render land more fertile? How do they prevent land from suffering from a drought? IIow do they render soil warmer?

What is meant hy a rotation of crops? What are the advantages of a rotation? Give examples of rotations sometimes adopted.

WINS. Agr. -8 


\section{CHAPTER VII.}

\section{ANIMALS.}

HE two forms of life upon the earth are plants and
animals. The chief purpose of regetable life is to supply the wants of animal life. The principal object in raising plants, or crops, in agriculture, is to obtain a supply of food for animals.

A knowledge of these crops is not completed until we have considered them as fed to animals to produce meat, milk, wool, work, ete.

It is very important to understand the nature, the peculiarities, the best methods of feerling, and the proper eare and management of our domestic animals.

The Composition of the Bodies of Animals. - The bodies of animals are composed of rery nearly the same clements as plants.

Some animals, like the cow or horse, live mostly upon regetation, and are called herbivorous, or plant-eating animals. Others, like the cat and dog, live largely upon the flesh of other animals, and are called camivorous, or flesh-eating animals. Some live partly upon plants and partly upon animals and animal products.

But animal products, as meat, milk, egres, etc., are produced from regetable matter, so that plants are the original source of all animal food.

The only substances that enter into the bodies of animals, apart from plants, and animal products produced (114) 
from plants, are water, oxygen from the air, and small quantities of mineral matter, such as salt, lime, potash, etc., with which animals must be supplied when these are not furnished in sufficient quantity in the regu. lar food.

The process of animal life consists in converting the substances of plants into the substances of the animal body, or in making them serve the different wants of the animal.

The substances forming the animal body may be divided into four classes :

1. Water. - Water is generally the largest ingredient, comprising from one third to two thirds of the entire weight. It is essential to plants, furnishing a medium through which the elements of food may be distributed. In animals, it fills a similar office. It forms four fifths of the blood, and exists in the juices throughout all parts of the body.

2. Nitrogenous Substances. - Nitrogenous substances, or substances containing nitrogen, are of first importance in the animal body. They make up the muscular tissue, or lean meat, the nerves, the skin, hair, wool, feathers, horns, etc. They also form a large part of the solid matter in the blood.

3. Fat. - Fat does not fill so important an office as the nitrogenous substances. It does not make up the tissues and other essential parts of the body. It is always present, however, in greater or less quantity. Particles of fat are to be found scattered between the fibers of the muscles. In well-fed animals fat is also stored up in large quantities beneath the skin, and about the bones and internal organs.

There are several varieties of animal fats, as stearin, 
palmitin, and olein. Some of them, like stearin, are hard, and some, like olein, are either fluids or are easily melted.

4. Ash. - The mineral parts of the animal are generally called the ash, because they are incombustible, or remain as ashes after burning. They are chiefly found in the bones, where they are needed to give firmmess and hardness. They are composed chiefly of phosphate of lime, carbonate of lime, phosphate of magnesium, and phospliate of potassium.

The following table will give an idea of the average pereentage composition of the bodies of domestic animals, after deducting the contents of the stomach and intestines : -

Composition of Bodies of Animals.

Per cent.

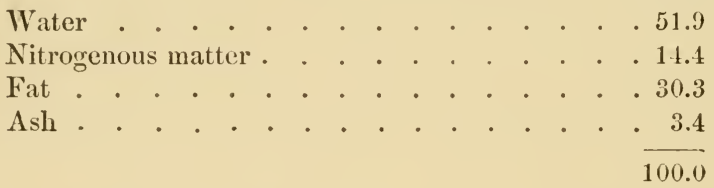

The Purposes of Food. - The different purposes which food must serve in the animal system are:-

1. To increase the Size of the Body. - Mature animals, whose size and weight remain constant, require no food for this purpose; but in young, growing animals, and those passing from a lean to a fat condition, the gradual increase in weight must come from the food consumed.

The formation of animal products, like milk, must be classed under this head, since the substances of which milk is composed first become a part of the animal, and are then converted into milk. 
2. To repair Waste or supply Mechanical Force. The particles of matter of which the bodies of animals are composed do not remain fixed and permanent. 'They are constantly being removed and replaced by new particles. After a time the particles become old, and no longer useful, and new particles are formed from the food to take their place.

A constant exchange is thus going on in all parts of the body, so that after a number of years a new body is formed, no part of the old remaining. The only exception to this is the enamel upon the teeth, which is believed to remain without change.

'This wasting, or wearing away, of the substances of the bocly is increased by work or muscular exertion. The body is never at rest. When asleep, or when perfectly quiet, the heart still beats to force the blood through the body, and the lungs are regularly expanded to draw the breath. Erery morement requires force, and this force is supplied either by food, or by particles of the body which must be replaced by the food.

The force that drives a train of cars comes from the consumption, or burning, of fuel under the boiler; so the force to produce motions of the body is obtained by chemical processes, which either consume the elements of food or particles of the body which have been formed from food.

3. To supply Heat. - The temperature of the hodies of animals, when in a healthy condition, is from $98^{\circ}$ to $100^{\circ}$. It cannot be allowed to vary many degrees from this point, for any considerable time, without causing death. In cold and hot climates, in winter and in summer, it must be kept constantly the same. When the 
body becomes too warm, it is cooled by the evaporation of perspiration from the skin.

As the air is generally cooler than the bodies of animals, it is constantly cooling them. To take the place of the heat thus withdrawn, it is necessary that a new supply be constantly furnished in the system. This is produced by burning, or oxidizing, a portion of the food, or particles of the body. The oxygen for this process is obtained from the air through the lungs.

The Composition of Foods. - The food of animals contains six different elasses of sulistances, as follows :-

1. Water. - All artieles of food contain more or less moisture. Hay and meal, which appear to be perfectly dry, contain from ten to twenty per cent. water. Succulent food, like green fodder and roots, may contain from serenty to ninety-fire per cent. water. In addition to that contained in the food, the animal must drink enough to supply the wants of the system.

2. Albuminoids. - The albuminoids of food, sometimes called protein, are the parts containing nitrogen. They are often called "flesh formers." They serve to form the flesh, or muscle, and the other nitrogenous parts of the borly.

The albuminoids contain not only nitrogen, which is used in forming the museles, but also other elements of an entirely different nature, which serve to supply heat or force. The albuminoids may thus be made to supply all the wants of the body; but to confine animals to a diet composed entirely of nitrogenous food would be a wasteful practice. The albuminoids contain a larger proportion of nitrogen than animals require. After a sufficient quantity of such food has been consumed to supply enough nitrogen, it is necessary to consume an 
additional quantity in order to obtain enough of those elements which supply heat and force. The nitrogen of this second quantity is wasted, since the animal has no further use for it. Heat and force may be more economically supplied with foods containing less nitrogen.

Amicles are another class of substances containing nitrogen. They exist to some extent in various kinds of food, particularly in green or immature fodder plants, and in regetables. They are less valuable than albuminoids, since their nitrogen eannot be used to form the tissues of the body. They can only serve, like fats and carbo-hydrates, to produce heat and force. As they are found only in small quantities, and are comparatively of little importance, they have not generally been distinguished from other elements in making an analysis of foods.

Protein is a term used to include both the albumi. noids and the amides, or all parts of food which contain nitrogen.

3. Fat. - The fatty parts of food correspond to the fats of animals. They are either oxidized to produce heat and mechanical energy, or are stored up in the system for future use. They are the most valuable class of substances for producing heat and energy. For these purposes they are worth about twice as much as the same amount of albuminoids. As they do not contain nitrogen, they cannot be used in forming the tissues of the body.

4. Carbo-hydrates. - The carbo-hydrates of food comprise such substances as starch, sugar, cellulose, etc. They are composed of carbon, hydrogen, and oxygen. The term hydrates is applied to them from the Greek word hudor, meaning water, because their hydrogen and 
oxygen when separated from the carbon would form water.

They are either oxidized in the body to produce leat and energy, or are converted into fat. 'They are the least valuable of the digestible parts of food. Starch is an important part of these substances, and about two and one half parts of starch are required to produce the same effect as one part of fat.

5. Fiber. - Most kinds of food contain more or less crude woody fiber, which is mostly indigestible and hence has little value as food.

6. Ash. - The mineral substances in food, or those which would remain as ashes after burning, are also neeled by the animal in about the same proportion as they exist in the average of the different varieties of food. When animals are confined to one particular kind of food, some of these substances may be deficient. Although the amount required is small, they cannot be dispensed with. Animals fed exclusively upon corn meal sometimes lose the use of their legs from the want of sufficient mineral matter to form bones.

On the page opposite is a tahle of some of the more common foods, with their average percentage composition, as determined by chemical analysis.

While the list gives the average results from a large number of separate tests, and must be approximately correct, it should be remembered that different samples differ widely in their nature.

There would be a wide difference, for instance, between the composition of early and late cut hay, or between unripe and mature corn fodder.

While these figures may not accurately represent the composition of any particular sample of food, they 
will serve well enough as a general guide for practical purposes.

Averaye Percentage Composition of Articles of Food.

\begin{tabular}{|c|c|c|c|c|c|c|c|c|c|}
\hline \multicolumn{4}{|c|}{ Kinds of Food. } & \multirow{2}{*}{$\frac{\text { Wuter. }}{11.32}$} & \multirow{2}{*}{$\begin{array}{l}\text { Ash. } \\
5.76\end{array}$} & \multirow{2}{*}{$\begin{array}{c}\begin{array}{c}\text { Albumi- } \\
\text { noids or } \\
\text { Protein. }\end{array} \\
8.51\end{array}$} & \multirow{2}{*}{$\begin{array}{l}\text { Fat. } \\
2.21\end{array}$} & \multirow{2}{*}{$\begin{array}{c}\begin{array}{c}\text { Carbo- } \\
\text { hydrates. }\end{array} \\
41.38\end{array}$} & \multirow{2}{*}{$\begin{array}{l}\text { Fiber. } \\
30.82\end{array}$} \\
\hline Averige hay . & - & & . & & & & & & \\
\hline Clover hay. & . & . & . & 12.56 & 6.10 & 12.61 & 2.48 & 39.62 & 26.63 \\
\hline 'limothy liay. & • & . & . & 11.07 & 4.06 & 6.02 & 2.16 & 45.80 & 30.89 \\
\hline Oat straw . & • & . & . & 9.62 & 5.20 & 3.51 & 2.21 & 36.09 & 43.37 \\
\hline Wheat straw & • & . & - & 6.50 & 6.96 & 4.98 & 1.49 & 41.99 & 38.08 \\
\hline Rice straw . & • & - & . & 3.66 & 10.71 & 4.68 & 1.74 & 50.90 & 28.31 \\
\hline Corn fodder . & . & . & & 3205 & 4.32 & 4.29 & 1.24 & 35.96 & 22.14 \\
\hline Fodder corn ( $\mathrm{g}$ & rree & en & & 80.98 & 1.13 & 1.62 & 0.41 & 10.62 & 5.23 \\
\hline Ensilage (Nortl & her & $n$ & corns) & 70.55 & 1.05 & 2.65 & 0.90 & 18.84 & 6.00 \\
\hline Ensilage (West & ter & 11 & ol'n) & 80.47 & 1.35 & 1.51 & 0.70 & 10.21 & 5.77 \\
\hline Cow-pea vines & (dr & ried & & 11.05 & 8.41 & 15.68 & 2.87 & 42.17 & 19.82 \\
\hline Indian corn. & . & - & - & 10.10 & 1.55 & 10.34 & 5.13 & 70.59 & 2.29 \\
\hline Oats... & . & . & . & 10.94 & 2.97 & 11.38 & 4.81 & 60.05 & 9.85 \\
\hline Barley . . & & & . & $10.9 \cdot 2$ & 2.38 & 1239 & 1.86 & 69.88 & 2.57 \\
\hline Wheat . . & & . & . & 10.54 & 0.86 & 11.80 & 2.11 & 72.89 & 1.80 \\
\hline Rice . . . & & . & . & 14.80 & 0.30 & 7.50 & 0.50 & 76.00 & 0.90 \\
\hline Buckwheat. . & & & . & 12.60 & 2.00 & 10.00 & 2.20 & 64.50 & 8.70 \\
\hline Peas . . & & & 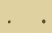 & 14.30 & 2.40 & 2240 & 2.00 & 52.50 & 6.40 \\
\hline Sorghum (grai & in) & & 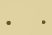 & 12.52 & 1.80 & 8.88 & 3.65 & 71.27 & 1.88 \\
\hline Wheat bran & . & & . & 12.42 & 5.68 & 15.03 & 3.74 & 54.17 & 8.96 \\
\hline Wheat middlin & & & . & 12.00 & 3.18 & 14.83 & 3.89 & 61.55 & 4.55 \\
\hline Cotton-seed me & eal & $\rightarrow$ & . & 8.33 & 7.25 & 42.06 & 19.24 & 23.43 & 5.69 \\
\hline -I inseerl meal (o & old & pr & oces & 9.20 & 5.87 & 31.58 & 7.78 & $36: 34$ & 9.28 \\
\hline Gluten meal. & . & & . & 9.15 & 0.78 & 29.88 & b.11 & 52.62 & 1.46 \\
\hline Brewers' grains & is $(i$ & dric & ed) & 8.19 & 3.58 & 19.89 & 5.56 & 51.75 & 11.03 \\
\hline Apples . & & . & . & 8.3 .1 & 0.4 & 0.4 & & 11.8 & 4.3 \\
\hline Pumpkins . & • & * & . & 89.1 & 1.0 & 0.6 & 0.1 & 6.5 & 2.7 \\
\hline Potatoes. & - & . & . & 75.0 & 0.9 & 21 & 0.2 & 20.7 & 1.1 \\
\hline Turnips . . & - & . & . & 92.0 & 0.7 & 1.1 & 0.1 & 5.3 & 0.8 \\
\hline Beets (sugar). & - & . & . & 87.0 & 0.9 & 2.0 & 0.1 & 9.2 & 0.8 \\
\hline Milk . & 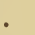 & $\cdot$ & $\theta^{\circ}$ & 87.5 & 0.7 & 3.2 & 3.6 & 5.0 & . \\
\hline s'kimmed milk & & r & ${ }^{\circ}$ & 90.0 & 0.8 & 3.5 & 0.7 & 50 & . . \\
\hline Buttermilk. & . & . & • & 90.1 & 0.5 & 3.0 & 1.0 & 5.4 & . $\cdot$ \\
\hline Whey . . & . & • & . . & 92.6 & 0.7 & 1.0 & 0.6 & 5.1 & \\
\hline
\end{tabular}

The Value of Foods. - The ralue of any food is determined, not by the substances which it contains, but by. 
the amount of these substances that can be digested and hecome useful to the animal.

There are but few artieles of food of which all the albuminoids, fats, and carbo-hydrates can be thus digested. The indigestible part is of no value for food.

The table on the opposite page gives the percentage of rigestible albuminoids, fats, and carbo-hydrates contained in the different articles of food, and the value of one hundred pounds of each varicty.

In reckoning these values, the digestible albuminoids and fats are, according to the usual eustom, regarded as worth $4 \frac{1}{3}$. cents per pound, and the digestible earbohydrates as worth $\frac{9}{10}$ of a eent per pound.

The results are, of course, only relative, and will vary aceording to the market ralue of the standard articles of food in any locality. If arerage hay is worth sixtyfour cents per hundred pounds, or \$12.80 per ton, then the other articles will be worth the sums given in the table as compared with hay.

If in any loeality, or any year, the market value of hay, corn, oats, or other articles commonly used, is greater or less, upon the average, than the table indieates, then the figures for all the articles mentioned must be increased or diminished accordingly.

The table affords a general guide for selecting and purchasing foods, but it must not be depended upon for great exactness. No article of food can, in reality, have an absolute value of its own. The true value of any article as food depends upon its combination with other foods, the nature of the animal to which it is fed, and the purpose to be accomplished. In order to make an intelligent selection, it is necessary to understand what particular kinds of food are needed in the given case. 
Percentage of Digestible Substances and Value of 100 Pounds of the Food.

\begin{tabular}{|c|c|c|c|c|c|c|c|}
\hline \multicolumn{4}{|c|}{ Kinds of Food. } & \multirow{2}{*}{$\begin{array}{c}\begin{array}{c}\text { Albuminoids } \\
\text { or } \\
\text { Protein. }\end{array} \\
5.40\end{array}$} & \multirow{2}{*}{$\begin{array}{l}\text { Fat. } \\
1.00\end{array}$} & \multirow{2}{*}{$\frac{\begin{array}{c}\text { Carbo- } \\
\text { hydrates, in- } \\
\text { cluding Fiber. }\end{array}}{41.00}$} & \multirow{2}{*}{$\frac{\begin{array}{c}\text { Value of } \\
100 \text { Pounds. }\end{array}}{\$ 0.64}$} \\
\hline Average hay & . & . & - & & & & \\
\hline Clover hay . & • & . & . . & 7.82 & 1.49 & 40.25 & 0.77 \\
\hline 'Timothy hay & . & . & . . & 4.67 & 1.03 & 41.25 & 0.62 \\
\hline Oat straw. & . & . & - & 1.44 & 0.66 & 42.62 & 0.47 \\
\hline Wheat straw & . & . & . & 0.85 & 0.54 & 37.70 & 0.39 \\
\hline Rice straw . & & & . & 1.92 & 0.52 & 40.40 & 0.46 \\
\hline Corn forlder . & . & & 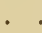 & 3.00 & 0.93 & 40.00 & 0.53 \\
\hline Fodder corn (gr & ree & & . & 1.19 & 0.31 & 10.87 & 0.16 \\
\hline Ensilage (WVest & tern & $\mathrm{co}$ & orn) & 1.10 & 0.53 & 10.99 & 0.17 \\
\hline Cow-pea vines & (dr & ied & & 9.56 & 1.34 & 37.02 & 0.80 \\
\hline Indian corn . & • & . & - & 8.16 & 4.36 & 65.64 & 1.13 \\
\hline Oats . . & . & 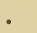 & - & 8.46 & 3.94 & 46.11 & 0.95 \\
\hline Barley . . & . & - & - & 9.64 & 1.86 & 60.77 & 1.04 \\
\hline Wheat. . & . & - & . & 9.32 & 1.79 & 66.52 & 1.05 \\
\hline Rice . . & 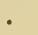 & . & • & 5.92 & 0.42 & 70.71 & 0.91 \\
\hline Buckwheat . & . & - & . & 7.70 & 1.84 & 49.21 & 0.86 \\
\hline Peas . . & - & . & - & 20.20 & 1.70 & 54.40 & 1.44 \\
\hline Sorghum (grain & & . & . & 6.81 & 2.99 & 53.06 & 0.90 \\
\hline Wheat bran & . & . & . & 11.72 & 2.58 & 44.66 & 1.02 \\
\hline Wheat midlding & gs & . & . & 11.60 & 2.68 & 48.87 & 1.06 \\
\hline Cotton-seed me & al & . & . & 35.75 & 11.65 & 22.25 & 2.25 \\
\hline Linseed meal (o & ld 1 & pro & ces: & 25.85 & 7.08 & 26.52 & 1.66 \\
\hline Gluten meal . & . & . & . & 23.30 & 3.85 & 50.92 & 1.68 \\
\hline Brewers' grains & $(d s$ & ried & 1) & 14.52 & 4.77 & 37.41 & 1.20 \\
\hline Apples. . . & $\bullet$ & & 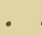 & 0.3 & & 12.9 & 0.18 \\
\hline Pumpkins . & . & . & . & 0.4 & 0.1 & 7.1 & 0.08 \\
\hline Potatoes . . & . & . & - & 2.1 & 0.2 & 21.8 & 0.30 \\
\hline Turnips . . & . & . & - & 1.1 & 0.1 & 6.1 & 0.11 \\
\hline Milk • • . & " & . & 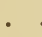 & 3.2 & 3.6 & 5.0 & 0.34 \\
\hline Skimmed milk & . & • & - & 3.5 & 0.7 & 5.0 & 0.23 \\
\hline Buttermilk . & . & . & . & 3.0 & 1.0 & 5.4 & 0.22 \\
\hline Whey . • & . & . & . & 1.0 & 0.6 & 5.1 & 0.11 \\
\hline
\end{tabular}

Economy in Feeding. - There are two general precepts to be observed in connection with the economical feeding of stock:-

1. Feed animals as much as they can digest without injuring their health.

The profits of feeding stock come either from the 
work which they are enabled to perform, or from growth and animal products.

It requires a certain amount of food to maintain life. If just enough is fed to keep up the vital processes of the animal and prevent shrinkage of weight, it is evident that the cost of keeping is absolutely lost to the owner, unless, on account of the variation of market prices, the animal is to be worth more at some future time.

Whatever the animal consumes, digests, and assimilates, in excess of what is required to maintain life, will be a somrce of profit, as it will yield either force for work or animal products.

Generally speaking, the more food the animal eats and digests, the greater is the profit, as the ratio of gain to the foor consumed is greater. If it should require ten pounds of food per day to maintain the life of a certain animal, and three pounds of food in addition to produce a gain of one pound of flesh, then a ration of thirtecn pounds of food would produce a daily gain of one pound of flesh. $\Lambda$ ration of sixteen pounds would produce a gain of two pounds of flesh. In the former case the ratio of gain to food is one to thirteen, and in the latter case one to eight.

This principle is limited, howerer, by the digestive power of the animal. Any excess of food above the quantity that can. be properly digested may lead to disease and loss.

2. Feed a balanced ration.

Animals should be supplied with food, the composition of which is in proportion to their needs.

As the fats and carbo-hydrates of food are of a similar nature, and serve a similar purpose, it is customary, for 
the sake of convenience, to class them together. The fats are reckoned as worth 2.44 times as much as carbohydrates; hence, in combining the two, we multiply the number of pounds of fat by 2.44 , and add the number of pounds of carbo-hydrates, giving what may be called the equivalent of carbo-hydrates contained in the food.

The question of food for any animal, and for any purpose, becomes a question of the proper proportion of albuminoids and carbo-hydrates. The animal needs, for its special requirements, a certain definite proportion of each.

If we furnish a food eontaining too large a proportion of either albuminoids or carbo-hydrates, the excess of either above what is required to make up the proper proportion for the given purpose may be in part wasted, and may become an injury rather than a benefit to the animal. The animal must consume a larger quantity of the food than would otherwise be necessary, in order to obtain the required quantity of that substance in which the food is most deficient.

The Nutritive Ratio. - The nutritive ratio of a food is simply the ratio, or relation, between the quantity of digestible albuminoids, and of digestible carbo-hydrates or their equivalents, which it eontains. Average hay, for instance, contains about eight times as much of digestible carbo-hydrates as of albuminoids, and hence the nutritive ratio of the food is as 1 to 8 .

The following tables give the nutritive ratio of the different kinds of food, and the number of pounds of digestible albuminoids and carbo-hydrates which should properly be contained in the daily ration of animals under different circumstances, for one thousand pounds of live weight. The quantity for animals weighing more or 
less than one thousand pounds is found by increasing or diminishing the given amounts proportionately. Thus, a horse weighing twelve hundred pounds should receive one fifth more than the amounts given for one thousand pounds.

Albuminoids, Equivalent of Carbo-hydrates, and Nutritive Ratio.

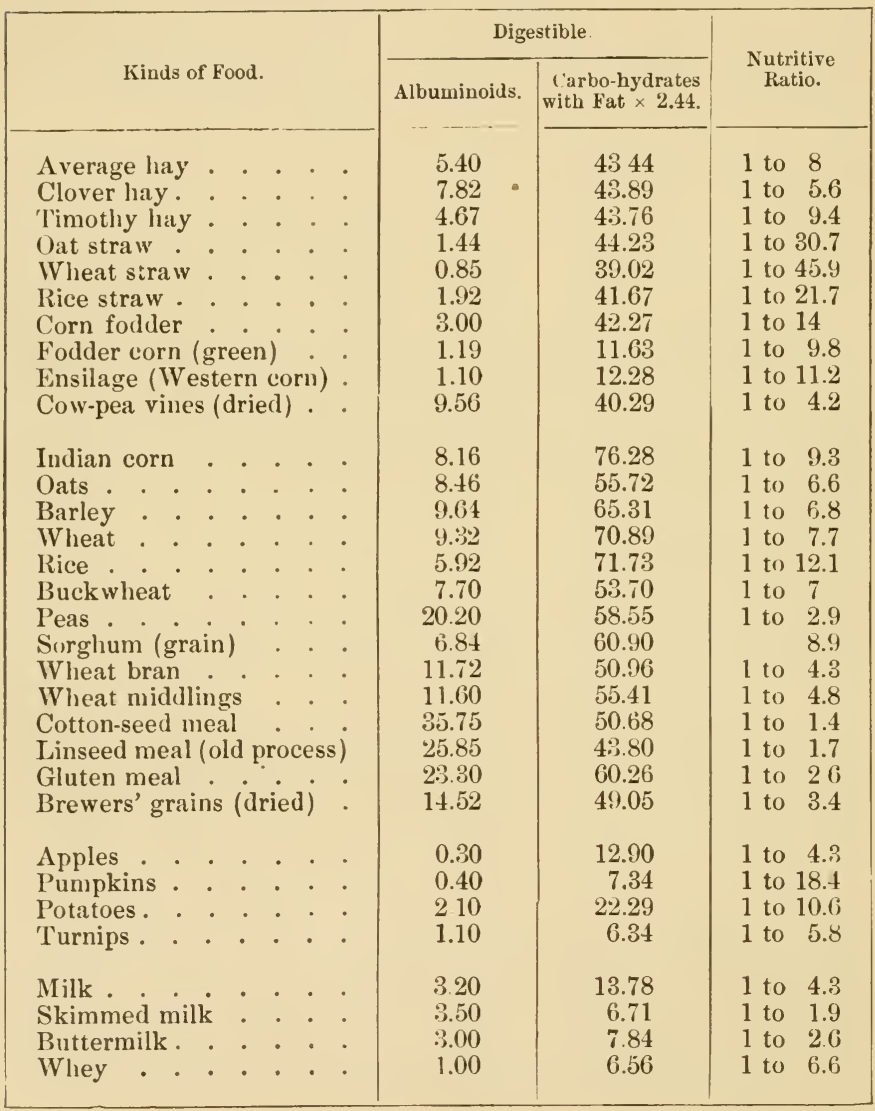


Food required for different Animals, for 1,000 Pounds, live weight.

\begin{tabular}{|c|c|c|c|}
\hline $\begin{array}{l}\text { Animals in different } \\
\text { Circumstances. }\end{array}$ & $\begin{array}{c}\text { Digestible } \\
\text { Albuminoids. }\end{array}$ & $\begin{array}{c}\text { Digestible } \\
\text { Carbo-lydrates } \\
\text { with equivalent } \\
\text { of Fat. }\end{array}$ & $\begin{array}{c}\text { Nutritive } \\
\text { Ratio. }\end{array}$ \\
\hline $\begin{array}{l}\text { Horses in light work. } \\
\text { Horses in heavy work } \\
\text { Oxen at rest. } \\
\text { Oxen at work } . \\
\text { Oxen fattening: } \\
\text { Cows in milk } . \\
\text { Growing cattle: } \\
\text { Fattening swine } \\
\text { Fattening sheep }\end{array}$ & $\begin{array}{l}\text { lbs. } \\
1.8 \\
2.8 \\
0.7 \\
2.4 \\
3.0 \\
2.5 \\
1.6 \\
4.0 \\
3.5\end{array}$ & $\begin{array}{r}\text { Ibs. } \\
12.6 \\
15.5 \\
8.3 \\
14.4 \\
16.5 \\
13.5 \\
12.7 \\
24.4 \\
15.6\end{array}$ & 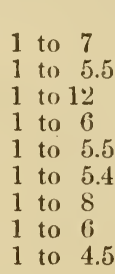 \\
\hline
\end{tabular}

Rations. - To make up a balanced ration, we have simply to reckon the quantity of digestible albuminoids and carbo-hydrates contained in a certain amount of the different articles of food in question, varying the quantity of each article to meet the wants of the case.

If, in making up a trial combination, we find we have too large a proportion of albuminoids, then we should increase the proportional part of those articles in the ration which are more largely composed of carbohydrates, and vice versa.

Strict accuracy is not necessary. If the result is within a fraction of what is theoretically required, it is near enough for practical purposes.

The question whether the ration is properly balanced should always be considered in making a combination of foods. It is not always necessary, however, to follow the theory strictly. Some allowance may be made for market prices.

If either the nitrogenous foods or the carbonaceous foods are relatively much cheaper in the markets, a larger proportion of the cheaper class may be admitted 
into the ration for the sake of economy. The difference in cost may be sufficient to overeome the loss caused by feeding an incorrect ration.

The following sample rations will illustrate the method :- -

Ration for a Cow, weighing 1,000 Pounds, giving Milk.

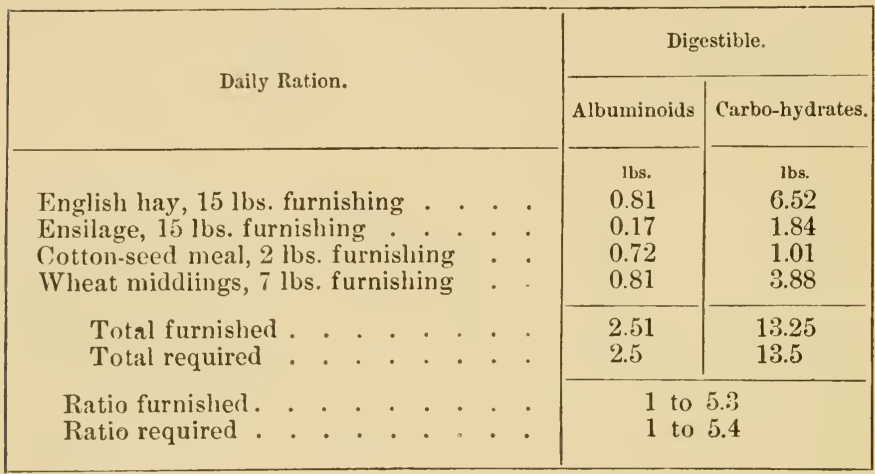

Ration for a IIorse, weighing 1,200 Pounds, at light Work.

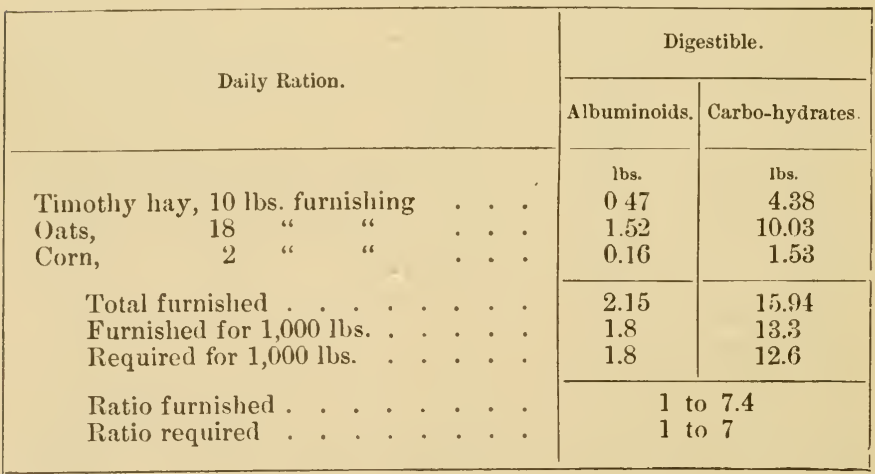


Ration for a Fattening Hog, weighing 200 Pounds.

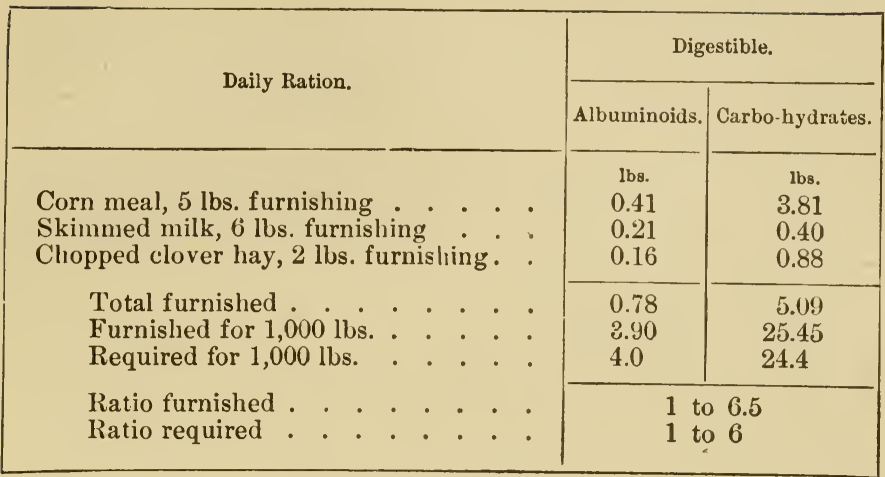

Variety of Food. - In order that animals may be always kept in a healthful and thriving condition, they should be supplied with a variety of food. Although a single kind of food, or some particular combination of two or more kinds, may contain the albuminoids and carbo-hydrates in proper proportion, it is unwise to confine an animal to one special diet for a long time. The appetite and digestion are improved by furnishing a greater variety.

In computing a ration, we do not take into account the mineral substances contained in it. Although the quantities of these required are small, they are essential to perfect health. A particular ration may not contain sufficient quantities of all of these, and after a time the lack may cause injurious results. By furnishing a greater variety, or changing the ration frequently, we may keep the various wants of the animal more perfectly supplied.

The Manurial Value of Food. - In selecting food for animals upon the farm, the cost of the food and its value for supporting animals are not the only points to be

Wins. AGR. -9 
considered. We should also take into account its manurial value, or value as a fertilizer.

Any kind of food has a certain value as a fertilizer, and may be used directly for that purpose if it is not too expensive.

Cotton-seed is extensively used in this way in the South.

The manurial value, as in ordinary fertilizers, is determined by the amount of nitrogen, phosphoric acid, and potash contained.

The following table shows the number of pounds of the three substances contained in one ton of each variety of food, and the manurial value of a ton. This value is, of course, variable, depending upon the market value of the three substances for the locality and the season.

Manurial Substances in a Ton of Food, and their Value.

\begin{tabular}{|c|c|c|c|c|c|c|c|c|c|}
\hline \multicolumn{6}{|c|}{ Kinds of Food. } & Nitrogen. & $\begin{array}{l}\text { Phosphoric } \\
\text { Acid. }\end{array}$ & Potash. & $\begin{array}{c}\text { Value in } \\
\text { a Ton. }\end{array}$ \\
\hline Cotton-seed $\mathrm{m}$ & ieal & & . & & & $\begin{array}{c}\text { lbs. } \\
124.0\end{array}$ & $\begin{array}{c}\text { lbs. } \\
59.0\end{array}$ & $\begin{array}{c}\text { lbs. } \\
42.0\end{array}$ & $\$ 26.66$ \\
\hline Linseed meal & . & • & . & . & . & 90.0 & 39.2 & 29.4 & 19.01 \\
\hline Wheat bran & . & . & . & . & . & 44.0 & 64.6 & 29.6 & 13.69 \\
\hline Beans . & . & 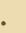 & & 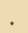 & . & 82.0 & 23.2 & 24.0 & 16.18 \\
\hline Peas. . & . & • & • & 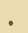 & . & 72.0 & 17.6 & 19.6 & 13.91 \\
\hline Oats.. & . & . & . & . & . & 41.2 & 12.4 & 9.0 & 8.03 \\
\hline Barley . & . & • & . & 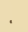 & . & 34.0 & 14.6 & 9.8 & 7.10 \\
\hline Wheat . & . & . & 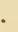 & . & . & 37.6 & 16.0 & 10.8 & 7.84 \\
\hline Indian corn & . & . & . & 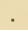 & . & 33.2 & 12.2 & 7.2 & 6.65 \\
\hline Buckwheat. & . & 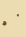 & . & . & . & 28.8 & 8.8 & 4.2 & 5.52 \\
\hline Average hay & . & • & & 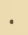 & 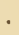 & 31.0 & 7.6 & 33.6 & 7.25 \\
\hline Timothy hay & . & • & - & . & . & 31.0 & 13.6 & 34.4 & 7.77 \\
\hline Dead ripe hay & & • & - & . & ${ }^{*}$ & 24.0 & 5.8 & 10.0 & 4.80 \\
\hline Clover hay . & . & & & . & ${ }^{\circ}$ & 39.4 & 11.2 & 39.0 & 9.15 \\
\hline Bean straw . & . & & & . & . & 20.0 & 8.2 & 51.8 & 6.45 \\
\hline Oat straw & . & & & 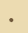 & - & 10.0 & 5.0 & 20.8 & 3.04 \\
\hline Wheat straw & . & • & & . & - & 9.6 & 5.2 & 11.6 & 2.53 \\
\hline Corn fodder & - & • & • & . & . & 16.0 & 15.2 & 66.4 & 7.10 \\
\hline Potatoes. & $\cdot$ & • & & $\cdot$ & - & 6.8 & 3.6 & 11.2 & 1.94 \\
\hline Turnips . . & . & ${ }^{\circ}$ & • & . & . & 3.6 & 1.2 & 5.8 & 0.96 \\
\hline
\end{tabular}


Differences in the quality of the food will also cause variation, as in reckoning the feeding value.

The figures given are obtained by reckoning the nitrogen at sixteen cents per pound, the phosphoric acid at eight cents, and the potash at five cents.

The values of these substances are reckoned the same, in whatever food they are found. There is, however, some difference in point of fact, since in some articles of food they are in a more available condition than in others, and can be made more immediately serviceable as fertilizers.

The Value of Manure from Food. - To determine the real value of the manure from different kinds of food, a deduction must be made from the total manurial value for certain losses that occur.

1. We must deduct the amount which the animal removes from the food in digestion. This may be reckoned upon the average at fifteen per cent.

2. The three substances are not $g$ nerally so valuable in stable manure as in commercial fertilizers, because they are not so largely available at first, and are subject to greater losses before they can be used for plant food. Probably twenty per cent. should be deducted on this account.

It must also be remembered that, in addition to these deductions, there is always more or less loss from fermentation and drainage; but this is so variable that it cannot be definitely stated. It can only be estimated in individual cases, after a knowledge of the facts involved.

All articles of food fed to stock upon the farm have thus a double value: a feeding value, determined by the digestible albuminoids and carbo-hydrates; and a manurial value, determined by the amount of nitrogen, phosphoric acid, and potash in the manure. 
The following table gives these two values separately and combined: -

Double Value of Food, per Ton.

\begin{tabular}{|c|c|c|c|c|c|c|c|c|c|c|}
\hline \multicolumn{8}{|c|}{ Kinds of Food. } & \multirow{2}{*}{$\begin{array}{c}\text { Value for } \\
\text { Feeding. }\end{array}$} & \multirow{2}{*}{$\begin{array}{c}\begin{array}{c}\text { Value of } \\
\text { Manure. }\end{array} \\
\$ 18.13\end{array}$} & \multirow{2}{*}{$\begin{array}{c}\begin{array}{c}\text { Double } \\
\text { Value. }\end{array} \\
\$ 63.13\end{array}$} \\
\hline Cotton-seed I & neal & . & . & . & . & . & . & & & \\
\hline Linseed meal & . & . & . & . & 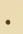 & . & . & 33.20 & 12.93 & 46.13 \\
\hline Wheat bran & - . & . & . & . & . & 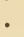 & . & 20.40 & 9.31 & 29.71 \\
\hline l'eas . . & • . & . & - & . & - & . & . & 28.80 & 9.46 & 38.26 \\
\hline Oats . & . & . & - & . & - & 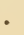 & - & 19.00 & 5.46 & 24.46 \\
\hline Barley. . & . . & . & . & . & - & . & . & 20.80 & 4.83 & 25.63 \\
\hline Indian corn & . . & . & . & . & - & . & . & 23.00 & 4.52 & 27.52 \\
\hline Buckwheat & $\cdot$ & . & . & . & • & . & . & 17.20 & 3.75 & 20.95 \\
\hline Average hay & . & . & . & . & - & . & . & 12.80 & 4.93 & 17.73 \\
\hline Timothy hay & . & . & . & . & • & . & - & 12.40 & 5.28 & 17.68 \\
\hline Clover hay & •. & 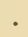 & . & . & • & • & . & 15.40 & 6.22 & 21.62 \\
\hline Oat straw & . . & . & . & . & 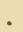 & - & . & 9.40 & 2.07 & 11.47 \\
\hline Corn fodder & . . & . & . & . & • & . & . & 10.60 & 4.83 & 15.43 \\
\hline Potatoes. & . . & . & . & . & . & . & . & 6.00 & 1.32 & 7.32 \\
\hline Turnips . & · . & - & - & . & . & • & - & 2.20 & 0.65 & 2.85 \\
\hline
\end{tabular}

The True Cost of Food. - In estimating the real expense involved in the food furnished to stock, the value of the food as a source of fertility to the farm should be deducted from its cost or market value. The results will vary widely with the variation in market prices.

The following table will illustrate this point:-

Cost of Food in Excess of Value of Manure.

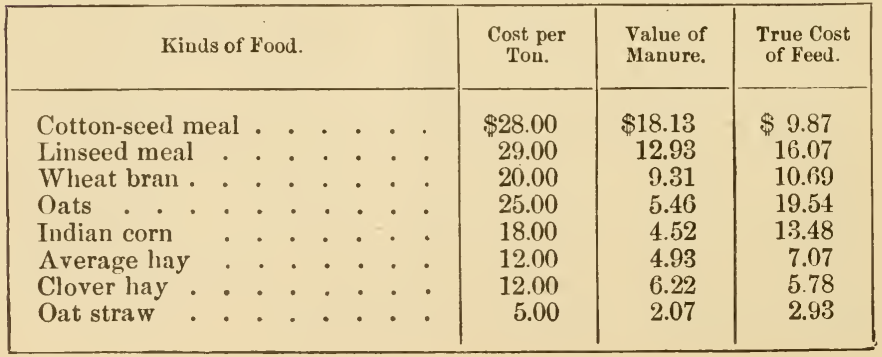


Digestion. - The purpose of digestion is to dissolve food and change its nature, preparing it to enter the blood, and to sustain the life and growth of the body. As the food of plants is slowly prepared to enter the sap by chemical processes in the soil, so the food of animals is prepared in their digestive organs to enter the blood by similar processes, although much more rapidly.

The Mouth. - The process of digestion begins in the mouth. The food is not only ground into a fine condition by mastication, and better prepared for chemical action, but is also mixed with the saliva.

This is a liquid consisting mostly of water, but containing substances suited to produce some chemical action . upon the food. It is secreted,

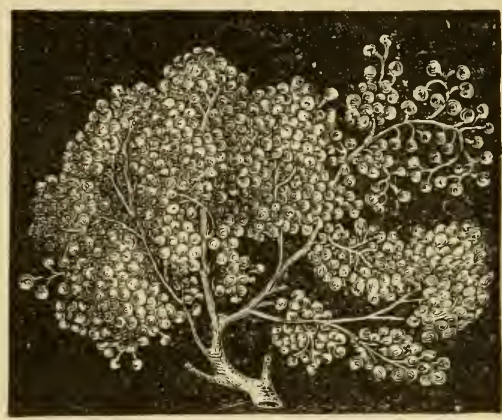

One of the Salivary Glands. or separated from the blood, by a number of organs called glands, situated in different parts of the mouth. $\Lambda \mathrm{s}$ the blood passes through these glands, the saliva is taken from it and poured into the mouth as it is needed to moisten the food. It is formed quite rapidly while the animal is eating. It is said to be produced in the mouth of a horse or an ox, at such times, at the rate of four quarts per hour.

The Stomach and Intestines. - After the food which has been moistened by the saliva passes into the stomach, it is mixed with other liquids, which are withdrawn from the blood and poured into the stomach. 
The mixture is kept constantly in motion by the action of the museular walls of the stomach, until the food becomes softened or dissolved. It then passes into the intestines.

The intestines consist of a long tube folded together so as to oceupy a small space. The portion nearest the stomach is the smaller in diameter, and is ealled the small intestine. The remainder is larger, and is called the large intestine.

The intestines of an ox have an average length of about 150 feet, and those of a sheep or a pig of about 90 feet.

In the intestines, the food is still further mixed with chemical liquids, and converted into different forms. As it is thus rendered suitable for nourishment, either in the stomach or the intestines, it is alssorbed by the membranous lining, and passes through minute tubes called the lacteals into the blood-vessels, to be carried by the circulation of the blood to all points of the system where it is needed.

The Stomachs of Ruminants. - Such animals as the cow, the sheep, and the goat are called ruminants, because they ruminate, or "chew the cud."

As these anirnals naturally live upon food containing large quantities of hard, woody fiber, their digestive system is different from that of other animals whose food is more concentrated and more easily digested. The chief point of difference is, that, in addition to the regnlar stomach of other animals, the ruminants have three preliminary stomachs in which coarse food is prepared to enter the stomach proper.

The first stomach, or paunch $(p)$, into which coarse food first passes as it is swallowed, is very large. It is 
several times as large as the other three stomachs combined. In a large ox it contains about sixty gallons, and occupies nearly the whole length of the left side of the abdomen, or internal cavity of the body back of the lungs.

The second stomach $(b)$ is in reality only a part of the first, as there is a free passage connecting the two. The membrane lining its interior is curiously formed into an arrangement of cells like honeycomb.

The third stomach $(f)$ is provided with a great number of hard, hooked projections, which hold the food until it has been rendered fine enough to pass through into the fourth stomach.

The fourth stomach (c) is the true digesting stomach,

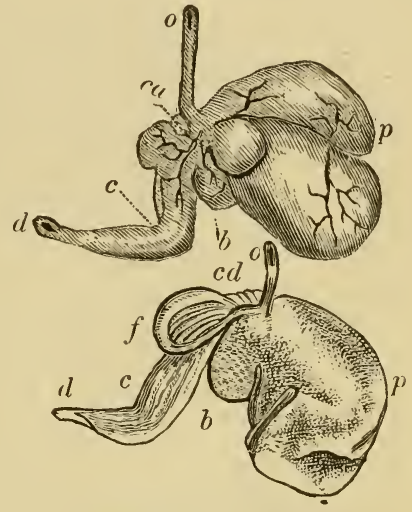

Stomach of a Ruminant. corresponding to the stomach of the horse or the pig.

The gullet, or tube (o) through which the food passes from the mouth to the stomach in swallowing, is, in ruminanits, provided at its lower end with a peculiar canal, by which the food as it is swallowed may pass either into the first two stomachs on the one hand, or on the other hand into the third stomach. All food of a coarse, fibrous nature generally passes into the first two stomachs, but that which is fine and soft, requiring no further preparation, may pass at once into the third and fourth stomachs.

Rumination. - Rumination, or the chewing of the cud, is a very interesting process. As the first stomach is 
well filled, partly with solid food, and partly with liquids, a small quantity of the food near the lower entrance to the gullet is floated upward by the liquid into the mouth by a slight contraction of the stomach. The animal grasps the solid part in its mouth, swallows the liquid, and proceeds to masticate the food, reducing it to a finer and softer condition. As this is again swallowed, such parts as are sufficiently fine and soft pass into the third and fourth stomachs, and the remainder passes into the paunch to be returned to the mouth a second time.

In order that rumination may go on, it is necessary that the paunch be quite well filled, and that there shall be enough liquid to separate and float the solid food frecly.

Ruminants, when supplied with sufficient water, are able to live without food for a long time, as they are able to make use of the large store of food in the paunch, which is gradually reduced to a fine condition, and passed along to the fourth stomach and intestine $(d)$ for digestion.

The Blood. - The blood, in its circulation, is the carrying system of the animal body. The tubes through which it passes become so small by subdividing that the blood is practically brought in contact with, and noistens, all parts of the system.

As the substances formed from the food pass from the stomach and intestines into the blood, they are immediately carried forward with the current and distributed through the system.

The blood is foreed along by the pumping action of the heart. On leaving the heart, it passes into large tubes called arteries $(a, a, a)$. These soon begin to subdivide into smaller arteries, and these again into still 
smaller, until they become a multitude of minute tubes, called capillaries, passing through every part of the body. At length these again gradually unite in veins $(v, v, v)$, through which the blood is returned to the heart. It is

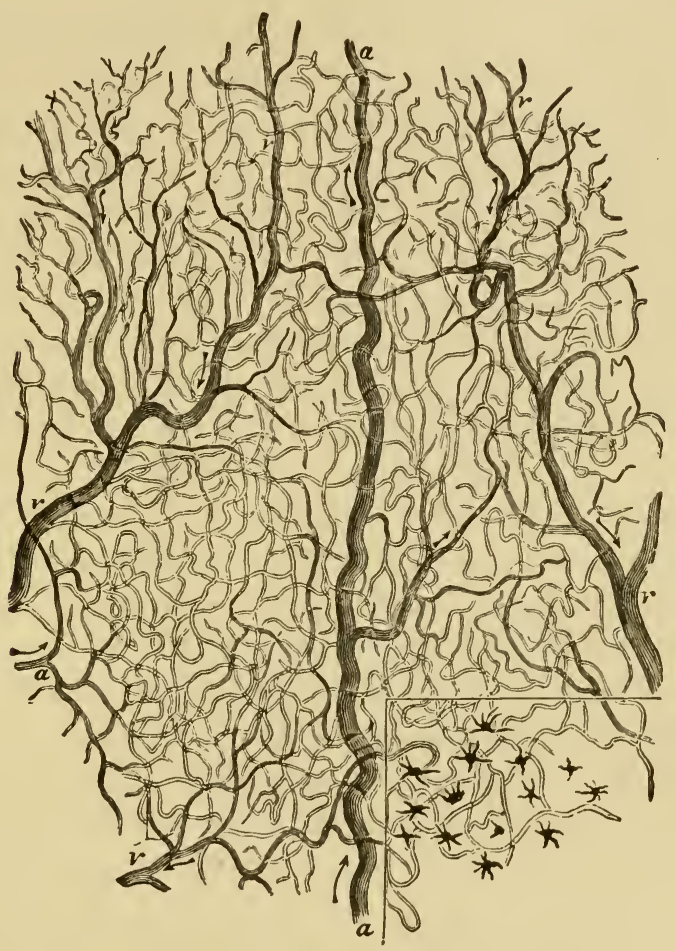

Arteries, Capillaries, and Veins.

then sent out through another set of tubes, which conduct it through the lungs, where it is brought in contact with the air taken into the lungs in breathing, becomes purified, returns to the heart, and starts again on its original course. 
The blood consists of a colorless fluid, containing an immense number of little flattened disks, called corpuscles. Most of these are red, and give the blood its color.

The purpose of these disks seems to be to absorb oxygen from the air in the lungs, and carry it through the body, until it is needed to oxidize the elements of food in the blood, or the tissues of the body.

As the disks return from the lungs they have a bright red color, which is supposed to be due to the presence of oxygen that they have absorbed. On returning to the heart, after passing through the body, they assume a purple shade.

The elements of food in the blood are burned, or oxidized, by uniting with the oxygen of the corpuscles, producing animal heat or force. Particles of the body are also oxidized and replaced by new particles.

Excretion. - The blood not only brings together food and oxygen to produce this oxidation, but carries away the waste products.

When the carbo-hydrates and fats of food are burned in the system, the result is carbonic acid and water. When nitrogenous substances are burned, not only carbonic acid and water are produced, but also certain salts, the most important of which is called urea.

Carbonic acid escapes from the blond partly through the skin, but mostly through the lungs; urea and other salts, through the kidneys; and water, through the skin, lungs, and kidncys.

The Nature of Animals. - An animal upon the farm may be regarded as a kind of machine, capable of performing a certain amount of work.

This work consists in converting food into flesh, milk, wool, etc., or into mechanical force, for the service of 
man. The better the animal, the better the work accomplished.

A locomotive engine supplied with water and fuel is able to draw a train of cars. Another engine, more perfectly constructed, but supplied with the same amount of fuel, might produce force enough to draw a train much heavier. The same is true in feeding animals. Economy and profit in stock husbandry require that poor animals shall be discarded, and that the crops of the farm shall be fed only to such as are able to render good returns.

Health. - The health or thrift of animals is a matter that should receive careful attention. $\Lambda$ s good health promotes comfort, we should care for the health of our animals on the ground of humane treatment. But the question has a practical bearing also upon the profits of feeding. The more vigorous the health, the greater the returns for the food. One animal may thrive and increase in weight upon food with which another, in less vigorous health, would grow poor.

One cow with the same food as another may produce much more milk, on account of being in better health, and possessing greater power to digest food.

Breeds. - By the law of heredity, animals tend to transmit to their young their own qualities and peculiarities. It is therefore important, in selecting young animals to be raised, to make choice of those descended from animals known to possess desirable qualities.

The common pure breeds are simply families of animals whose ancestors were selected for their excellence in certain directions.

The advantage of thoroughbred animals consists in the fact that they possess certain particular qualities in 
a higher degree than others. An opportunity is offered to choose such breeds as are best adapted to the purpose required. One breed of cows may have a natural tendency to take on fat, or produce beef, while another will tend to produce milk. One breed of horses is adapted for speed, and another to draw heavy loads. Some breeds of pigs will fatten rapidly while young, and others not until they become older and larger.

Eeonomy requires that we select such breeds of the different animals as possess in the most marked degree the peculiarities required for the special purpose to which they are devoted.

Care. - The general eare and treatment of animals is as much a source of profit as a matter of sentiment. 'To shelter stock in warm stables in winter prevents a loss of animal heat. The amount of food required to keep the body warm depends largely upon the question how fast the body is cooled from without. When stock is kept in tightly built stables, the warmth from the body is not removed by drafts, but remains to elevate the temperature of the air in the stable, and so prevents a rapid cooling of the animal.

Food that is not needed to produce animal heat is free to serve other purposes. The extra food required to keep up the temperature of a herd of animals in a cold apartment would, in a single winter, pay the cost of rendering the apartment tight and warm.

Kindness. - There is profit as well as sentiment in "kindness to animals." The digestive and nutritive processes are largely influenced by the condition of the nervous system. Animals which are disposed to fight or annoy each other will not thrive so well as if kept apart, or in more congenial company. A horse with an irrita- 
ble driver will grow poor, while with kinder treatment and the same feed and work he might maintain a good condition.

It is true of the lower animals, as of man, that "it is worry, and not work, that kills." Many a farmer reduces the income from his stock by abusive treatment.

Conclusion. - A knowledge of the principles of agriculture is simply a knowledge of some of the laws of nature, which have a divine origin.

To understand these principles, and to observe them in practice, is simply to place ourselves in conformity with natural laws which are based upon the strictest propriety and economy.

Success and failure in agriculture turn upon this point. The heedless and indifferent can never receive so large a share of the bounties of our mother Earth as those who are on the alert to catch the lessons which nature teaches, and to profit by them. "If ye be willing and obedient, ye shall eat the good of the land."

\section{QUESTIONS.}

What are the two forms of life? What is the chief purpose of vegetation? Ars the bodies of animals composed of the same materials as plants? What is the difference between herbivorous and carnivorous animals? What is the nature of the process of animal life?

Name the different classes of substances in the body of an animal. What proportion of the body is water? What is the use of water in the body? What parts of the body are composed of nitrogenous substances? Where is fat to be found in the body? Explain the different kinds of fat. What elements are included in the "ash"?

What are the different purposes of food? What use do young animals make of food different from mature animals? Do the bodies 
of mature animals remain constantly the same? What is the source of muscular power? How is animal heat supplied by food? At what temperature must the body be kept? How is it cooled when too warm in hot weather?

Of what substances is food composed? Are any kinds of food absolutely dry? How much moisture do some succulent foods contain? What are the albuminoids of food? What parts of the body do they form? May they be used to produce heat? Is this an economical use of them? Name some kinds of food which are especially rich in albuminoids. Could an animal live entirely upon albuminoids? What are the amides? In what kinds of food are they chiefly found? How do they differ from albuminoids? What is protein? What uses are made of the fats of food? Why can they not be used for constructing the tissues of the body? Name some of the different kinds of fats. Name some articles of food which are rich in fats.

What are the carbo-hydrates? Why are they so called? What use is made of them? How valuable are they? Could an animal live entirely upon fats and carbo-hydrates? Name some kinds of food which are largely composed of carbo-hydrates. Has woody fiber any value as food?

What is meant by the "ash" of foods? Of what substances is the ash composed? Are these substances essential in the food of animals? Name some kinds of food which are especially rich in albuminoids. Name some in which the fats and carbo-hydrates preponderate.

Upon what does the value of food depend? Has the indigestible part any value? Name some kinds of food which are wholly digestible. Name some kinds of which a large part is indigestible.

What two rules should be generally followed in feeding stock? Why should animals generally be fed as much as they can digest? Is there danger in feeding too much? What is meant by a "balanced ration"? Why is a part of a ration that is not well balanced wasted?

What is the nutritive ratio of a food? How is a balanced ration made up? Name articles of foor which might be combined to form a proper ration for oxen at work. For fattening sheep. What is the advantage of furnishing a variety of food?

What is meant by the "manurial value" of food? How is this value 
determined? Is the manurial value of the same variety of food always the same? Are the manurial substances of the same value in whatever food they are found? Name articles of food which have a high manurial value. Wha is the difference between the manurial value of food, and the value of the manure from the food? What items must be deducted from the one to obtain the other? What circumstances increase and diminish this difference?

What are the two values of food? How is the true cost of food to be reckoned in farming? Name articles which cost but little according to this method of reckoning.

What is the purpose of digestion? Do plants digest their food, like animals? How does digestion begin in the mouth? What is the saliva? How fast is it formed? Explain the action of the stomach. Describe the intestines. How long are they? What becomes of the food after it is digested?

Name the animals called "ruminants." Why is their digestive system different from that of other animals? What is the ehief difference? Describe the first stomach. What is the second stomach?

What service does the third stomach perform? Which stomach corresponds to that of other animals? Into which stomach does the food first pass, when swallowed? In what way is the "cud" brought to the mouth? Into which stomach does it pass when swallowed again? What may be the difficulty with animals unable to chew the cud? Why are ruminants able to live longer without food than other animals?

What is the use of the blood? In which parts of the body is it to be found? Describe the system of tubes through which the blood passes. Why does it pass through the lungs? Of what does the blood consist? What is the purpose of the corpuscles? From what does blood derive its color? Why is the color different in different parts of the body?

What other office does the blood fill besides conveying nourisinment to the body? Name the other waste products of the body besides undigested food. Name the different methods by which they escape from the body.

How does an animal resemble a machine? Why is one animal more profitable than another for a given purpose? For what two reasons should the health of animals be cared for? 
What is the origin of different breeds of animals? What advantage is there in thoroughbred animals? What advantage is there in a variety of breeds? Why is it profitable to provide shelter for stock? For what two reasons should animals receive kind treatment? How does unkind treatment reduce the income from animals? 


\section{GLOSSARY.}

Al-bū'mi-noids . . A class of substances in foods which contain the most of the nitrogen.

Al'ka-li . . . . . A class of bases including ammonia, soda, potash, etc.

Al'ka-line .... Resembling or possessing the qualities of the alkalies.

Al-lü'vi-al . . . . Pertaining to a river. Alluvial deposits are deposits from the washing of rivers.

Am'roes . . . . . A class of substances contained in foods.

An-ti-cy'clone... The opposite of cyclone. Winds moving in the opposite direction from those of a neighboring storm, or cyclone.

Ap'a-tite . . . . A A greenish mineral composed of phosphate of lime. As-sim'i-late . . . . To convert the food into the substances of the body. Cal-ca're-ous ... Consisting of lime, or containing lime.

Ca'lyx........ The outer covering of a flower.

Cap'il-la-ries .... The smallest tubes through which the blood passes in its circulation.

Car-bo-hy'drates . A large class of substances in foods, composed of carbon, hydrogen, and oxygen.

Car-bo-na'ceous. . Containing carbon, or composed of carbon.

Car-niv'o-rous . . . Feeding upon the flesh of animals.

Cel'lu-lose .... A A substance of which the membranes of cells of plants are largely composed.

Con-glom'er-ate. . Heaped together.

Co-rol'la...... The inner covering of a flower.

Cor'pus-cles . . . Minute, disk-shaped particles, floating in the blood.

Cot-y-le'don . . . . One of the two seed leaves of a plant which first appears.

Cy'clone . . . . . A storm, the winds of which blow in a circuit.

De-com-po-si'tion. Decay, or a chemical change into other substances. 
Dis-in-te-gra'tion . Destruction, or separation into parts.

Ex-crêtion.... Throwing off useless matter from the animal system.

Glā'cier ....... An immense mass of moving ice.

Her-biv'o-rous .. Eating herbs. Living upon vegetation.

Hü'mus . . . . . A dark or brown substance, common in soils.

[n com-bus'ti-ble. Not capable of being burned.

['so-bar . . . . . A A line indicating the points where the height of the barometer is the same.

I'so-therm .... A line indicating points where the temperature is the same.

Lac'te-als . . . . . Passages through which blood is conveyed from the stomach and intestines to the blood-vessels.

Le-gū'mi-nous . . Pertaining to a class of plants, including peas, beans, clover, etc.

Ni-tri-fi-ca'tion . . A natural process by which nitrates are formed in the soil.

Ni-trog'e-nous . . Pertaining to nitrogen, or containing nitrogen.

O'le-in . . . . . . . The oily part of foods in the animal body.

Pal'mi-tin..... . One of the kinds of animal fat.

Pet'ri-fied . . . . . Converted into stone, or into a substance like stone.

Plū'mule . . . . . The first bud, or ascending part of a young plant.

Pro'te-in . . . . . Those parts of food which furnish nitrogen.

Ru'mi-nate. . . . . To chew the cud.

Ru'mi-nant .... An animal that chews the cud.

Sal'i-va-ry ..... Producing saliva.

Se-crete' . . . . . To Toparate ; as to separate fluids from the blood.

Ste'a-rin....... One of the hard kinds of fat in the animal body.

Sto'ma-ta .... Minute mouths or openings on the surface of leaves.

Tu'ber-ous . . . . Covered with or containing tubers.

U're-a ....... One of the waste substances of the system, sepa. rated from the blood by the kidneys. 


\section{N D E X.}

A.

Absorbing power of roots . . 68

Absorption, of water by plants . $\quad 62$

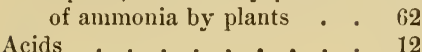

Acids, bases, and salts . . . . 12

Adhesion . . . . . . . 14

Age of the earth . . . . . 27

Agriculture, effect of . . . . 78

Air, composition of . . . . . 41

necessary for roots . . . 101

purified by plants . . . . 61

Albuminoids . . . . . 118

Alkalies . . . . . . . 13

Alum . . . . . . . . 17

Alumina . . . . . . 23

Aluminium . . . . . . 23

Alluvial soil . . . . . . 32

Amides . . . . . . . . 119

Ammonia . . . 11, 13, 18, 21

absorbed by foliage . . . 62

carbonate of . . . . . 82

formation of . . . 81,82

Ammonic chloride . . . . . 13

Animal heat . . . . 117, 140

Animals, remains of . . . . 37

breeds of . . . . 139, 140

care of . . . . . 140

composition of bodies of . . 114

health of . . . . . 138

kindness to . . . . 140

nature of . . . . . 138

young . . . . . . 116

Apatite . . . . . . . . . 85

Application of fertilizers . . $\quad 89$

Asplication of manure . . . . 94

Arteries, the . . . . . 136, 137

Artificial fertilizers . . . . $\$ 3$
Ash of animal bodies PAGE

of food

Atmosphere .. . . . . . 31, 41

weight of . . . . . 42

Atomic theory . . . . . 8

Atoms . . . . . . . 8, 11

B.

Balanced ration . . . 124, 125

Barometer . . . . . . 43, 44

Bases . . . . . . 12, 13

Beans . . . . . . . . 62

Beets . . . . . . . 63

Biennial plants . . . . . 62

Blight . . . . . . . . $\quad 69$

Blood, the . . . . 136, 137, 138

Blue litmus . . . . . . 66

Bodies of animals . . 114, 115, 116

Bones as a fertilizer . . . . 84

Bone-black . . . . . . 84

Bowlders, origin of . . . . . 34

Breathing . . . . . . . 13T

of plants . . . . . . 61,62

Breeds of animals . . 139, 140

Breezes . . . . . . . . 45

Brimstone . . . . . . 24

Buttercups, roots of . . . . 63

C.

Calcareous soil . . . . 39

Calcium . . . . . . . 23

carbonate . . . . 23

hydrate . . . . . 86

oxide . . . . . 19,86

phosphate . . . . . 22

Calyx . . . . . . . 74

(147) 


\begin{tabular}{|c|c|c|c|c|c|c|c|c|c|c|}
\hline & & & & & PAGE & & & & & \\
\hline la thistles & . & & 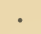 & & 63 & Combustion $\cdot \cdot$ & & & & - \\
\hline gar . & . & . & - & - & 12 & Composition of foods & & & & \\
\hline ots . & - & . & • & & 64 & & - & & & \\
\hline the & . & . & • & . & . 137 & ents, formatior & $\mathrm{n}$ of & & & \\
\hline tract & ion. & & 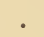 & & 67 & f the body & & & & \\
\hline & . & . & & & 68 & fs . . . & & & & \\
\hline s . & . & . . & . & & . & al, effects of & & & & \\
\hline Irates & . & . & . & & 119,120 & scles . . . & & & & \\
\hline & . & 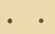 & & & . 21 & Cotton . . . & & & & \\
\hline e air & & & - & & 60,61 & fiber. . . & & & & \\
\hline f am & mol & nia & & & . 82 & Cranberry plants & & & & \\
\hline & & & & & 19 & tation of & & & & \\
\hline & & 14 & & & 20,4 & zing . . & . & & & \\
\hline & & & & & 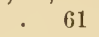 & of snow. & " & & & \\
\hline & & & & & . 1 & ion & & & & \\
\hline & & & & & . 10 & p . . . & & & & \\
\hline & & tation & & & 3 & loed crops & & & & \\
\hline & & & & & 14 & oses of . & & & & \\
\hline us ani & mals & & & & . 114 & shallow & & & & \\
\hline
\end{tabular}

Carrots . . . . . . . . . 63

Caustic potash . . . . . 23

Caustic soda . . . . . . 23

Cells . . . . . . . . . 68

form of . . . . . 70

growth of . . . . . 69

of a potato . . . . . $\quad 69$

of ripe fruit . . . . . 69

Cellulose . . . . . . 60

Charcoal . . . . . . 21

as a filter . . . . . 14

Chemical action . . . . . 11

in soil . . . . . . . 80

Chemical affinity $\quad . \quad$. $\quad . \quad$. $\quad 9$

Chemical equations . . . . . 12

Chemicals, use of . . . . . 88

Chewing the cud . . . 135, 136

Chlorate of potash . . . . . 23

Chloride of potash . . . . 13,85

Chlorine . . . . . . . 22

Circulation of the blood . . . 136

Clay . . . . . . . 22

Clayey soil . . . . . . 38

Climate . . . . . 50, 51

Clouds . . . . . . . 47

Clover . . . . . $62,63,73$

roots . . . . . . 64

Coal, origin of . . . . 37

Cohesion . . . . . . 14

Cold wave . . . . . . . 49

Combustible matter . . . 18

D.

Dark weather, effect of . . 61

Decomposition . . . . 20

of soil . . . . . . . 101

Deep cultivation . . . . . 107

Deep plowing . . . . . . . 104

Dew . . . . . . . . 48

Diamonds . . . . . . . 21

Diffusion . . . . . . . 65

in plants . . . . . . 68,72

Digestible parts of food . . . 121

Digestion . . . . . . . 133

Disks of the blood . . . . . 138

Drainage, by deep tillage . . . 104

Draining . . . . . . 108 cold soil . . . . . . . 110

Drains, to prevent effect of drought . . . . . . . 109

\section{E.}

Earth, its original condition . . 26

its age. . . . . . . 29

its interior . . . . . 26

Earthquakes . . . . . . 26

Economy in feeding. • . 122, 123

Effect of agriculture . . . . 78

Effervescence . . . . . . 14

Elementary substances . . . 8 


$\begin{array}{llllr} & & & & \\ \text { EAGE } \\ \text { Erigenia }\end{array}$

\section{F.}

Farm, care of . . . . . . 92

Farm manure . . . . . . . 90 nature of . . . . 90,91

Fat, animal . . . . . 115 in food . . . . . . . 119 varieties of . . . 115, 116

Feed, true cost of . . . . . 132

Fermentation of manure . . . 92

Fertile soil . . . . . . . 77

Fertility . . . . . . . 37 maintained . . . . . 79

reduced by weeds . . . . 102

Fertilizers . . . . . . . 77 artificial . . . . . 83 prepared . . . . . . 85

Fiber in foods . . . . . . . 120 of wood . . . . . 70

Fibrous roots . . . . . . . 63

Flow of sap . . . . . 65, 72

Flowers . . . . . . . 73

Fogs . . . . . . . . . . 47

Food of plants . . . . . 60,65

Food, purposes of . . . 116, 117

digestible parts of . . . 122

quantity profitable . . . 124

variety of . . . . . . 129

Foods, composition of . . 118, 121

double value of . . . 131, 132

manurial value of . . 129,130

true cost of . . . . . 132

value of . . . . . 122

G.

Germ of seeds . . . . 54

Germination . . . . . 57

Glaciers . . . . . . 34

Glands, salivary . . . . . 133

Glass . . . . . . . 22

Granite . . . . . . . 22

soil from . . . . . 79

Graphite * : . . . 23

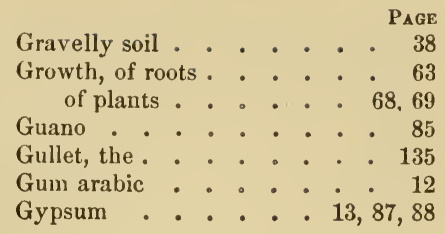

H.

Hail . . . . . . . 47

Hard pan . . . . . . . 31

Harrowing, purposes of . . . 106

thorough . . . . . . 106

Health of animals . . . . 139

Heat, effect of . . . . . 16 animal . . . . . 117

in germination . . . . 58

Herbivorous animals . . . 114

Hills . . . . . . . . . 32

formation of . . . . . 29,30

worn away by winds . . . 35

Hoed crops, cultivation of . . 107

Humus . . . . . . . . 35

Hydrochloric acid . . . 11-13, 22

Hydrogen . . . . . . 20

\section{I.}

Ice, effect of, upon soil . . . . 32

Impurities of the atmosphere $\quad 42$

Indian corn, roots of . . . . 64 mixture of . . . . . . 74

Insects, avoided by rotation . . 112

Intestines, the . . . . . 133

length of . . . . . 133

Iron . . . . . . . . . 125

K.

Kidneys, the . . . . . 138

Kindness to animals . . . 140

L.

Lacteals, the . . . . . . 134

Leguminous plants . . . . . 62

Lime . . . . 12, 13, 19, 41, 86

benefit of, in soil . . . . 87

Limestone . . . . 23, 32, 37 


\begin{tabular}{|c|c|c|c|c|c|c|c|}
\hline \multirow{2}{*}{\multicolumn{5}{|c|}{ Limestone soil from }} & \multicolumn{3}{|r|}{ PAGE } \\
\hline & & & & & & • & . $\quad 79$ \\
\hline Limy soi & & & . & • & - & . & 41 \\
\hline Liquid $n$ & nanı & Iure & - & - & - & - & 94 \\
\hline Litmus & - & - . & - & - & - & - & 66 \\
\hline Loam & & - . & - & - & . & . & 39 \\
\hline Lucerne & & . $\cdot$ & • & - & . & $\bullet$ & 62 \\
\hline I.ungs, $t$ & the . & & & - & & & - 138 \\
\hline
\end{tabular}

\section{M.}

Magnesia . . . . . 13, 23

Manure . . . . . . . 90 application of . . . . 94 fermentation of . . . . . 92 from foods, value of . . . 131 losses of . . . . . 92, 93, 94

Manurial value of foods $129,130,131$

Marble . . . . . . 23, 31

Marl . . . . . . . . 87

Alastication . . . . . . 133

Matter, nature of . . . . . 10

Mist . . . . . . . . 47

Moisture of climate . . . 51, 52 in germination . . . 55, 58 regulated by cultivation $\quad .103$ withdrawn by weeds . . . 102

Mold, vegetable . . . . . 79

Molecules • . . . . . . 9

Mountains . . . . . . 29, 32 formation of . . . . 27

Mouth, the . . . . . . 133

Mouths of leaves . . . 61

Muck . . . . . . . 95, 96 value of . . . . 96,97

Muck beds . . . . . . . 35

Mucky soil • . . . . . . 39

Muriate of potash . . . . . 85

Muriatic acid . . . . . 13, 22

N.

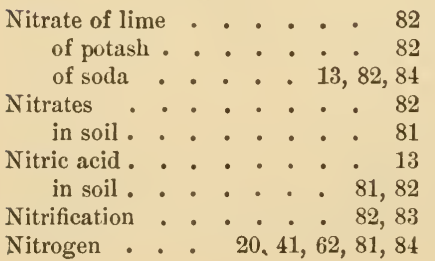

Nitrogen as food for plants . . 62

North America, formation of $\quad 27$

Nutrition in plants . . . . . 72

Nutritive ratio . . . 124, 126

0.

Oak trees, roots of . . . . 63

Ocean, affecting climate . . . 51

soil formed by . . . . . 32

Organic matter . . . . 17, 18

Osmose . . . . . . . 62

in plants . . . . . 71

Oxidation . . . . . 19, 20

of plants . . . . . 62

Oxide of iron . . . . . . 13

Oxides . . . . . . . 19

Oxygen . . . . . 19, 20

in germination of plants . 56

in soil . . . . . . 101

in the blood . . . . . 61

\section{P.}

Paunch, the . . . . . . 134

Peas . . . . . . . . 62

Peat . . . . . . . 35, 37

Peaty soil . . . . . . . 35,39

Perspiration, effect of . . . 118

Petals . . . . . . . 74

Phosphate of lime . . . . 13, 84

Phosphoric acid . . 13, 22, 83, 84

Phosphorus . . . . . . . 22

Pistils . . . . . . . . 74

Planting, depth of . . . . 57

Plants, growth of . . . . 68

breathing of . . . . . 20

food of . . . . . 60

instinct of . . . . . 59

leguminous . . . . 62

structure of . . . . . 68

Plant food, formation of . . 101

Plaster, land . . . . . 87

Plowing . . . . . 103, 104

subsoil . . . . . 105

time for . . . . 105, 106

Plumule, the . . . . . . 59

Pores of wood . . . . . 15

Porosity of matter . . . . . 15

Potassium . . . . . . 23 
PAGE

Potash . . . . . 23, 83, 85

salts . . . . . . 85

Potato, cells of . . . . . 69

Prepared fertilizers . . . 85,86

Pressure of the air . . . . 43

Protein . . . . . . 118, 119

Q.

Quartz rock . . . . . 22

Quicklime . . . . 13,86

R.

Radicle, the . . . . 59, 62,63

Rain . . . . . 42, 45, 46, 47

Rainless regions . . . . 47

Rain water, a fertilizer . . 108

Ratio, nutritive . . . . . . 125

Ration, balanced . . . . . 125

Rations, how made up . . . . 127 examples of . . . . . 128, 129

Requirements of animals . . . 127

Respiration . . . . . . 20

Rice plants . . . . . . 101

Rochelle powders . . . . 13

Rocks, ancient . . . . . 30

Rolling land . . . . . . 107

Rootlets . . . . . . 64

Roots . . . . . . 63, 64

air necessary for . . . 101

in wet soil . . . . 108

of buttercups . . . . 63

of clover . . . . . 64

of the maple. . . . . 63

tap. . . . . . . 63

tuberous . . . . . . 63

Rotation of crops . . . .110-112

Ruminants . . . . . .13t-136 stomachs of . . . . . 134, 135

Rumning water, effect of . . 31

"Run out" land . . . . 79

S.

Saliva . . . . . . 133

Salivary glands . . . . . 133

Salt . . . 11, 12, 17, 65, 87

Saltpeter . . . . . . 84

Sandstone . . . . 22, 31, 32
Sandy soil . . . . . 37, 38, 105

Sap of plants . . . . . . 65

flow of . . . . 71,72

Saturated soil. . . . . 101

Sea breezes . . . . . . . 45

Seeds . . . . . . . 54

unripe . . . . . . . 55

Selection of food by plants . . 73

Sepals . . . . . . . 74

Shallow cultivation . . . . 107

Silicates . . . . . . 22

Silicon . . . . . . 22, 73

Silicic acid . . . . . 13

Simple substances . . , . 7

Slag . . . . . . . . 85

Slaked lime . . . . . . 12

Smoked glass . . . . . . 21

Smut . . . . . . . 69

Snow . . . . . . 47

crystals . . . . . , 17

Sodium . . . . . . 13,23

Soil, formation of . . . 27,30

alluvial . . . , 105

composition of . . $3 r, 35,78$

fertile . . . . . 77

from granite . . . . 79

from limestone . . . . . 79

sandy . . . . .37, 38, 105

warmth of . . . . . 110

Solids, liquids, and gases . . 16

South Carolina rock . . . . 85

Squashes, mixture of . . . . 74

Stamens . . . . . . . 74

Starch . . . . . . . 60

of potatoes . . . . . 69

Stomach, the . . . . 133, 134

Stomachs of ruminants . . . 135

Stomata . . . . . 60,61

Storms . . . . . . . 50

Subsoil . . . . . . . 104

plowing . . . . . . 105

Substances, simple : . . . . 7

Success in agriculture . . . 141

Sugar . . . . . . 10,60

Sulphates . . . . . 13, 84

Sulphate of ammonia . . . 84

of lime . . . . . 13

of potash . . . . . . 23

Sulpliur . . . . . . . 22

Sulphuric acid . . 10, 13, 21, 22, 66 


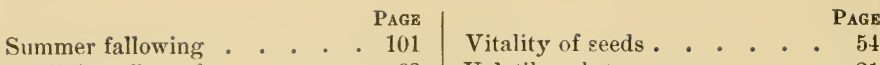

Sunlight, effect of . . . . 62

Volatile substances . . . . 21

T.

Tap-roots . . . . . . 63

'Temperature . . . . . 44, 50

Thermometer . . . . . . . 44

Tillage, deep . . . . . . 104

Time to plow . . . . . 105

Timothy grass . . . . . 73

Tuberous roots . . . . . 63

Turnips . . . . . . . 63

U。

Underdrains . . . . . 108

Unripe seeds . . . . . . 55

Urea . . . . . . . 138

\section{V.}

Valleys, cause of . . . . 30

Value of foods . . . . . 121, 122

Variety of food . . . . . 129

Vegetable matter . . . . . 35

Vegetable mold . . . . 35, 79

Vegetable tissue . . . . . 69

Vegetation, carboniferous $\quad . \quad 36$

Veins, the . . . . . 137

\section{W.}

Warm wave . . . . . . 49

Warmth for germination . . . 56

Water, magnified . . . . . 9 in foods..... . . 118 in the animal body . . . 115 molecule . . . . . . 11 vapor . . . . . . . 41

Watering plants . . . . . 62

Weather, the . . . . . . 49

Weeds . . . . . . . 102

Wet land . . . . . . . . 109

White clover . . . . . 63

Wind . . . . . 34, 35, 44, 45

Wood, composition of . . . 7

Wond, porosity of . . . . 15

Work, effect of . . . . 117

Y.

Young animals . . . . 116

Z.

Zinc . . . . . . . . 11, 12

Zinc chloride . . . . . . 12 


\section{The Natural Geographies}

\section{NATURAL ELEMENTARY GEOGRAPHY}

Linen Binding, Quarto. 144 pages . . . Price 60 cents

NATURAL ADVANCED GEOGRAPHY

Linen Binding, Large Quarto, 160 pages . . . Price $\$ 1.25$

By Jacques W. Redway, F.R.G.S., and Russell Hinman, Author of the Eclectic Physical Geography.

The publication of The Natural Geographies marks a new era in the study and teaching of geography. Some of the distinctive features which characterize this new series are :

I. A Natural Plan of Development, based on physical geography and leading in a natural manner to the study of historical, industrial, and commercial geography.

2. Clear and distinct political maps showing correctly the comparative size of different countries, and physical maps showing relief by contour lines and different colors, as in the best government maps.

3. Inductive and comparative treatment of subjects according to the most approved pedagogical principles.

4. Frequent exercises and reviews leading to the correlation and comparison of the parts of the subject already studied.

5. Topical outlines for the language work required by the Courses of Study of the best schools.

6. Supplementary Exercises including laboratory work and references for collateral reading.

7. Numerous original and appropriate pictures and graphic diagrams to illustrate the text.

8. Clear explanations of each necessary term where it first occurs, and omission of formal definitions at the beginning of the book.

9. Strict accordance, in method and treatment, with the recommendations of the Committee of Fifteen.

Illustrated Circulars describing the plan and method of The Natural Geographies will be sent free to any address on application.

Copies of The Natural Geographies will be sent, prepaid, to any address on receipt of the price by the Publishers:

\section{American Book Company}

New York

Cincinnati

Chicago

(sog) 


\section{A School History of the United States}

By JOHN BACH McMASTER

Professor of American History in the University of Pennsylvania

Linen, 12mo, 507 pages. With maps and illustrations . . $\$ 1.00$

This new nistory of our country is marked by many original and superior features which will commend it alike to teachers, students, and general readers. The narrative is a word-picture of the great events and scenes of American history, told in such a way as to awaken enthusiasm in the study and make an indelible impression on the mind. From the beginning the attention of the student is directed to causes and results, and he is thus encouraged to follow the best methods of studying history as a connected growth of ideas and institutions, and not a bare compendium of facts and dates. Special prominence is given to the social, industrial, and economic development of the country, to the domestic life and institutions of the people, and to such topics as the growth of inventions, the highways of travel and commerce, and the progress of the people in art, science, and literature. The numerous maps give vivid impressions of the early voyages, explorations, and settlements, of the chief military campaigns, of the territorial growth of the country, and of its population at different periods, while the pictures on almost every page illustrate different phases in the civil and domestic life of the people.

Copies will be sent, prepaid, on receipt of the price by the Publishers:

\section{American Book Company}

New York

Cincinnati

Chicago

(Ix6) 


\title{
Milne's Plane and Solid Geometry
}

Half Leather, I $2 \mathrm{mo}, 384$ pages. Price, $\$ 1.25$

\section{Milne's Plane Geometry_Separate}

Half Leather, $12 \mathrm{mo}, 242$ pages. Price, $\$ 0.75$

\author{
By William J. Milne, Ph.D., LL.D. \\ President State Normal College, Albany, N. Y.
}

This new text-book in geometry embodies many original methods of treatment, which while novel and attractive, are based on sound mathematical and pedagogical principles. The author's aim has been to combine the valuable features of inventional and concrete geometry with the forms of rigid deductive reasoning, which is one of the chief objects sought in this branch of study.

In this work the student is introduced to geometry through the employment of inventional steps, supplemented by demonstrations of the fundamental propositions of the science. Every theorem is introduced by questions designed to lead the student to discover the geometrical concept clearly and fully before attempting a demonstration. The laboratory method is introduced at the beginning and is continued throughout the book. A great abundance of undemonstrated theorems and of unsolved problems is supplied for supplementary and original work. Summaries showing the subjects covered and the truths established in the chapters to which they are appended are an original feature of the book. These will be found of great practical value to the student, both in reviewing his work and in preparing him for advanced steps. The diagrams and other figures used in the demonstrations are all that could be desired in a text-book on geometry.

Copies of Milne's Geometries will be sent, prepaid, to any address on receipt of the price by the Publishers:

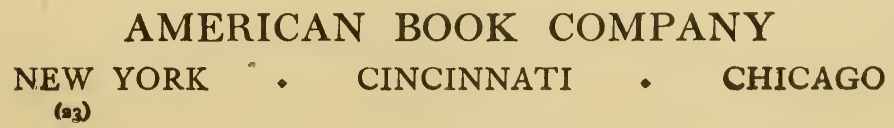




\title{
Text-Books in Geology
}

\author{
BY JAMES D. DANA, LL.D.
}

Late Professor of Geology and Mineralogy in Yale University.

DANA'S GEOLOGICAL STORY BRIEFLY TOLD . . . $\$ 1.15$

A new and revised edition of this popular text-book for beginners in the study, and for the general reader. The book has been entirely rewritten, and improved by the addition of many new illustrations and interesting descriptions of the latest phases and discoveries of the science. In contents and dress it is an attractive volume, well suited for its use.

DANA'S REVISED TEXT-BOOK OF GEOLOGY . . . $\$ 1.40$

Fifth Edition, Revised and Enlarged. Edited by William North Rice, Ph.D., LL.D., Professor of Geology in Wesleyan University. This is the standard text-book in geology for high school and elementary college work. While the general and distinctive features of the former work have been preserved, the book has been thoroughly revised, enlarged, and improved. As now published, it combines the results of the life experience and observation of its distinguished author with the latest discoveries and researches in the science.

DANA'S MANUAL OF GEOLOGY . . . . . . $\$ 5.00$

Fourth Revised Edition. This great work is a complete thesaurus of the principles, methods, and details of the science of geology in its varied branches, including the formation and metamorphism of rocks, physiography, orogeny, and epeirogeny, biologic evolution, and paleontology. It is not only a text-book for the college student but a handbook for the professional geologist. The book was first issued in I862, a second edition was published in 1874 , and a third in 1880 . Later investigations and developments in the science, especially in the geology of North America, led to the last revision of the work, which was most thorough and complete. This last revision, making the work substantially a new book, was performed almost exclusively by Dr. Dana himself, and may justly be regarded as the crowning work of his life.

Copies of any of Dana's Geologies will be sent, prepaid, to any address on receipt of the price.

\section{American Book Company}

New York

Cincinnati

Chicago

(177) 


\section{Primers in}

\section{Science, History, and Literature}

Bound uniformly in flexible cloth, $18 \mathrm{mo}$ - - Price, 35 cents each

\section{SCIENCE PRIMERS}

Edited by Professors HUXLEY, ROSCOE, and STEWART introductory....... T. H. Huxley

Chemistry.......... E. E. Roscoe Physics..........Balfour Stewart Physical Geography ....A. Geikie Geology .............. Geikie Physiology and Hygiene

M. Foster and R. S. Tracy Astronomy ........J. N. Lockyer Botany...........J. D. Hooker Logic ............W. S. Jevons Inventional Geometry

Pianoforte Playing.....F. Taylor Political Economy..W. S. Jevons Natural Resources of the United States. .J. H. Patton Scientific Agriculture . N. T. Lupton History of Philosophy. .T. Hunter

\section{HISTORY PRIMERS}

Edited by J. R. GREEN, M.A.

Greece............. A. Fyffe

Rome. . M. Creighton

Europe..........E. A. Freeman France ..... Charlotte M. Yonge Old Greek Life.... J. P. Mahaffy
Roman Antiquities..A. S. Wilkins Geography........ George Grove Mediaeval Civilization. G. B. Adams Roman Constitution...... A. Tighe Egypt.......... C. H. Wendel

\section{LITERATURE PRIMERS}

Edited by J. R. GREEN, M.A.

American Literature. M. C. Watkins English Literature

$$
\text { Stopford A. Brooke }
$$

English Grammar......R. Morris English Exercises......R. Morris English Composition..John Nichol
Philology ............ J. Peile Shakespeare........E. Dowden Studies in Bryant.......J. Alden Greek Literature ......R. C. Jebb Homer.........W. E. Gladstone Classical Geography. M. F. Tozer

Copies sent, prepaid, to any address on receipt of the price.

\section{American Book Company}

New York

Cincinnati

Chicago

(으) 


\title{
Webster's School Dictionaries
}

\author{
REVISED EDITIONS
}

WEBSTER'S SCHOOL DICTIONARIES in their revised form constitute a progressive series, carefully graded and especially adapted for Primary Schools, Common Schools, High Schools, Academies, and private students. These Dictionaries have all been thoroughly revised, entirely reset, and made to conform in all essential respects to that great standard authority in English,-Webster's International Dictionary.

WEBSTER'S PRIMARY SCHOOL DICTIONARY . . . $\$ 0.48$

Containing over 20,000 words and meanings, with over 400 illustrations.

WEBSTER'S COMMON SCHOOL DICTIONARY . • . $\$ 0.72$

Containing over 25,000 words and meanings, with over 500 illustrations.

WEBSTER'S HIGH SCHOOL DICTIONARY • • • • $\$ 0.98$

Containing about 37,000 words and definitions, and an appendix giving a pronouncing vocabulary of Biblical, Classical, Mythological, Historical, and Geographical proper names, with over 800 illustrations.

WEBSTER'S ACADEMIC DICTIONARY. Cloth, $\$ 1.50$; Indexed, $\$ 1.80$

The Same . . . Half Calf, $\$ 2.75$; Indexed, $\$ 3.00$

Abridged directly from the International Dictionary, and giving the orthography, pronunciations, definitions, and synonyms of the large vocabulary of words in common use, with an appendix containing various useful tables, with over 800 illustrations.

SPECIAL EDITIONS

Webster's Countinghouse Dictionary . . Sheep, Indexed, $\$ 2.40$

Webster's Condensed Dictionary . Cloth, $\$ 1.44$; Indexed, 1.75

The Same . . . Half Calf, \$2.75; Indexed, 3.00

Webster's Handy Dictionary • • • • • • .15

Webster's Pocket Dictionary. Cloth . . . . . .57

The Same. Roan Flexible . . . . . $\quad .69$

The Same. Roan Tucks . . . . . . 78

The Same. Morocco, Indexed . . . . $\quad .90$

Webster's American People's Dictionary and Manual . . $\quad .48$

Webster's Practical Dictionary. . . . . . . 80

Copies of any of Webster's Dictionaries will be sent, prepaid, to any address on receipt of the price by the Publishers:

\section{American Book Company}

New York

Cincinnati

Chicago

(104) 


\section{Zoölogy and Natural History}

BURNET'S SCHOOL ZOÖLOGY

75 cents

A new text-book for high schools and academies, by a practical teacher; sufficiently elementary for beginners and full enough for the usual course in Natural History.

\section{DODGE'S INTRODUCTION TO ELEMENTARY PRACTICAL}

BIOLOGY . . . . . . . . . . $\$ 180$

A laboratory guide for high school and college students, intended to develop the power of personal investigation. Under each section are given questions on the structure and the physiology of a series of common animals and plants typical of their kind. Directions are given for the collection and preservation of specimens, for preparing them for examination, and for performing simple physiological experiments.

\section{NEEDHAM'S ELEMENTARY LESSONS IN ZOÖLOGY . 90 cents}

A text-book for high schools, academies, normal schools, and preparatory college classes. Special attention is given to the study by scientific methods, laboratory practice, microscopic study, and practical zoötomy.

ORTON'S COMPARATIVE ZOÖLOGY . . . . . $\$ 1.80$

Structural and systematic. For use in schools and colleges. The distinctive character of this work consists in the treatment of the whole Animal Kingdom as a unit; in the comparative study of the development and variations of organs and their functions, from the simplest to the most complex state; in withholding systematic zoölogy until the student has mastered those structural affinities upon which true classification is founded.

HOLDERS' ELEMENTARY ZOÖLOGY • . • . . \$1.20

A text-book for high school classes and other secondary schools.

MORSE'S FIRST BOOK IN ZOÖLOGY . . . . 87 cents

For the study of the lower and plainer forms of animal life. The examples presented are such as are common and familiar.

STEELE'S POPULAR ZOÖLOGY . . . . . . $\$ 1.20$

For academies, preparatory schools, and general reading. The treatment is marked by the same clearness and interest that characterize all Professor Steele's text-books in the Natural Sciences.

TENNEYS' NATURAL HISTORY OF ANIMALS-Revised • • \$1.20

This new edition has been thoroughly revised, the recent changes in classification introduced, and the book in all respects brought up to date.

Copies will be sent, prepaid, to any address on receipt of the price.

\section{American Book Company}

New York

Cincinnati

Chicago 


\section{Text-Books in Chemistry}

\section{STORER AND LINDSAY'S ELEMENTARY MANUAL OF}

CHEMISTRY. . . . . . . . . $\$ 1.20$

A standard manual for secondary schools and colleges. This textbook is a thorough revision of Eliot, Storer, and Nichol's Elementary Manual of Chemistry, rewritten and enlarged to represent the present condition of chemical knowledge, and to meet the demands for a class book on Chemistry, at once scientific and clear in method. It presents the leading facts and theories of the science in such a simple and concise manner that they may be readily understood and applied by the student.

\section{CLARKE'S ELEMENTS OF CHEMISTRY . . . . \$120}

A scientific book for high schools and colleges intended to provide a complete course for schools and to serve as a substantial basis for further study.

\section{COOLEY'S NEW TEXT.BOOK OF CHEMISTRY}

90 cents

An elementary course designed for use in high schools and academies. The fundamental facts and principles are treated in a simple, concise, and accurate manner.

STEELE'S POPULAR CHEMISTRY .

$\$ 1.00$

A popular treatise for schools and private students in which the study is made interesting as well as instructive by the clearness and sim. plicity of the treatment.

BREWSTER'S FIRST BOOK OF CHEMISTRY . . 66 cents

Designed to serve as a guide for beginners in the simplest preliminary chemical operations. The experiments are of the most elementary character, and only the simplest apparatus is employed.

\section{Laboratory Methods}

ARMSTRONG AND NORTON'S LABORATORY MANUAL OF CHEMISTRY

50 cents COOLEY'S LABORATORY STUDIES IN CHEMISTRY . 50 cents KEISER'S LABORATORY WORK IN CHEMISTRY . . 50 cents IRISH'S QUALITATIVE ANALYSIS FOR SECONDARY SCHOOLS . . . . . . . . 50 cents STODDARD'S OUTLINES OF QUALITATIVE ANALYSIS . 75 cents

Copies will be sent, prepaid, to any address on receipt of the price.

\section{American Book Company}

New York

Cincinnati

Chicago

(I60) 





\section{LIBRARY OF CONGRESS}

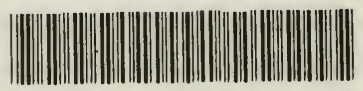
00025864049 